$$
\text { - DOE/OR/21389--T22 }
$$

\title{
NORTHEAST REGIONAL BIOMASS PROGRAM
}

\section{FIRST QUARTER REPORT}

OCTOBER - DECEMBER 1993

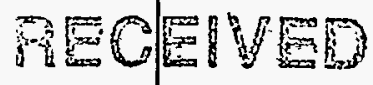 APR 231997 \\ OST:}

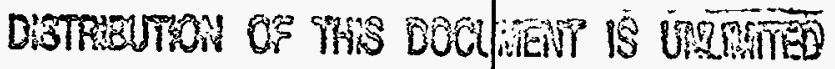
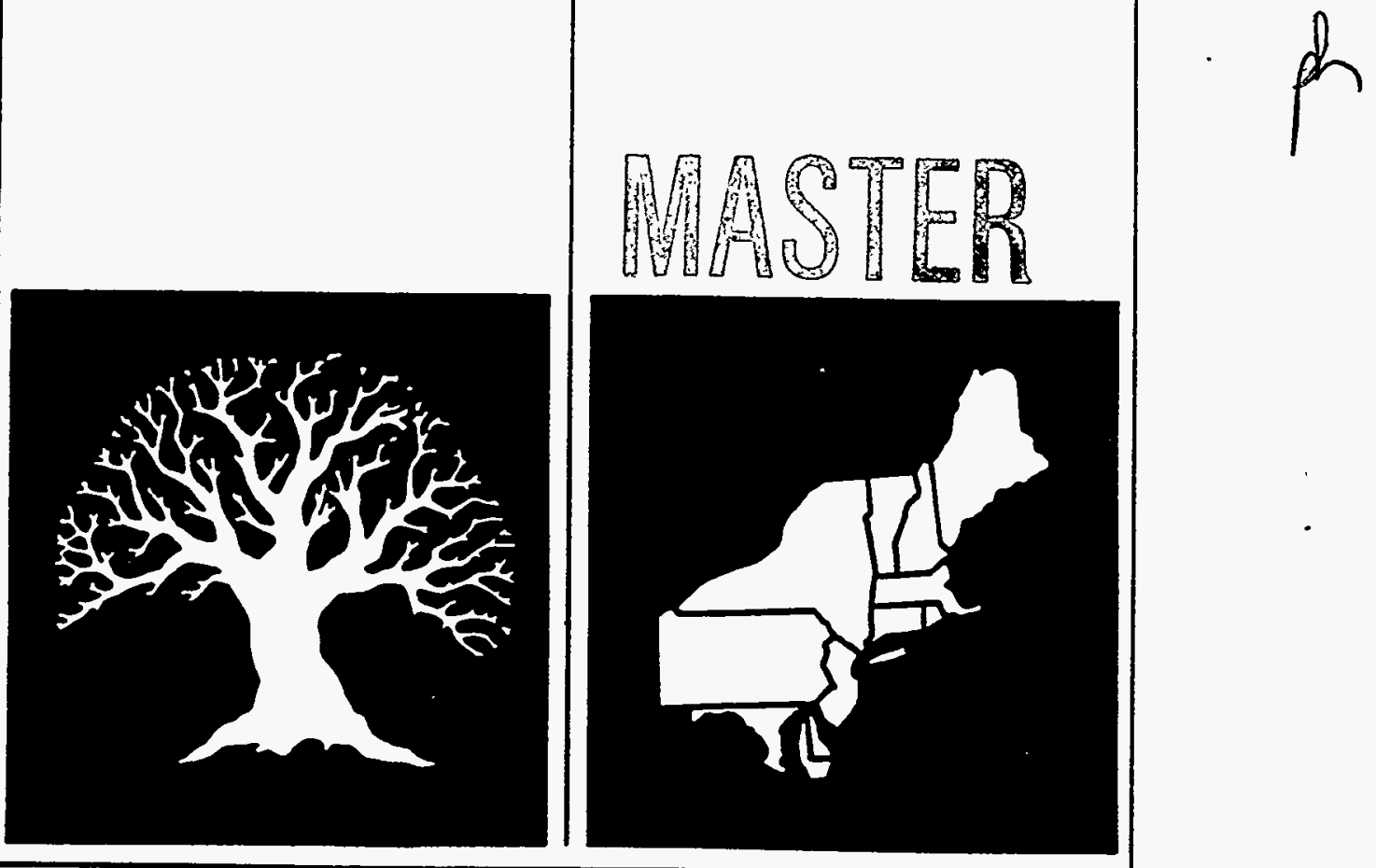

NORTHEAST REGIONAL BIOMASS PROGRAM 


\section{DISCLAIMER}

This report was prepared as an account of work sponsored by an agency of the United States Government. Neither the United States Government nor any agency thereof, nor any of their employees, make any warranty, express or implied, or assumes any legal liability or responsibility for the accuracy, completeness, or usefulness of any information, apparatus, product, or process disclosed, or represents that its use would not infringe privately owned rights. Reference herein to any specific commercial product, process, or service by trade name, trademark, manufacturer, or otherwise does not necessarily constitute or imply its endorsement, recommendation, or favoring by the United States Government or any agency thereof. The views and opinions of authors expressed herein do not necessarily state or reflect those of the United States Government or any agency thereof. 


\section{DISCLAMMER}

Portions of this document may be illegible in electronic image products. Images are produced from the best available original document. 


\section{NORTHEAST REGIONAL BIOMASS PROGRAM}

FIRST QUARTER REPORT

OCTOBER - DECEMBER 1993

CONEG POLICY RESEARCH CENTER, INC.

400 NORTH CAPITOL STREET, NW

SUITE 382

WASHINGTON, D.C. 20001

RICK HANDLEY, PROJECT MANAGER

MAY 1994

Prepared for the U.S. Department of Energy under Grant Number DE-FG42-93R208010 


\section{NORTHEAST REGIONAL BIOMASS PROGRAM \\ Applied Research \& Technology Transfer}

Technical Projects - Status Report

December 1993

Title: Evaluation of the Performance of Wood Chip

Heating Systems in Institutional Buildings

Rationale: The engineering community demonstrates persisting skepticism about the performance efficiency of wood combustion systems despite hundreds of successful and cost-effective applications.

Objectives: The objective of this project is to determine fuel and capital costs, combustion efficiencies, O\&M costs, and overall system performance of wood . residue to energy systems.

Approach: The objectives will be accomplished by conducting field evaluations of direct combustion and gasification wood chip or residue systems over a period of at least one full heating season. A comparison will be made with comparable sized units fueled by other energy sources, in the case of retrofitted systems, the pre-and post-conversion costs and benefits. A performance analysis will be conducted on at least seven systems, at least one of which will be wood gasification. The systems selected will range from .5 to 5 million Btu/hour. Combustion efficiency testing will be conducted at all seven sites.

Tasks:

(1) Identify $5,000+$ persons as audience for project

(2) Compile candidate list of 12 wood-fired systems (0.5-10 million Btu's/hr) from 11 state region

(3) Select seven sites for final study, with guidance from Advisory Committee

(4) Evaluate performance of these 7 institutional/commercial systems for two heating seasons

(5) Provide high-fire, steady state efficiency test at all 7 sites, with a minimum of 3 tests over 2 week period 
(6) Measure fuel consumed in standby mode (min. of three 2-hr. periods)

(7) Prepare description of O\&M problems, frequency, costs

(8) Conduct combustion efficiency tests at a total of seven sites.

(9) Write a case study of each facility

(10) Prepare reports, conduct interim and final project meetings with Advisory Committee

Status: Report and Executive Summary Completed

Contractor: Commercial Testing \& Engineering Co. (SGS Group)

Lombard, llinois. Contract Mgr.: W.E. Katterhenry

(708) 953-9300

NRBP Funding: $\$ 36,469$

Contract Period: Twelve (12) months starting March 1, 1992. Extension granted until June 1, 1993. Executive Summary Completed November 1993

\section{Principal Findings and Accomplishments to Date:}

The contractor undertook case studies at seven sites, including schools, a prison and an abbey; these facilities are located in five states. The combustion efficiency testing, following a standard heat loss methodology adopted by the American Society of Mechanical Engineers (ASME), revealed a range from $62 \%$ to $69 \%$. The efficiency numbers are based upon a chemical analysis of the fuel and flue gas and combustion air and flue gas temperatures.

Thermal efficiency testing, designed to calculate how well the steam or hot water generator converts the chemical energy from the wood into steam or hot water, also takes into account unaccounted-for losses such as radiation. The thermal efficiencies ranged from $75 \%$ to $87 \%$. These efficiencies contributed to system performances which generally assured fuel savings sufficient to return the capital and operating costs of the conversions within the projected payback periods. Three (3) of the facilities previously were oilheated, three (3) were electrically-heated; one had utilized both electricity and oil for space heat. 
The report observed that six of the seven tested systems were oversized. This very conservative sizing led to difficulties in achieving efficient combustion at both low and full loads. The report recommended systems in which an automatic control with a 3:1 ratio of high to low fire can handle the entire spectrum of loads. A supplemental fuel back-up system was also recommended to handle the extreme loads required on the very coldest days during the heating season.

Most of the wood-fired systems are in the 1 to 5 million BTUs/hour range. Conversion costs for the commercial facilities ranged from $\$ 118,000$ at a University of Maine site to $\$ 150,000$ at the Camp Gabriel Correctional Center in New York. Among the four facilities where fuel cost records were complete, fuel cost savings ranged from $\$ 4,500$ to $\$ 33,470$ annually.

Case studies for each facility address fuel storage, feeding systems, ash removal, system controls and back-up systems. Site solutions were screened to assure a representative mix. The system included a pile burner, movable grate, movable step grate and pin hole grate. Fuels included green wood chips and sawmill residues. Facilities managers also received technical assistance and recommendations for improving the performance of each system.

The next step in the project is the dissemination of the report's executive summary to the intended audiences: architects and engineers; school superintendents and business managers; other government agency procurement directors and maintenance supervisors; energy offices; and wood energy equipment manufacturers and distributors. The contractor has compiled a list of 5,000 names and addresses for these and related trades and professions in the Northeast. A mailing is planned for early in 1994.

\section{Report Executive Summary}

While the forest products industry has been utilizing wood energy boilers successfully to provide steam and electricity to sawmills, paper mills and furniture manufacturers for more than two decades, skepticism about system efficiency and overall performance has been a barrier to the adoption of wood energy systems by schools, municipal buildings, and small and medium commercial facilities. To educate architects, engineers, energy professionals and facility managers about the system efficiencies, overall performance, and economic paybacks of conversions from oil to wood systems in these applications, the Northeast Regional Biomass Program (NRBP) contracted with Combustion Testing \& Engineering to evaluate seven representative wood energy boilers operating at sizes between 500,000 and 12.5 million BTUh. This evaluation took place in the late winter of 1993. 
The seven facilities are located in five Northeastern states from Maine to Pennsylvania. Three public schools, a college building, an abbey, a prișon and a housing development participated in the study. Four of the facilities converted from electricity to wood for their space heating load; three converted from oil to wood. Virgin wood chips is generally the feedstock; for a few of the facilities the chips are supplemented with saw mill residues.

As Table 1 illustrates, the thermal and overall combustion efficiencies at the seven facilities are very similar to, or slightly below, that typical of fossil fuel systems. Thermal efficiencies, a measure of how well the steam or hot water generator converted the chemical energy from the fuel into usable heat, ranged from $72-81 \%$. Combustion efficiencies, a measure of how well the furnace converted the chemical energy in the fuel, ranged from $62-69 \%$. An alternative combustion efficiency methodology which systematically accounts for the fuel moisture content would raise the combustion efficiency numbers to a range of $68-77 \%$.

The testing methodology generally followed the American Society of Mechanical Engineers (ASME) Power Test Code PTC 4.1. The calculations are based on the ultimate and proximate analysis of the wood chip fuel and a test for Loss on Ignition (LOI) for the ash. This data was integrated into the standard heat loss method recommended by ASME. The thermal efficiency testing used the results of the combustion efficiency analysis and also included the assumed unaccounted for losses due to radiation and other noncombustion factors. The combustion efficiency calculations are based upon the certified chemical analysis of the fuel, flue gas analysis, combustion air temperatures and flue gas temperatures.

Incomplete pre-retrofit fuel records at several of the sites precluded generalizations about system paybacks after conversions to wood. Total installed costs for systems ranged from $\$ 105,000$ for a 2.2 million BTU system to $\$ 750,000$ for a rated 12.5 million BTU system. Fuel savings ranged from $\$ 8,500$ annually to an estimated $\$ 50,000$.

\section{Instrumentation Lacking, Fuel Storage Varied}

The lack of instrumentation caused problems in the calculation of energy output. Pump motor amperage and name plate data provided assumptions for several sites. Isolation of the feedwater system and calculation of the differential head of feedwater over time in a cylindrical, horizontal tank provided an index of steam flow, which lead to an output calculation in one case. Combustion controls were fully automated at only one site: the others relied upon on/off settings. 
Wood energy systems require a sizable fuel storage capacity, prompting a variety of solutions at converted facilities. One site utilized a parked trailer visited by a "skip" loader to offload the chips and deposit them in a "live" feed hopper. More typical was an enclosed fuel storage area with an automatic, mechanical conveyance system which delivered fuel to the live feed hopper before being fed to the furnace on demand from the boiler. Ash removal varied from daily, manual removal to an automated, continuous ash removal conveyor system.

\section{Systems Qversized}

At six of the seven sites, the furnaces were oversized. This led to difficulty in tuning the systems to operate efficiently at both low and full loads. A very conservative engineering design approach, geared to the most severe winter weather, and perhaps the industry's relative inexperience with small and medium-sized systems led to this situation. The contractor recommends sizing the units such that an efficient, automatic control over a 3:1 turndown (high fire to low fire) to handle the entire load. The contractor also recommends sizing the wood systems smaller to handle the typical range of cold temperatures and to provide a small supplemental fuel backup to handle the few coldest days. So doing would improve the efficiency of the wood systems and lower overall fuel costs, even taking into account the supplemental fossil fuel usage.

The study suggests that proper attention to boiler sizing, tuning and modulating fuel feed and combustion air with microprocessor controls should generate significant increases in efficiencies in the next generation of heating system installations. 


\section{Facility Boiler Summaries}

\begin{tabular}{|c|c|c|c|c|c|c|c|}
\hline . & $\begin{array}{l}\text { Moune: } \\
\text { yiew : }\end{array}$ & $\begin{array}{l}\text { Camp } \\
\text { Gabr: }\end{array}$ & $\begin{array}{l}\text { Green } \\
\text { Acres }\end{array}$ & Calais.. & L\&G & o of & $\because$ St. Jo \\
\hline Facility & School & Prison & Housing & School & School & College & Abbey \\
\hline Installed Cost & $\$ 385 k$ & $5750 \mathrm{k}$ & $\$ 105 x$ & $\$ 162 \mathrm{k}$ & $\$ 465 \mathrm{k}$ & $\$ 118 \mathrm{k}$ & $\$ 174 \mathrm{k}$ \\
\hline $\begin{array}{l}\text { Combustion } \\
\text { Efficiency } \\
\end{array}$ & $62 z$ & $65.5 \%$ & 67\% & 698 & 698 & $66 t$ & $64 t$ \\
\hline $\begin{array}{l}\text { Transfer } \\
\text { Efficiency }\end{array}$ & $81 \%$ & $75 t$ & 758 & 878 & $82 \%$ & $72 t$ & $75 t$ \\
\hline $\begin{array}{l}\text { Rared } \\
\text { Capacity BTU }\end{array}$ & $10.8 \mathrm{Mil}$ & $22.5 \mathrm{Mil}$ & $2.2 \mathrm{Mil}$ & $.52 \mathrm{Mil}$ & $45 \mathrm{HP}$ & $2.1 \mathrm{M} 1 \mathrm{I}$ & $\begin{array}{rl}.84 & M \\
6 \mathrm{~K} & s t \\
\end{array}$ \\
\hline Fuel Type & Chips & Chips & Chips & $\begin{array}{l}\text { Chips } \\
\text { Mill Res }\end{array}$ & Chips & $\begin{array}{l}\text { Mill } \\
\text { Residue }\end{array}$ & $\begin{array}{l}\text { Mill } \\
\text { Res }\end{array}$ \\
\hline $\begin{array}{l}\text { Annual } \\
\text { Consumption Tons }\end{array}$ & 1.278 & 2.583 & 450 & 140 & 180 & 653 & 358 \\
\hline Cost/Ton & $\$ 23$ & $\$ 23$ & $\$ 25$ & $\$ 25$ & $\$ 29$ & $\$ 22.40$ & $\$ 17.50$ \\
\hline Fuel Savings & $\$ 8,536$ & $\mathrm{NA}$ & $\$ 33.470$ & $\$ 19,375$ & $\$ 50,000$ & 54,466 & $\mathrm{NA}$ \\
\hline $\begin{array}{l}\text { Combustion } \\
\text { Process }\end{array}$ & $\begin{array}{l}\text { Recipric. } \\
\text { Grate }\end{array}$ & $\begin{array}{l}\text { Step } \\
\text { Grate }\end{array}$ & $\begin{array}{l}\text { Stoker } \\
\text { Feed }\end{array}$ & $\begin{array}{l}\text { Direct } \\
\text { Burn } \\
\end{array}$ & $\begin{array}{l}\text { Gasifica } \\
\text { tion }\end{array}$ & $\begin{array}{l}\text { Afterbr } \\
\text { Tube } \\
\end{array}$ & $\begin{array}{l}\text { Step } \\
\text { Grace } \\
\end{array}$ \\
\hline $\begin{array}{l}\text { Conversion } \\
\text { From }\end{array}$ & Oil/Elec. & oil/Elec & Elec. & Elec. & Elec. & oil & oil \\
\hline
\end{tabular}




\title{
NORTHEAST REGIONAL BIOMASS PROGRAM \\ Applied Research \& Technology Transfer
}

\author{
Technical Projects - Status Report
}

December, 1993

\section{Title: Wood Fuel Pellet Forum}

Rationale: The chicken-and-egg problem constraining the demand for pellet stoves requires a discussion among experts to understand the problems and. formulate strategies for overcoming them.

Objectives: Primary goals are to bring together key people representing various aspects of wood fuel pellet manufacturing and use in a problem solving forum designed to identity problems and potential solutions to expanded production and use of pellets in the region; to develop a plan of action that specifies activities and tasks, and responsibilities for actions needed to overcome identified problems.

Approach: CONEG and the Northeastern Forest Alliance (NEFA) are jointly funding a regional wood fuel pellet forum to explore the barriers and limitations confronting pellet production and use in the Northeast, and to prepare an agenda for action. The Maine Planning Office (SPO) shall be the lead agency in planning, organizing, and conducting the forum; and in the preparation of a final report (action agenda). A planning committee will be formed to guide the formulation of a forum program and other session details. Members shall be drawn from Center, NEFA, Fiber Fuels Institute, and other major participants in pellet manufacturing and use. The forum shall be run by professional facilitator, experienced in conducting problem solving exercises.

Tasks:

(1) Form steering committee. This task is completed, with help of supporting organizations listed above.

(2) Prepare forum program. This Task is completed, with help of supporting organizations listed above.

(3) Contact and confirm key participants. Initial and confirming contact by phone during March and April, followed by confirmation letter. The target date for completion is April 30, 1993. 
(4) Arrange for program facilitator. Begin inquiries as soon as possible, with selection and arrangements to be made by April 30, 1993.

(5) Prepare materials for program facilitator. An on-going task, which begins upon settling forum facilitation arrangements and requiring close collaboration up to the conduct of the wood pellet forum.

(6) Arrange meeting site and facilities. The date and location of the wood pellet forum shall be determined by the steering committee. This task has a target completion date of April 15, 1993.

(7) Organize and conduct the session. This task shall begin upon confirmation of participants and selection of meeting site and continues through the forum session. Tentative target date for the conduct of the forum is June, 1993.

(8) Capture a record. This task includes making all necessary arrangements with meeting site, facilitator, and any other providers to record the proceedings, and to record the names, addresses, and affiliations of participants and attendees suitable for subsequent use by forum organizers.

(9) Prepare draft report. The Subcontractor shall ensure that an initial draft report is prepared for review and comments by steering committee members, forum participants, and appropriate representatives of forum organizers. The target date for completing this task is mid-July 1993.

(10) Final report. The Subcontractor will ensure that all draft report review comments and suggestions are incorporated into a final draft report for review by NEFA and Center. The target date for the completion of this task is mid-September 1993.

(11) The Subcontractor shall publish 50 copies of the Wood Fuel Pellet Action Plan and distribute them to NEFA and the Center. The target date for the completion of this task is mid-October 1993. 
Status: Experts identified; first forum is scheduled for June 13 in Mass. in conjunction with Northeast Hearth Products Association Annual meeting.

Contractor: Northeastern Forest Alliance, Maine Forest Service, Augusta, Me.

NRBP Funding: $\$ 20,000$

Contract Period: April, 1993 - December, 1993

\section{Principal Findings and Accomplishments to Date:}

The NRBP and the Northeast Forestry Alliance held the region's first Wood Fuel Pellet Forum in Bedford, New Hampshire on June 28 and 29 in Bedford, New Hampshire. The 65 invited participants addressed the major barriers to pellet stove and fuel sales in the Northeast and suggested strategies for overcoming them. The focus was limited to the residential market; the feedstock, to woody fuels. Benefitting from the skilled facilitation of three United States Forest Service professionals, the attendees listened to initial presentations describing stove and fuel production and sales trends nationally and regionally; the economics of fuel production facilities; and the impact of air quality regulations on the wood appliance industry. The rest of the forum was devoted to group brainstorming, identifying dilemmas and recommending actions to accelerate the growth of the industry.

Jack Whittier of NEOS Corporation observed that an estimated 7,300 pellet stoves were sold in the region during 1992, and pellet sales were approximately 35,000 . There are four pellet manufacturing plants in the region. The Northeast is also experiencing one of the fastest growing pellet markets in the nation.

\section{Characteristics of Successful Pellet Operations Identified}

Whittier identified several key factors associated with successful pellet fuel operations:

- feedstocks available at less than $\$ 10 \mathrm{dry}$ ton

- diverse supply sources

- stable feedstock contracts

- manufacturing plants which start with low production

- product of consistent quality assured through continual testing

- provision of reliable supply to dealers

- distribution featuring a back haul market

- location close to market 
- a marketing alliance with many dealers established before plant built Industry representatives, all members of the Fibre Fuels Institute, presented case histories consistent with Whittier's observations.

\section{Critical Barriers Qutlined}

The participants were carefully selected and to represent every major stakeholder group in the industry: pellet appliance and fuel manufacturers, retailers, stove installers, lumber manufacturers, pellet users, foresters, government officials and regulators. Meeting in four groups facilitated by the USFS professionals, the participants discussed the key barriers to faster growth in the industry:

- retailers who do not understand and/or do not accurately communicate accurately to customers the advantages and disadvantages of pellet stoves over other solid fuel appliances;

- inadequate training to stove installers.

- a relatively uninformed understanding of the customer market and customer motivations in the Northeast.

- unacceptably wide variations in the quality and consistency of the fuel, especially ash content; and the absence of appliances capable of cleanly burning fuels with higher ash content.

- high feedstock, processing, and freight costs relative to other home heating fuels, except electricity.

- the absence of a serious air quality problem associated with residential solid fuels combustion, unlike the Rocky Mountain and Northwest states.

The forum participants achieved a high degree of consensus on these obstacles.

\section{Recommendations to Overcome Barriers}

Not surprisingly, the participants moved next to address the barriers, asking umbrella organizations, government, and nonprofit organizations to educate consumers, stimulate the industry with tax incentives, and trumpet the environmental benefits of pellets. Specifically, the forum participants suggested that: 
- manufacturers better educate dealers about proper operation of pellet stoves, and that certification programs be established; a similar . certification process should improve the quality of appliance installations among chimney sweeps.

- engage government and nonprofit organizations such as the Regional Biomass Programs to print brochures, produce videos, testimonials, convene conferences and generate news releases which describe accurately to consumers the advantages of pellet stoves, and their proper installation, maintenance and operation;

- industry and government both champion the establishment of pellet fuel standards to insure uniformity, consistency, lower ash contents;

- manufacturers improve the technology of appliance designs so that "clinkers" do not materialize in the combustion chamber from impurities in pellet fuels;

- through market research, retailers improve their understanding of present and prospective residential pellet burners;

- encourage government incentives, including tax and emission credits for pellet stoves.

The participants agreed almost unanimously that a regional conference for a wider audience should focus on stakeholder group education sessions. The NRBP, Fibre Fuels Institute, Northeast Hearth Products Association, and Northeast Forestry Alliance are planning to stage such a conference during the spring of 1994. 


\section{Title: Wood Stove Stress Test Workshop}

Rationale: Acceptance by the wood stove manufacturing industry of documented persistence problems in maintaining low particulate emissions has been a continuing problem. The workshop was proposed to share with industry the methodology and results of the previous year's stress testing sponsored by NRBP and co-sponsored by EPA, and the Northwest RPB and the Canadian Combustion Research Laboratory. The intention is to stimulate changes in woodstove design to improve long-term performance of the appliances.

Objectives: To educate manufacturers about the methodology and results of the wood stove stress testing project and to inspire changes in wood stove design; and to accept suggestions from manufacturers which might improve the methodology.

Approach: To maximize the attendance and to enable direct observation of stress testing in the laboratory, a one-day workshop at the testing facility was proposed. To assure maximum objectivity and a variety of perspectives, representatives of EPA and the Hearth Products Association were also invited to speak at the workshop. The workshop would focus as much on the testing methodology as on the results and the implications for stove design.

Tasks:

(1) Organize Agenda and Conference Date.

(2) Solicit Speakers for the Workshop.

(3) Complete mailing for participants.

(4) Prepare materials for the workshop.

(5) Host the workshop.

Status: Project completed 2/93.

NRBP Funding: $\$ 7,000$.

Contract Period: August 1992 to February 1993. 


\section{Principal Findings and Accomplishments to Date}

Under the aegis of the Northeast and Northwest Regional Biomass Programs, Omni Environmental Services and the Hearth Products Association (HPA) held a workshop in Portland, Oregon on February 9 to discuss research findings and woodstove design applications from stove stress testing carried out in Omni's laboratory over the past two years. The stress testing was carried out to simulate in the laboratory homeowner operation of a woodstove over the duration of a heating season. The stress testing methodology was developed to assist manufacturers in their designs of stoves which can maintain low emissions for many years.

Thirty-five people, representing more than 15 manufacturers and over half of all stoves manufactured in North America, attended the Omni workshop. The workshop also featured remarks by regulators from the Environmental Protection Agency (EPA) and the Oregon Department of U.S. Environmental Quality (DEQ). Bob McCrillis, an EPA official very instrumental in sponsoring wood stove research over the past eight years, introduced the workshop by outlining the sponsors' goal: He stressed that the objective of the study is to identify lingering design problems and stimulate manufacturer design changes with the assistance of this new tool, the stress test. Mr. McCrillis emphasized that EPA had no plans to change the current regulation, or make anything more burdensome on an already downsized industry. He observed that the existence of the current EPA regulations certifying low emissions appliances had improved the efficiency and emissions of the appliance quite significantly: "Today's wood stove is engineered, not patched together," he concluded.

John Crouch and Gary Satterfield of HPA remarked that the certification test method required by EPA resulted in stoves designed to pass the standard, but not necessarily to meet durability objectives. Mr. McCrillis agreed, and cited Omni's earlier work pointing to specific design flaws promoted by the test standard.

Several manufacturers did acknowledge the value of the earlier CONEG Policy Research Center and BPA RBP studies, asserting that they give numerical values and identified trends only rumored in the industry--that early catalytic and noncatalytic stoves were poor performers in the field.

Industry representatives cautioned that manufacturers needed more advance warning before having to adapt to new regulations. One manufacturer noted that stove sales today are approximately 150,000 annually, one-tenth the sales of ten years ago. Therefore it will take a decade 
of sales at this pace to change out one year of dirty stoves sold a decade ago.

John Crouch presented the HPA position on stress testing, making five general points:

(1) The marketplace works, so additional regulations are not required. It works because industry responds when the typical 2-3 warranties are called upon by dissatisfied customers. Either design changes are made or dealers stop carrying the stove.

(2) Designing for the certification test does not design for long-term durability. The test is a flawed representation of the real world operation.

(3) There are some people who will abuse any stove, no matter how well engineered and manufactured. These abusers represent a very small percentage of all users, but they are the cause of much of the publicity about the nondurability of stoves.

(4) The Omni stress test results only proves that one can design a test which can abuse a stove. In other words the Omni stress test simulates not real world experience, but rather demonstrates that you can ruin anything if you try hard enough.

(5) The appropriate regulatory response to stove air pollution is opacity limits, the route taken in Washington state and Albuquerque.

These regulations more appropriately regulate the stack, not the stove. A $20 \%$ opacity limit is a fair test of air pollution.

Omni's presentation of the stress test results emphasized its match to measured field conditions after one heating season of operation. By burning at high burn rates, leaving ajar stove loading doors, leaving open bypasses for twenty minutes or more at a time, obtaining strong drafts, and continuously firing the stove for a period of ten days to two weeks, Omni's researchers provoked warping in door openings, around bypasses, and in baffles. Catalysts failed and emissions increased two-three fold. and door openings badly warped.

Manufacturers unanimously responded that the stress test was not a reflection of actual stove owner behavior, and noted as evidence the very few certification recalls they experienced. Most said they had never seen stoves so deteriorated in the field. 
We might summarize this very successful industry/regulator/research community dialogue as follows:

1. Manufacturers have paid too little attention to the quality of component materials and to the quality of welds and other manufacturing details in their engineering of certified appliances.

2. Catalysts fail or degrade much more quickly than manufacturers admit, or consumers realize;

3. Design and materials quality and manufacturing quality control can improve the next generation of stoves;

4. EPA regulatory changes of any kind are unlikely;

5. The stress test must be modified so as not to be quite so damaging so quickly if it is to gain any credibility among manufacturers;

6. Local and state opacity standards as an alternative vehicle for enforcing particulate controls, in combination with consumer education activities and stove changeout promotions, are worthy alternatives for regulators to consider in some locations. 
STATUS REPORTS: ACTIVE PROJECTS 


\title{
NORTHEAST REGIONAL BIOMASS PROGRAM Applied Research \& Technology Transfer
}

\author{
Technical Projects - Status Report
}

December, 1993

\section{Title: Booklet for Key Decision Makers on Potential for Wood Chip Heat in Commercial \& Industrial Facilities}

Rationale: Even though wood chip combustion facilities have been in existence for several decades, the technology is unfamiliar to most engineers and facility managers outside the forest products industry.

Objectives: The objective of this booklet is to provide a simple, usable working tool to enable public boards, administrators and other decisionmakers, including private owners of commercial or industrial facilities in the Northeast to:

(1) Consider the replacement of existing energy systems (or the installation in new facilities) of wood-chip energy systems;

(2) Investigate the economics of wood-chip heat, hot water, and drying and process steam applications, using life-cycle cost and cash-flow analyses;

(3) Compare different types of wood-chip systems and select a system appropriate to the needs of their facilities;

(4) Implement wood-chip energy projects.

The target applications (new and retrofit) fall in the 1-10 MMBTU range and are generally on a turn-key basis.

Approach: Contractors will employ an extensive review of secondary data on wood-chip installations and will conduct a phone survey of a representative range of installations and decision makers. Contractors will draw upon their own project team expertise and may interview CONEG membership. Site visits will be undertaken to a select group of installations that provide unique or instructive installations. A booklet will be produced based upon RFP guidelines on content which will draw upon the above data. 
Tasks:

(1) Research applicable wood-chip systems in the NE and E.Canada through review of secondary research and by conducting a phone survey of applications

(2) Research wood-chip supply throughout the NE region

(3) Conduct Existing Chip System Site Visits (unique or instructive applications only); report observations, including photos

(4) Develop Guidelines and Tools for Economic Analysis of Prospective Wood-Chip Systems

(5) Research Financing Options for Wood-Chip Installations

(6) Examine Varying Modes of Project Management and Implementation

(7) Develop Guidelines for Assessing the Efficiency, Stack Emissions and Safety of Manufacturers' Wood-Chip Combustion Systems

(8) Describe Options for Public Participation and Education in a Wood-Chip Project

(9) Categorize Operational Issues for a Successful Wood-chip System

(10) Develop Outline of Booklet Content following RFP guidelines for project management prior approval

(11) Produce 300 Copies of Booklet,estimated at 60 pages. Retain a nontechnical professional editor and professional graphics personnel to assure professional quality production. Coordinate with Vermont Steering Committee and CONEG.

(12) Prepare Timely Progress Reports for CONEG Policy Research Center, including quarterly written reports and oral presentations to the project Advisory Committee 
Status: Draft guide completed and under review.

Contractor: Energy Efficiency Associates, Calais, Vt.

Tim Maker (802) 223-6918

NRBP Funding: $\$ 18,725$

Cont. Period: February - October 1993

Extension until January 1994 


\title{
NORTHEAST REGIONAL BIOMASS PROGRAM Applied Research \& Technology Transfer
}

\author{
Technical Projects - Status Report
}

\section{December 1993}

Title: Impediments to Development of Landfill Gas Recovery Projects in the Northeast

Rationale: The technology of converting landfill gas to energy (LFG) has been known for some time and LFG projects have been operating in the West; however, the development of such projects has been slow in the Northeast.

Objectives: To assist potential developers of landfill gas to energy sites in the Northeast and associated policy and regulatory personnel to understand the current state of the industry and to realize new development opportunities. In addition, the project will identify candidate landfill sites in the Northeast for LFG recovery; estimate the total energy potential available from LFG in the Northeast and will provide information that could be used to affect state and federal energy policy.

\section{Approach:}

PHASE I: A survey of the LFG industry will identify the parameters for a successful project and identify any impediments to success. Contractors will employ a data search, data from the surveys, other secondary data and their own expertise to develop a handbook providing project feasibility criteria, strategies to overcome both technical and non-technical barriers to development, and technical siting criteria.

PHASE II: A review of existing landfill databases and visits to up to four NE states will provide input to a new database of active landfills larger than 100 TPD, with emphasis on the 60 sites receiving 500+ TPD. The contractors will apply criteria developed in Phase I to rank landfills by state for attributes favoring development. A software package will be developed for estimating LFG yield and economic feasibility. 
Tasks:

\section{PHASE I}

(1) Conduct a literature review and prepare a summary report addressing the technical, economic, institutional and environmental aspects of developing LFG recovery projects. The discussions will emphasize changes the industry has undergone over the past five years.

(2) Interview LFG developers, owners, utilities, financiers, and others to determine national and regional perspectives

(3) Identify project feasibility criteria for the following: landfill characteristics; energy sales agreement; regulatory/environmental conditions; tax incentives and subsidies; landfill owner-LFG developer procurement.

(4) Describe barriers to success, ranking relative difficulty, and provide options to overcome each potential barrier

(5) Provide guidelines for technical siting decisions in Northeast

(6) Identify non-technical factors critical to success

(7) Prepare a draft handbook with products and data from steps 1-6 for review (4 copies)

\section{PHASE II}

(1) Compile Landfill Database

(2) Identify and Group Landfills for LFG Development Based on Technical Criteria

(3) Rank Landfills for LFG Development, Applying Non-Technical Factors

(4) Develop Criteria and Methodology or Qualifying Landfills for LFG Development (software model)

(5) Produce final handbook (including Phase I draft material); provide LFG recovery economic model in hard copy and disks 
Contractor: SCS Engineers, 11260 Roger Bacon Drive, Reston VA, 22090. Attn: Mike McGuigan (703)471-6150.

NRBP Funding: $\$ 68,801$

Cont. Period: 12 months, starting February, 1993

Status: Phase I completed

Phase II completion expected March 1994

\section{Principal Findings and Accomplishments to Date:}

Phase I has been completed. The interviews and analyses focused on the technical, economic, and institutional barriers to siting LFG-to-energy projects. The technical elements for a successful project features an active landfill with several years of future life; at least 30 acres; and 2 million tons or more in place. LFG recovery systems must overcome barriers presented by unachievable production estimates; elevated liquid levels; and condensate management problems. Utilization systems with proven equipment, 1-2 M minimum size and standardized plant designs are most likely to succeed. Utility avoided costs at 6 cents or higher; low financing costs; and the ability to access tax credits are the keys to economic projects.

Landfill owner perceptions and utility interests in small power purchases are the key institutional issues. A landowner experienced with LFG issues; a landowner responsible for the supply of LFG; and a proactive electric utility are critical components of a successful institutional strategy. Air, water and solid waste regulations must also be met: early meetings with state regulators and a sound management strategy of condensate with landfill leachate are important. Regulatory issues of concern include air emissions in nonattainment areas; complying with several different permitting jurisdictions; and implementation of the proposed New Source Performance Standards expected from EPA in the spring of 1994.

The final task of the project is the identification of candidate landfills for possible LFG utilization. The contractor has identified $\mathbf{5 3 0}$ landfills in the region; of these 202 are considered good candidates for their size, composition, and age. There are currently 41 existing LFG projects, led by New York's 16 and Pennsylvania's 8 . Another 22 are planned in the region. 


\title{
NORTHEAST REGIONAL BIOMASS PROGRAM \\ Applied Research \& Technology Transfer
}

\author{
Technical Projects - Status Report
}

May, 1993

\section{Title: Lessons Learned II: Woodstove Emissions}

Rationale: There is too little consumer awareness about the advantages in efficiency and air emissions improvement in the certified wood stove. That the certified stove demonstrates $25 \%$ efficiency improvements and $200 \%$ emissions improvements over conventional airtight stoves sold before 1989 is a well-kept secret. Stove sales are today about $20 \%$ of what they were ten years ago. Both the pace of stove changeouts and consumer interest in purchasing wood stoves for the first time would improve if accurate, compelling information could be directed to consumers.

Objectives: To increase awareness among consumers of improved safety and performance of wood stoves and to enhance consumer purchases of clean-burning wood stoves in the Northeast.

Approach: Working closely with the Northeast Hearth Products Association, develop a retail promotion strategy designed to sell stove change-outs. The campaign will be designed to build upon an earlier NRBP project which developed promotional and educational materials and employed mass media channels. Retailers would pay for electronic media "time" or for costs of print media. This project would provide ad slicks, newspapers inserts, radio promos, and other promotional materials. The campaign will last from midJanuary to the end of February and encompass New England and New York.

\section{Tasks:}

(1) Develop a retail promotional campaign based on the theme of Old Stove Amnesty, include retailer and project management input to improve impacts

(2) Develop a name, a logo, two print advertisements, camera-ready headlines and copy points, a sore banner design, and a product hang tag.

(3) Establish media targets among print, radio and TV in seven state region. 
(4) Designate an expert and organize a radio tour to promote "Clean Heat Woodstove Exchange"; draft press release for media; release wire photo for AP and UPI to accompany newspaper articles; produce video news release for TV stations.

(5) Document impact of campaign through retailer surveys, phone interviews, review of sales data, or other suitable methods

Status: Tasks 1-3 Completed; Tasks 4 to be completed by mid-December

Contractor: Kelliher/Samets/Volk , Burlington, VT, (802)862-8261

NRBP Funding: $\$ 50,000$

Contract Period: June 1993 - March 1994

Principal Findings and Accomplishments to Date:

The NRBP contractor has worked successfully with an Advisory Committee comprised of three state Steering Committee members, the Northeast Hearth Products Association (NHPA), the NRBP Technical Coordinator and Program Manager. NHPA has, in turn, assigned a five-person advisory committee of retailers, distributors and manufacturers to work with the project. More than 50 retailers have formally agreed to participate in the Stove Changeout campaign, and will take out newspaper advertisements announcing the rebates for new stoves in exchange for pre-certified stoves turned in by, customers.

The contractor has developed the logo, two print advertisements, product hang tags and promotional brochures for retailers. A video news release has been produced and will be mailed to more than 50 TV stations in the region. A radio talk show expert has been briefed for the campaign and a news release suitable for the print media has been produced. The state of New York has volunteered once again to field all consumer telephone calls at its 800 number telephone hot line.

The campaign will kick-off January 18 and continue through the end of February. The contractor, with the assistance of NHPA, will track stove sales during this period. The goal is 1500. NHPA is also responsible for recruiting volunteers to cart the old stoves away to metal recyclers. None of the old stoves turned in will be resold. 
The news releases and video news release stress the air pollution advantages of the EPA-certified stoves. The video news release calls attention to the brochure published in Phase I of this project, completed in 1992. The brochure, in turn, advises the consumer on stove purchase, installation, operation and maintenance issues. 


\title{
NORTHEAST REGIONAL BIOMASS PROGRAM Applied Research and Technology Transfer
}

\author{
Technical Projects - Status Report
}

December 1993

\section{Title: Comparative Analysis of Landfill Gas Technologies .}

Rationale: The LFG industry is still emerging in the United States. There are four-five technologies which are recently commercialized or not yet commercialized which are deserving of comparative analysis for their application to landfills.

Objectives: To compare and evaluate several gas-to-electricity technologies for their economic and environmental costs and benefits

Approach: Through interviews, literature reviews and analysis, compare costs and benefits of alternative conversion technologies

Tasks:

(1) Select and describe a typical landfill gas composition.

(2) Perform a comparative analysis among several technologies, looking at both economic and environmental (air emissions) costs and benefits, including economic incentives which may be available to LFG projects.

(3) Given the system designs developed for Task 1, estimate capital investment, operating and maintenance costs.

(4) Examine existing and pending regulations in the 11-state region as well at the federal level to ascertain whether reduction of emissions due to LFG energy projects qualify for any economic incentives, including off-site emissions reduction credits.

(5) Determine the types of project partnerships that are necessary to maximize federal economic incentives, in terms of the PTC or the REPI, for each technology considered.

(6) Obtain from Public Utilities Commissions current purchase prices regulated electric utilities are required to offer for electricity from LFG projects of $5,000 \mathrm{KW}$ capacity or less. 
(7) Obtain from each state's Public Utilities Commission what Environmental Externalities monetary values for air emissions, if any, which are either in effect or being considered.

(8) Using the information developed in the preceding tasks, perform a comparative analysis (within the 1000 to $3000 \mathrm{KW}$ range) between all conversion technologies under consideration to compute and tabulate all pertinent parameters associated with each technology, including the following:

- efficiency;

- capital cost (in total $\$$ and in $\$ / K W$ installed);

- power generation cost, cents/Kwh

- air emissions in lbs/Kwh.

(9) Prepare a tabulation comparing each conversion technology's air emissions (in lbs./kWh) to those in the system margin of each utility, to the extent available data permit.

(10) Review the CAAA and state regulations to ascertain whether a case could be made for legislative and regulatory action establishing mechanisms to credit the emissions reductions achieved by LFG projects and to enable such credits to be sold to help generate economic incentives for such projects.

(11) Prepare a tabulation comparing information obtained in Task 5 and 6. Also, indicate the states with monetary values for Environmental Externalities that allow trading of off-site emission reduction credits, similar to the case in Massachusetts.

(12) Prepare a tabulation showing air emissions changes at the landfill site (before and following implementation of each LFG conversion technology considered) for several source pollutants.

Status: Began in October 1993

Contractor: SCS Engineers

NRBP Funding: $\$ 40,000$

Contract Period: October 1993 - August 1994 


\section{Principal Findings and Accomplishments to Date}

The contractor has obtained reference data from the technology/equipment vendors for the IC engine, gas turbine, Organic Rankine and Stirling cycle. Conceptual designs of the $\mathrm{IC}$ and gas turbine system have been completed for 1 and $3 \mathrm{M}$ systems. Comparative analysis spreadsheets to tabulate performance data, costs, emissions, and environmental externalities have been developed.

The contractor also contacted all 11 PUCs to gather information concerning energy purchase prices, standard contracts and environmental externalities. The contractor met with our externalities contractor, Meridian, coordinate their investigations. The contractor completed a status report on energy purchase rates and externalities by state. 


\section{NORTHEAST REGIONAL BIOMASS PROGRAM \\ Applied Research \& Technology Transfer}

\section{Technical Projects - Status Report}

December 1993

\section{Title: Biomass Facilities Directory}

Rationale: A NRBP-sponsored 1987 directory of industries, businesses, utilities and institutional facilities in the eleven NE states listed about 400 facilities using wood to generate energy in 1986, with an emphasis on facilities using wood to generate more than 3 million BTUs (or 3,000 pounds of wood) per hour. It also provided more detailed information about the operation of biomass energy systems for about half of those facilities. The directory has proven to have widespread application to policy decision-makers and others in the region. Information in the 1987 directory is now six years old-its continued value is increasingly compromised.

Objectives: The primary objective of this project is to compile a comprehensive, updated database of industries, businesses, institutions and utility companies using biomass for fuel in the eleven northeastern states. The second objective is to input information into the modified Biomass Facilities information System (BFIS), an automated menu-driven database designed to run on any IBM PC or compatible available for bidders interested in developing a project.

Approach: Contractor will conduct a review of existing Directory listings to provide accurate current information in addition to the development of a data base in needed form on new facilities not previously listed. The current Biomass Facility Census Form will be revised to accommodate the data requirements of the BFIS. A report will be prepared describing any cases in which facilities have ceased to use wood since 1987. Quality control checks will assure accuracy of data.

\section{Tasks:}

(1) Obtain amendments to 1987 list of facilities from NRBP Steering Committee members (state contacts).

(2) Obtain lists of wood-burning facilities for the northeast region from trade associations and air quality offices.

(3) Revise Facility Survey Form ("Biomass Facility Census Form") to accommodate additional data to be collected for the modified BFIS.

(4) Update contact and profile information for existing facilities still using wood and compile contact and profile information for facilities to be added to the Directory this year. 
(5) Generate the following documents for the NRBP Steering Committee to review:

a. Hard copy of Facility Reports for all facilities in the database.

b. Disposition of all facilities surveyed, including facilities which were found not to be burning wood or other biomass, and facilities for which information could not be obtained despite efforts to contact and solicit information. (This disposition report will constitute the firm's record of attempted as well as successful contacts.)

c. Quality control report summarizing measures taken to ensure the accuracy of the information gathered and the data entered into the BFIS.

Status: Final Data Collection Format completed (Task 3); Tasks 1,2 \& 4 underway.

Contractor: Combustion Testing \& Engineering

NRBP Funding: $\$ 30,000$

Contract Period: September 1993 - June 1994

Principal Findings and Accomplishments to Date:

The contractor, Commercial Testing and Evaluation, has completed an extensive survey of state and regional air quality offices to discover the identity of all biomass facilities with a capacity of 5 million BTUs/hr or more. Written questionnaires and telephone interviews have revealed scores of facilities in the region not identified in the survey completed in 1987.

In the course of this investigation, the contractor has also discovered that many of the biomass facilities, most of which have a dual fuel capability, are not burning wood today. The declining real price of oil in the mid and late eighties caused many of these facilities, particularly those outside the forest products industry, to substitute oil for wood.

The major growth in wood-burning facilities has been the siting of independent power plants, including the siting of six in New Hampshire since the publishing of the report. There are currently 48 utility-sized boilers in the region, including 22 in Maine, 9 in New Hampshire and 8 in New York. Several schools in Vermont have recently converted to wood; a school in Pennsylvania has converted as well. The vast majority of new installations are expected to be found in the forest products industry, where feedstock costs are negligible or negative, due to disposal fees.

The contractor will commence surveying of individual facilities in February 1994. 
NORTHEAST REGIONAL BIOMASS PROGRAM

Applied Research \& Technology Transfer

Technical Projects - Status Report

December 1993

\section{Title: Resource Survey of Large-Scale Liquid Fuel Products From Biomass}

Rationale: There exists a variety of laboratory-tested technologies for converting woody and other biomass feedstocks into ethanol and other biofuels which can readily be used to displace fossil-based fuels in the generation of electricity. One key to successful transfer of current conversion technologies to commercial-scale liquid fuel production is the availability of a low-cost feedstock resource. The Northeast region is less well suited than other parts of the country to the development of short rotation crops as a competitive fuel feedstock. In the Northeast, a more economical feedstock may be biomass waste materials, such as waste paper, which have a low or even a negative value due to increasing disposal costs. Up-to-date information on available resources and on potential support or impediments to project development is needed by policy makers and potential commercial developers.

Objectives: The ultimate purpose of this project is to encourage the development, in the Northeast, of a large-scale demonstration project or commercial facilities using biomass waste materials to produce ethanol or other liquid fuels. The immediate objective of this stage of the project is to generate a base of information on the availability of economically competitive and sustainable biomass waste feedstocks which meet criteria for utilization with existing conversion technologies, including (but not necessarily limited to enzymatic and acid-based hydrolysis conversion technologies. NRBP seeks responses to the following questions:

(1) How much potential feedstock material exists?

(2) What is the cost to extract/obtain these materials as feedstock for the large-scale commercial generation of liquid fuel?

Approach: The project is envisioned to proceed in three phases: (1) Preliminary Resource Survey; (2) Further Evaluation of Potential to Support a Large-scale Biomass-to-Ethanol Conversion Facility; (3) Identification and Detailed Analysis of Candidate Demonstration Sites. The focus of this project is I: Resource Survey only. The survey will rely on existing research and data. 
Tasks:

(1) Establish the requisite characteristics (e.g., acceptable types of material, moisture content, etc.) needed to qualify potential biomass waste feedstock materials for both enzymatic and acid-based hydrolysis conversion processes.

INTERIM REPORT TO NRBP STEERING COMMITTEE: present criteria to be used in defining potential feedstock materials, and plan for proceeding with the regional resource assessment.

(2) Identify potential feedstock sources by state and county (or other jurisdictions, as appropriate), including both MSW and other significant sources which may not show up in the MSW stream.

(3) Describe any anticipated change in availability or value/cost of feedstock over next ten years.

INTERIM REPORT TO NRBP STEERING COMMITTEE: present findings of tasks 2 and 3.

(4) For areas within the region where potential resources and energy demand are concentrated, make a preliminary identification of the fuel most likely to be displaced, and any relevant environmental or regulatory barriers or incentives to development of a waste-to-ethanol site.

(5) DRAFT FINAL REPORT TO THE NRBP STEERING COMMITTEE: The draft final report will be distributed to the Steering Committee in time for the Committee to review the document prior to a presentation and discussion of the findings by the contractor.

(6) FINAL REPORT TO THE NRBP STEERING COMMITTEE. The final report should incorporate a discussion of the implications of the Resource Survey's findings for the development of ethanol to liquid fuel in the Northeast. The report will be made available to the Center both in hard copy and on diskette.

Status: Interim Report for Tasks 1-2 Completed.

Contractor: C.T. Donovan Associates

NRBP Funding: $\$ 40,000$

Cont. Period: July 1993 - May 1994 


\section{Principal Findings and Accomplishments to Date:}

The contractor, C.T. Donovan Associates, has identified the critical characteristics of biomass feedstocks which affect ethanol production:

carbohydrate content as a percentage of weight;

presence of inhibitory materials (e.g. preservatives);

potential yield in gallons per ton of material;

feedstock components suitable for co-product manufacture;

homogeneity;

stability during storage;

availability, both in quantity and by season;

total production yield in tons per year;

nutrient/mineral requirements during feedstock growth cycle;

competing uses;

disposal costs;

bulk density.

These characteristics assisted the analysis which narrowed the list of potential feedstocks to the following:

forestry wood wastes;

mill residues

urban wood wastes;

mixed waste paper;

paper sludge;

cheese whey.

The contractor is now determining the availability of each of these feedstocks. A partial inventory has yielded the following to date:

forestry wood. wastes: $18,641,000$ tons

mill residues:

$4,197,000$ tons

urban wood wastes:

$7,235,000$ tons

cheese whey:

$4,106,000$ tons

In 1994 the contractor will estimate the availability of mixed waste paper and paper sludge. Additional research will focus on competing uses and the feedstock costs of acquiring each of these resources. 


\title{
NORTHEAST REGIONAL BIOMASS PROGRAM Applied Research and Technology Transfer
}

\author{
Technical Projects - Status Report
}

December 1993

\section{Title: A Methodology for Environmental Externalities: Accommodating Biomass Feedstocks}

Rationale: In the valuation processes undertaken by public utility commissions, woody biomass are penalized because their full fuel cycle environmental impacts are not taken under consideration in the calculation of environmental externalities. As a result biomass technologies are treated comparable to coal-burning in impacts.

Objectives: To propose a credible methodology for incorporating the $\mathrm{CO} 2$ sequestration impacts of growing biomass in an externalities methodology; to identify existing PUC methodologies which are most amenable to such an application.

Approach: This project begins with an examination of proposed and existing regulations regarding economic and environmental externalities for PUC action, with an emphasis on how $\mathrm{CO} 2, \mathrm{NOx}$ and $\mathrm{SO} 2$ are handled; the project then turns to proposing an appropriate life-cycle evaluation process, considering total fuel-cycle impacts. Job creation and economic impact value-adders are also to be considered; and a strategy for promoting modifications to existing externality methodologies to incorporate these changes will be formulated.

Tasks:

(1) Carry out a literature review and interviews with consultants, PUC staff, and commissioners to understand and analyze current environmental externality methodologies, featuring total fuel-cycle analysis approaches and economic impacts of specific technologies.

(2) Draft report outlining the status and key features of existing/emerging technologies, documenting the impacts considered, how values are assigned to those impacts and applied to resource planning.

(3) Propose one or more approaches for appropriate life-cycle evaluation of biomass energy projects, considering total fuel-cycle impacts.

(4) Evaluate the arguments for and against establishing an absolute externality value or percentage adder to account for the development of economic development impacts of utilizing various energy resources. Propose an approach and approximate measures of job creation and associated benefits of 
energy from wood, natural gas, coal, and oil, for subregions within the Northeast.

(5) Project the likely impacts of the proposed methodology on electric power generation in the region, and on resulting total fuel-cycle emissions levels, electric rates, and job creation within the region as compared with the likely impact of two-three representative IRP methodologies now employed in the region. Address when and how quickly the proposed approach or approaches, if adopted, might affect the regional resource mix.

(6) Identify opportunities to influence or modify the region's resource planning processes. Assess the relative value of promoting such modifications. Given the prospects for adoption of total fuel-cycle approaches, and the likely resulting impacts on the resource mix, outline a strategy for pursuing the recommended modifications.

(7) Draft a final report incorporating the findings, analyses, methodologies and recommendations in Tasks 1-6.

Status: Project kick-off meeting occurred in November

Contractor: Meridian Corporation

NRBP Funding: $\$ 49,935$

Contract Period: October 1993 - August 1994

\section{Principal Findings and Accomplishments to Date:}

The consultant is interviewing PUCs and examining existing data bases to gather information concerning the present regulations and methodologies associated with environmental externalities. The contractor has conferred with the LFG technology contractor and the Economic Development contractor to coordinate data collection efforts. The initial report on this investigation is expected in the spring of 1994. 


\section{NORTHEAST REGIONAL BIOMASS PROGRAM \\ Applied Research and Technology Transfer}

Technical Projects - Status Report

December 1993

\section{Title: Update on Economic Impacts Study}

Rationale: The widespread public perception that wood energy is at best a marginal contributor to the energy mix handicaps the industry's clout in regulatory and public policy arenas. A well- documented study updating an older estimate of the job creation and economic development impacts of the industry would help improve its prospects.

Objectives: Document and estimate the dollar savings, direct and indirect economic impacts, including job creation, associated with the wood energy industry.y

Approach: Establish a structure and parameters of economic impact model. Provide a simplified version that states can run on a PC to determine the impact (on such outcomes as direct and indirect employment, income, and energy cost savings) of projects that increase the state's overall wood energy use. The model should at a minimum be able to estimate direct and indirect employment impacts, as well as impacts on income and fossil fuel displacement, and to distinguish between residential and commercial/industrial wood energy use impacts. The model should account for employment and income that might have been generated by energy sources (e.g., oil) displaced by wood energy. Data on employment and income and economic multipliers for oil and other energy sources will be calculated from available published and unpublished sources.

\section{Tasks:}

\section{Phase 1: Economic Impact Model}

Task 1.1 - Consult with CONEG and Northeast States on Final Product Needs.

Task 1.2 - Design Economic Impact Model.

Tasks 1.3 and 1.4 - Program and Test-Run Model on Mock Data.

\section{Phase 2: Survey Employment and Economic Characteristics of Wood Energy Industry}

Task 2.1 - Design a Survey of Employment and Salaries.

Task 2.2 - Conduct the Survey and Interpret the Results. 
Phase 3: Compile Data and Estimate Present Economic Impacts.

Task 3.1 - Compile Wood Fuel Use and Plant Data on a State-by-State Basis.

Task 3.2 - Estimate Present Wood Energy Use.

Task 3.3 - Run Model to Estimate Present Economic Impacts.

Phase 4: Develop Scenarios

Task 4.1 - Develop Wood Energy Use Scenarios for the States.

Task 4.2 - Run Model to Estimate Economic Impact through 2010.

Tasks 4.3 and 4.4 - Develop Simplified Project Version of the Economic Impact Model for PC and Write a Supporting Manual and Workbook.

Task 4.5 - Test and Assist States in Use of the Project Model.

Phase 5: Reporting and Presentations

Task 5.1 - Compile Final Report.

Task 5.2 - Regional Presentations

Status: Project underway in November 1993

Contractor: Resource Systems, with assistance from Energetics

NRBP Funding: $\$ 40,000$

Contract Period: October 1993 - August 1994

Principal Findings and Accomplishments to Date:

The contractor has met with the Steering Committee to identify facilities which have sufficiently detailed information to test the economic impact model. The assumptions underlying the economic impact model developed in 1985 are being changed to reflect existing conditions. The contractor has met with Meridian and SCS to coordinate the investigations which lead to the same organizational sources. The contractor has also spoken with the Facilities Directory contractor, Combustion Testing and Engineering, to obtain an updated estimate of the number and size of medium and large facilities in the region. This estimate will form the basis for much of the analysis which follows. 


\section{NORTHEAST REGIONAL BIOMASS PROGRAM \\ Applied Research and Technology Transfer}

Technical Projects - Status Report

December 1993

\section{Title: Wood Pellet Fuels Conference}

Rationale: The chicken-and-egg problem which has bedeviled the emergence of the pellets industry has many roots. Concerted and informed activity by government and industry will accelerate the penetration of both stove sales and pellet sales in the region. The Pellets Forum held last June created an Action Plan for both the private and public sectors: the Conference should gain attention for the Plan and afford participants with information and training to effect its recommendations

Objectives: To inform, motivate and train participants to carry out Action Plan drafted in last June's Forum. To update status of industry in the region.

Approach: To co-sponsor a conference of $150-200$ participants late in the spring or early summer of 1994.

\section{Tasks:}

(1) Form steering committee.

(2) Prepare Conference program.

(3) Contact and confirm key participants.

(4) Prepare program curricula materials for training sessions.

(5) Solicit exhibitors for Conference

(6) Arrange meeting site and facilities.

(7) Prepare a record of Conference.

Status: Underway as of November 1993

Contractor: New England Forestry Alliance

NRBP Funding: $\$ 25,000$

Contract Period: November 1993 - August 1994 


\section{Principal Findings and Accomplishments to Date:}

The conference recommended strongly by the participants in the June 1993 forum is now being planned. A conference advisory committee comprised of representatives of the Northeast Forestry Association, the Fibre Fuels Institute, the Northeast Hearth Products Association, and the Northeast Regional Biomass Program Steering Committee has been organized. Establishing a date, completing the two-day conference agenda and organizing curricula for chimney sweeps and fire inspectors; retailers; and energy officials is the priority for the first two months of 1994. The conference is planned for June, 1994.

The location for the conference will be southern New Hampshire. After a general information session, several breakout sessions to discuss trade-specific issues (e.g. setting standards for pellets, improving the designs to overcome ashing problems, lowering production costs among pellet manufacturers), and safety concerns, the conference will repeat the practices of the forum of utilizing facilitators to identify lingering barriers and suggesting solutions to overcome them. The conference is expected to attract $150-200$ participants. 
NORTHEAST REGIONAL BIOMASS PROGRAM

Applied Research \& Technology Transfer

Technical Projects - Status Report

December 1993

\section{Title: Governors' Round Table}

Rationale: Biomass is the Northeast's greatest renewable resource for energy production. Biomass, appropriately developed, offers numerous opportunities to diversify the Northeast energy base by reducing dependence on imported energy while meeting the regions's tough emissions requirements. The development of a locallybased biomass fuels industry would lead to the creation of jobs through all phases of the energy production cycle. Yet the potential and benefits of biomass have yet to be fully recognized by all stakeholders such as: policy leaders, investors, environmental groups; utilities; and government.

Objectives: The Biomass Round Table is a convening of invited stakeholders, representing all aspects of production, consumption and regulation of biomass derived energy. Meeting in facilitated sessions, the stakeholders will engage in open, frank, and substantive discussions. The outcome of these discussions will be to arrive at a consensus finding encompassed in an action plan. The action plan will specify: the tasks that must be completed to overcome any institutional, regulatory, or market barriers to increasing the utilization of biomass derived energy in the region; the organizations that must accomplish those tasks; the time frame in which the tasks must be completed and; an estimate of the resources that are needed to complete the tasks.

Approach: A series of professionally facilitated policy forums with an invited group of biomass stakeholders from the region to identify issues and jointly suggest solutions.

Tasks: 1) select a facilitator

2) select a stakeholder

3) conduct facilitated Round Table sessions

4) prepare a report on findings and present to CONEG Governors

Status: Task 1 is undenway and is expected to be completed by December 23. Task 2 is underway and should be completed by January $3,1994$.

Contractor: There is no contractor for this project. NRBP, CONEG, and Vermont DPS staff will be responsible for directing the facilitator and ensuring that the Round Table tasks are carried out.

NRBP Funding: $\$ 30,000$ has been allocated to cover the site costs, facilitator expenses, and travel costs for certain stakeholders. 
Contract Period: September 1, 1993 through June 30, 1994.

Principal Findings and Accomplishments to Date:

Governor Dean of Vermont has offered to chair the Roundtable. The NRBP has identified approximately 30 participants from the following constituencies to participate:

1) environmental organizations;

2) public utility commissions;

3) forest products industry;

4) wood energy equipment manufacturers/vendors;

5) Energy finance;

6) forest managers;

7) energy planners;

8) utility;

9) state air quality regulators;

10 ) independent power producers;

11) biomass research community.

The NRBP Planning Committee for the project has been organized and narrowed the list of facilitators to three organizations. Final selection of the facilitator shall take place in January. The facilitator is expected to organize 3-5 meetings, beginning in May. There will be a special focus on opportunities and constraints associated with large-scale facilities which generate electricity.

Invitations to participants should be mailed in February. 


\title{
NORTHEAST REGIONAL BIOMASS PROGRAM \\ Applied Research \& Technology Transfer
}

\author{
Technical Projects - Status Report
}

December 1993

\section{Title: Long Range Planning}

Rationale: A blueprint to guide the selection of technical projects will maximize the efficacy and efficiency of projects. Such a long-range plan was completed in 1984 and again in 1989.

Objectives: To guide project selection and project selection criteria over the next five years.

Approach: A written report will be available in the spring. Conference papers, interviews, issue discussions at Steering Committee meetings, technical committee forums, and other sources will assist the development of the Long Range Report. After a draft is completed, discussion and comments from the Steering Committee will precede Final Report.

Tasks:

PHASE 1. The first phase of the Long Range Planning exercise will be to map out the major resources, conversion technologies, and end uses/users, and identify in broad terms the opportunities for and barriers to forging and strengthening the connections between these categories. Tasks associated with this phase will be carried out primarily by $\mathrm{CCC}$ staff:

Task 1: Review literature and identify experts and representatives of key stakeholders who might make valuable contributions to the planning exercise.

Task 2: Attend conferences, notably the Biomass Conference of the Americas scheduled for August 30 - September 2 in Burlington, Vermont. (Also scheduled: Hearth Products Association Trade Show, March 11, 1994.)

Task 3: Prepare materials to inform and guide discussions (Phase II). 
PHASE II. The second phase of the Planning exercise will consist of focused discussions among Steering Committee members and Advisory Panels convened to address specific opportunities and barriers.

Task 4: $\quad$ Steering Committee invites experts to address specific opportunities and issues associated with specific topic areas.

Task 5: Major stakeholders invited to participate in Advisory panels, convened by teleconference.

Task 6: Integrate recommendations of the Governors' Biomass Policy Round Table.

Status: Underway since August

Contractor: Citizens Conservation Corporation

NRBP Funding: Part of Technical Support contract

Contract Period: August 1993 - May 1994

Principal Findings and Accomplishments to Date:

Issue discussion, fact-finding and research is almost completed. The report will be organized to discuss feedstock supplies, conversion technologies, and demand in three chapters. A chapter on approach will focus on dissemination of report findings and closer collaboration with DOE, its laboratories, EPA, and the other Regional Programs.

To date forums at steering committees, meetings of technical advisory committees and conferences have addressed the following issues:

1) wood stoves;

2) forestry management;

3) woodlcoal opportunities;

4) waste wood;

5) landifill gas;

Environmental concerns, especially air quality and soil and water contamination, are cross-cutting issues which infuse all of the issue forums. So too, opportunities for regional economic development and jobs creation will receive special attention.

The September 1993 First Conference of the Americas, held in Burlington, Vermont, offered particularly useful research papers and discussions on liquid fuels, wood wastes, independent power production and feedstock issues which will guide some of the long range planning agenda. 


\section{STATUS REPORTS: CONTRACTOR SELECTION OR NEGOTIATION PENDING}




\title{
NORTHEAST REGIONAL BIOMASS PROGRAM \\ Applied Research \& Technology Transfer
}

\author{
Technical Projects - Status Report
}

December 1993

\section{Title: Characterization of Woodstove Air Toxic Emissions}

Rationale: Emission factors (mass pollutants per mass fuel) are high for woodstoves as compared to industrial sources due to their relatively simple design and associated incomplete combustion of wood fuel. Their toxic content is particularly problematic because RWC pollutants are predominately either in respirable-sized particles or in the vapor phase. Such pollutants represent the highest human exposure risk due to their direct and penetrating entry into the respiratory system.

Little woodstove air toxic data exists. Most woodstove air quality research has dealt mostly with the criteria pollutants, carbon monoxide or PM10 (particulate material with an aerodynamic diameter less that 10 microns). The most notable air toxic research to date is either over a decade old or was performed with limited resources as part of the criteria pollutant work.

Objectives: To promote the appropriate use of wood energy by expanding the current RWC knowledge base on air toxins.

Approach: Contractor will employ reviews of secondary literature on air toxic data, prior testing data, and the results of laboratory testing (and optional field testing) of a selection of representative stoves. Contractors will confer closely with the Advisory Committee.

Tasks:

(1) Evaluation of testing parameters through study of 11 stoves in four categories: certified catalytic (3), certified noncatalytic (3) conventional airtight (3), and pellet (2). Contractors will prepare a pre-test report indicating rationale for selection of testing parameters and complete testing plan.

(2) Quantification of recognized air toxic compounds with emphasis on those most closely associated with human health impacts

(2a) Field validation of air toxics (optional, should lab testing prove invalid) 
Status: EPA has dropped its woodstove air testing program but the Canadian Combustion Laboratory (CANMET) has proposed to carry on the project with some modifications. Another solicitation of funding co-sponsors is underway.

\section{Contractor: CANMET}

NRBP Funding: \$

Contract Period: 1994

Principal Findings and Accomplishments to Date:

In the fall of 1993 two events dramatically changed the momentum of the planned project:

1) EPA's Office of Research and Demonstration (ORD) changed its research emphasis, dropping wood stove emissions research entirely from its portfolio and budgeting no dollars to FY 1994 wood energy research;

2) The Canadian Combustion Research Laboratory (CCRL) assumed responsibility for drafting a new workplan and volunteered to conduct the research with its own personnel.

As a result of these two efforts, other co-funders reassessed their interest and commitment to the effort. The new research design won acclaim from the entire advisory committee. Enthusiasm for the merit and methodology of the project grew stronger. The research focus on establishing a baseline of pre-certified stoves and comparing certified catalyst and non-catalyst brands against the baseline received unanimous support.

The other positive development associated with the CCRL research plan was the diminished funding commitment required of sponsors. Since CCRL was committing its own laboratory and own staff to the effort, the out-of-pocket costs are expected to be less than $\$ 70,000$ rather than the $\$ 325,000$ in the earlier EPA-driven design. Three of the remaining sponsors--HPA, NRBP, and NYSERDA felt the shared burden of $\$ 70,000$ would not be onerous to shoulder.

But two problems developed. The first was the absence of a United States air regulatory agency as a committed constituency for the project. If the research effort revealed troubling findings about the level of emissions from a known toxic compound, especially a known carcinogen, who would take up the cry to investigate further and/or recommend an abatement strategy? Both NYSERDA and NRBP decided this absence would preclude their funding commitment until or unless a committed air regulatory agency evidenced written support for the project. 
To that end, the NRBP staff sent out written inquiries to three additional EPA offices and the Northeast States Coordinated Air Use Management Agency to solicit their interest. As of this date, responses have not been received.

The second problem is associated with the transfer of the Pacific Northwest RBP to the Region X Support Office in Seattle. While the BPA Program Manager committed $\$ 30,000$ toward the 1992 research effort, there is no present decisionmaker to commit funding for 1994. We expect this problem to resolve itself in early 1994. 


\section{PROJECT CONCEPTS UNDER CONSIDERATION}




\section{PROPOSED PROJECT: WOOD WASTE ROUNDTABLES AND REPORT SUMMARY}

PROBLEM. Too much waste wood is landfilled because technical, regulatory and public policy decisions have not been coordinated to take advantage of this commodity as a feedstock fuel.

OVERCOMING THE OBSTACLES. A successful roundtable discussion in New York state last year and a national wood waste conference last fall highlight the challenges and opportunities facing some categories of processed wood waste. The challenge we confront today is largely that of dissemination and extended discussion among policy makers.

PROPOSED PROJECTS. There are two related projects proposed:

(1) Roundtable Workshops on the Technical, Regulatory and Public Policy Issues Affecting Waste Wood Processing and Combustion for Fuel in Selected Northeastern States. This would repeat the New York state experience in five states.

(2) Package and Disseminate Results of Wood Products in the Waste Stream Study. Summarize results of study; draft articles for trade press based on study results.

BUDGET: $1: \$ 35-45,000 ; 2 . \$ 10-15,000$. 


\section{PROPOSED PROJECT: CO-FIRING WOOD AND COAL IN UTILITY BOILERS}

PROBLEM: Outside of northern New England and upstate New York, there is not widespread public support for utilizing wood in utility boilers. Nuclear, coal, oil, gas, and a few hydroelectric plants have long dominated the mix of electric generating technologies for the past thirty years. The wood industry is dominated by hundreds of small firms, most of which think of wood fuel as a waste product of their core business activity. There is an abundance of wood available on a renewable basis, but demand for unmerchantable wood, stumps, and processed wood wastes has not materialized in much of the region.

Yet the Clear Air Act of 1990 and the continuing efforts to limit acid rain emissions places escalating pressures on state regulatory authorities to cut back usage of fossil fuels, except for natural gas. The usage of coal is particularly vulnerable in the decades to come, affording wood an opportunity as a co-fired fuel. Because wood has very low sulphur and low Nox emissions, it offers environmental advantages over coal.

OVERCOMING THE BARRIERS: In 1985 the NRBP conducted a study to determine the feasibility of co-firing wood with coal, focusing on industrial opportunities. Scott Paper Company in Westbrook, Maine has been co-firing with wood for more than a decade. A handful of smaller industrial boilers have also co-fired the two fuels during the past several years. The greater storage capacity, alterations in the handling system, and combustion grate modifications are all issues which have been addressed in these boilers. An unfamiliar procurement system, fuel quality variations, and fuel bridging problems are unique challenges faced by facility operators. A facility co-firing the two fuels will also experience a wider variance in combustion characteristics and a higher ash content. Fuel costs should be competitive or lower than coal on a delivered energy basis.

PROPOSED PROJECT: This project would begin with a retrospective survey of existing research and documentation of experience with co-firing in present facilities. The project would conclude with a test firing of wood at a coal-burning utility boiler. The test would encompass fuel mix, feed rates, energy output, air emissions, and ash production.

\section{BUDGET: $\$ 40,000$}


APPENDIX - DETAILED WORK STATEMENTS 
TITLE: BOOKLET FOR KEY DECISION-MAKERS ON POTENTIAL FOR WOOD-CHIP HEAT IN COMMERCIAL AND INDUSTRIAL FACILITIES

\section{SCOPE OF SERVICES}

The objective of this booklet is to provide a simple, usable working tool to enable public boards, administrators and other decision-makers, including private owners of commercial or industrial facilities in the Northeast to:

(1) Consider the replacement of existing energy systems (or the installation in new facilities) of woodchip energy systems

(2) Investigate the economics of wood-chip heat, hot water, and drying and process steam applications, using life-cycle cost and cash-flow analyses

(3) Compare different types of wood-chip systems and select a system appropriate to their facility's needs.

(4) Implement wood-chip energy projects

\section{PROPOSED SCOPE OF WORK}

\section{Section 1: General Discussion}

The following Scope of Work is intended to produce a final product which reflects the Objectives and Strategy of the RFP, and which meets and expands upon the requirements of the RFP's Task Description. This outline is generally organized according to necessary tasks for researching and producing the final booklet. Under the task area of writing the booklet (Element $\mathrm{J}$ below), a preliminary outline of the booklet organization is given. Certain topics for inclusion in the booklet, not listed under the research section, are listed here.

This Proposal assumes that the target type of wood-chip application for the booklet falls in the 1-10 MMBTU size range, in the institutional, commercial and light industrial sectors (not including the wood products industry), and that the systems are generally installed on a turn-key basis (rather than as separate components designed into systems by specializing engineers). Applications include both retrofit systems and systems in new construction.

There are three reasons for these assumptions. First, below 1 MMBTU the cost and size of a fuel storage facility, and the general unavailability of manufactured systems, tend to make projects uneconomic and difficult to justify. Second, for systems above 10 MMBTU it is common to hire a design engineer specializing in solid fuel combustion, storage and handling to select and assemble system components from a number of vendors. For these large systems, the owner is relieved of much of the responsibility for design and selection decisions. The last assumption is that the wood 
products industry is a specialized case of industrial use which is excluded from coverage because that industry already has the experience and knowledge in putting together wood combustion projects. In addition, the wood products industry operates in a different economic framework because it produces the fuel and so does not have to figure biomass fuel price into decision making.

\section{Section 2: Approach and Tasks}

\section{Booklet Research and Development:}

\section{A. Research applicable wood-chip systems in the Northeast region.}

The purpose of this element is to identify and collect information from existing woodchip burning facilities throughout the region and eastern Canada which might serve as models for different system types, illustrative models of different applications of the technology, examples of systems in different chip supply markets, and case study models of the process used in selecting and implementing systems. The experience of the contractor and subcontractors will be supplemented by the following tasks.

(1) Review the Northeast Directory of Biomass Facilities.

(2) Conduct phone interviews of the 11 Northeast Region State Biomass Contacts, to identify noteworthy systems of different types.

(3) Develop a survey tool for collecting information on existing systems.

(4) Interview selected system sites (operators and/or administrators) by phone to gather information on different types of systems throughout the region and eastern Canada, using the survey developed in Task 3 above.

(5) Compile survey results, using categories suggested in the following elements and tasks.

B. Research wood-chip supply throughout the Northeast region.

The intent of this element is to gain an understanding of chip markets in the region from the standpoint of prospective chip users, not to do an exhaustive survey of fuel supply. The focus will be on gathering information directly relevant to the content of the booklet.

(1) Collate data collected in phone interviews above (from Biomass Contacts and existing system sites).

(2) Research biomass cost, supply and delivery capability through phone interviews with biomass producers and users in different geographical areas.

(3) Investigate stability of chip supply, as indicated by historical pricing information provided by fuel suppliers and users. 


\section{Conduct Existing Chip System Site Visits.}

The visits will be to sites which will expand the knowledge base of the Project Team in ways which will directly benefit the usefulness of the booklet. The target area for systems will be the 11-state northeast region plus the eastern provinces of Canada.

(1) Based on the results of the phone survey, identify any existing sites which represent different, unique or instructive equipment configurations, storage facility designs, applications of wood-chip combustion or innovative linkages with fuel suppliers.

(2) Categorize and list sites which could be visited to advance the Project Team's knowledge of systems applicable to the objectives of the booklet.

(3) From the research of Topics 1 and 2 above, develop a trip itinerary of sites which could be visited on a cost-effective basis and which will yield optimal site experience relevant to the booklet's aims.

(4) Review trip itinerary with CONEG Advisory Committee which must approve any planned trips.

(5) Perform site visits and collect field data, including photographs.

\section{Develop Guidelines and Tools for Economic Analysis of Prospective Wood- Chipsystems.}

The purpose of this element is to simplify and clarify the financial decision-making process for building owners of different types: schools, hospitals, non-profits, heating applications in commercial buildings, industrial process steam users, etc.

(1) Identify the normal different financing methods and capital sources of prospective booklet users: public schools, non-profits, housing authorities, commercial building owners, industries, etc.

(2) Characterize the economic decision-making parameters for each type of financing framework, including expectations for return-on-investment, investment time horizons, types of financing used, etc.

(3) Conduct phone interviews of existing system owners or administrators to answer questions or exemplify areas in need of clarification.

(4) Develop or characterize methodologies for performing financial feasibility analysis in key applications (including simple payback analysis, life-cycle-costing, cashflow projections, etc.). In the final text, explain life-cycle cost, cash-flow, and other relevant tools for analyzing the economics of a wood-chip project, and produce worksheets or similarly practical guidelines for applying these analyses to actual commercial, industrial, and institutional projects. 
(5) Develop worksheets to simplify and summarize the analysis in the key types of applications.

(6) Based on previous phone interviews, compile examples of the use of the worksheets, for inclusion in the booklet appendix. Illustrate the use of these worksheets or guidelines with at least one example from each sector and each basic type of application (e.g., process steam in an industrial application, space heat in a commercial facility, and hot water in an institutional setting).

\section{E. Research Financing Options for Wood-Chip Installations.}

This element will assemble information on the financing options for installing woodchip systems in different types of applications.

(1) Research and identify available grant programs (state, DOE, etc.).

(2) Research state-aid school construction financing available for energy projects in typical northeastern states.

(3) Explore loan availability for biomass projects: commercial loans, special energy loan programs, bond financing (including municipal bond banks), etc.

(4) Investigate and identify sources for third-party financing, leasing, shared savings and installations by energy service companies.

\section{F. Examine Different Modes of Project Management and Implementation.}

The purpose of this element is to systematize the different ways in which a successful biomass project can be structured and implemented, with particular emphasis on human resources.

(1) Using data gathered in phone interviews and site visits to existing installations (sections $A$ and $C$, above), identify different modes of using human resources and professional resources in a biomass project.

(2) Categorize modes in the following areas: use of professional design assistance (engineers, system suppliers, biomass system designers); role of the owner; role of volunteer committees (for public institutions); production of bid specifications; the role of competitive bidding; the interaction of different design professionals (architects, mechanical and structural engineers, design-build project managers); and contracting for wood-chip system installation (contractor role vs. general construction contract sub-contractor role).

(3) Develop guidelines on the importance of including the owner's maintenance staff early in the planning process, in supporting the concept of wood-chip burning, and in designing and installing systems which do not impose an undue burden on maintenance time, interest and capability. 


\section{G. Develop Guidelines for Assessing the Efficiency. Stack Emissions and Safety of Manufacturers' . Wood-Chip Combustion Systems.}

This element will focus on assembling known information on how these areas of concern can be addressed by lay decision makers, project managers and engineers with little or no prior experience in wood-chip systems. One emphasis will be on judging manufactured products which have not been independently tested for efficiency, stack emission quality or safety. This work will systematize and expand upon CANMETs extensive work in research and testing of biomass combustion systems.

(1) Review the status of efficiency testing, stack emission testing and safety testing for manufactured units in the 1-10 MMBTU size range, focusing on regional regulatory venues and on systems available in the Northeast region.

(2) Develop a set of guidelines for each of the three areas, to assist decision makers in judging the design and performance of combustion systems available from a variety of manufacturers.

\section{H. Study Ways of Including Public Participation and Education in a Wood-Chip Project.}

The purpose of this element is to collect information on successful and unsuccessful projects, in the areas of public information on wood-chip systems and creating a positive atmosphere in which the public can address its concerns about particular implementation projects.

(1) Using Project Team experience and data gathered in phone interviews and site visits to existing installations (Elements $A$ and $C$, above), assemble a list of important public information and participation issues, including concerns about air quality and odor, visual appearance of systems, and truck traffic.

(2) Develop guidelines for prospective system owners to present biomass systems in a positive light, with respect to such areas as the use of biomass as a locally produced renewable fuel, impacts on the local economy, and fuel price stability.

\section{Categorize Operational Issues for the Successful Operation of a Wood-Chip System.}

Since the successful operation of a wood-chip burning system is largely dependent on pieces that are put in place during the study and installation phases of the project, it is important for prospective system owners to be aware of these operational issues from the start. Through this work, the existing knowledge base of system operation and maintenance will be expanded.

(1) Review the Project Team's extensive experience in actual system operation, as well as its knowledge derived from prior contacts and interviews with system 
operators throughout the northeast region, the upper midwest and eastern Canada.

(2) Review and collate data from phone interviews of elements listed above and from site visits, relative to fuel procurement (including quality control and moisture monitoring), start-up trouble-shooting, warranty work, on-going maintenance (including maintenance contracts), ash disposal options, system monitoring and record keeping.

\section{BOOKLET WRITING:}

The work of the following elements will systematize the results of the research and development activities listed above into an outline and then into the finished text of the booklet.

\section{J. Organize Booklet Material into Outline Form.}

The following is a listing of anticipated main booklet topics. Sub-topics listed are intended to indicate the inclusion of areas which may not have been listed specifically in the research and development section above.

\section{Applications of Wood-Chip Energy Systems}

- Assessing the needs for a wood-chip system

- Differences in the needs of institutional, commercial and industrial users

- Types of energy use: heat, hot water, warm air, drying, process steam

- Retrofit vs. new construction

- Requirements for manual or automatic operation

o Site constraints

\section{Elements of a Wood-Chip Energy System}

- Storage facility and loading system

- Chip handling equipment

- Chip combustion equipment and controls

- Stack emission control systems

- Ash disposal systems

\section{Wood-Chip and Other Biomass Fuel Supply}
- Mill and whole-tree wood chips
- Other biomass products
- Characteristics of hardwood, softwood and different species
- The role of fuel moisture
- Sources of wood-chip supply
- Fuel cost and availability, including price stability 
4. The Relationship Between Fuel Source, Delivery Vehicle. Type of Fuel Storage and Fuel Handling Equipment

- Fuel suppliers and haulers

- Types of delivery vehicles

- The relationship between delivery vehicle and storage loading system

- Electrical energy use of bin loading equipment

- The relationship between fuel characteristics and handling equipment

\section{Wood-Chip Combustion Systems and Related Components}

- Combustion types: gasifiers, direct burn systems, two-compartment burners

- Heat exchangers

- Generic types of fuel handling equipment

\section{Human Resource for Studying and Installing Wood-Chip Systems}

- Resources for energy and financial analysis

- Chip system designers

- Consulting and mechanical engineers

- The role of the project manager

- Governmental and public technical resources

- The use of volunteer committees in institutional projects

- The importance of the facility's maintenance staff

\section{Economic Feasibility Analysis of Wood-Chip Systems}

- The different types of economic analysis

- Matching the type of economic analysis to the owner's needs

- Identifying sources of financing

- Integrating characteristics of sources of capital into the analysis

- Use of booklet financial analysis worksheets

\section{Putting Together and Implementing a Wood-Chip Project}

- Public involvement in implementing a wood-chip system

- Public education and dealing with misconceptions about biomass combustion systems

- Decision-making based on financial analysis

- Assembling the project team

- Writing performance specifications

- The importance of competitive bidding

- Assessing bids: cost, efficiency, air quality and safety

- Project management for the system installation 


\section{Operating and Maintaining a Wood-Chip System}

- Initial system start-up

- System adjustments during the warranty period

- On-going maintenance

- Maintenance contracts

- Ash disposal

- Performance monitoring and record keeping

K. Write the Booklet Text.

(1) Write text for the main body of the booklet, and employ a professional editor to complete draft.

(2) Assemble and/or write appendix material.

\section{Coordinate Peer Review.}

(1) Work closely with Vermont Steering Committee representatives on each task; meet telephonically with CONEG Project Review Committee to review outline, each draft chapter, and appendices for text. The Advisory Committee will review and critique all text. The Committee membership is comprised currently of Steering Committee representatives from Maine, New Hampshire, Delaware, and Vermont; the CONEG Policy Research Center's RBP Manager and the Technical Coordinator.

(2) Collate responses from reviewers and revise text as necessary.

Format, Layout, Edit and Print the Booklet:

\section{Assemble and Select Photographs.}

This Proposal assumes there will be an appropriate number of black-and-white photographs in the booklet. These will illustrate the exterior appearance of wood-chip systems and will include close-ups of key system components. The Proposal assumes that up to 15 color slides may need to be converted to prints for use in the booklet. Illustrations, if any, will be added if necessary to clarify areas which cannot be presented adequately with photographs.

\section{N. Edit Final Draft of Text.}

An independent non-technical editor will read the final draft for clarity and to suggest appropriate changes to the text. 


\section{O. Dessign Booklet Presentation, Including Lavout, Format and Cover.}

The contractor will hire, as part of the Proposal price, a graphic designer to lay out and format the booklet, design the cover, and oversee the printing and production. The cover will be a simple but attractive graphic design appropriate to the text. The final booklet design will be closely coordinated with the Technical Review Committee.

\section{P. Print 300 Copies of the Booklet.}

The Proposal includes the cost of printing, binding and producing 300 copies of the booklet. The Proposal assumes the booklets will be approximately 60 pages long, will be center-stapled, and will have durable cover stock. The Proposal includes delivery of the $\mathbf{3 0 0}$ booklet copies to the Vermont State Biomass Contact in Montpelier, Vermont.

\section{Q. Report Project Progress to CONEG Policy Research Center.}

This Proposal includes written progress reports, at least every three months, in addition to less formal and more frequent reports to the Project Advisory Committee. A presentation to the September meeting of the Steering Committee will take place.

This is a fixed price contract of $\$ 18,725$. 
TITLE: IMPEDIMENTS TO DEVELOPMENT OF LANDFILL GAS RECOVERY PROJECTS IN. THE NORTHEAST

SCOPE OF SERVICES

PHASE I - Characterize LFG-to Energy Industry in the Northeast

The project objectives for this phase are:

- Through a survey of the LFG recovery industry, identify the parameters for a successful project.

- Identify impediments to a successful project.

- Provide recommendations on how barriers can be surmounted.

The contractor must complete the following tasks to meet the project objectives:

- Task 1 - Literature Review

- Task 2 - Interview LFG Developers

- Task 3 - Project Feasibility Criteria

- Task 4 - Barriers and Means to Overcome

- Task 5 - Technical Siting Criteria

- Task 6 - Non-Technical Factors

- Task 7 - Draft Report/Handbook

\section{TASK 1 - LITERATURE REVIEW}

\section{APPROACH}

The contractor will review current literature and prepare a summary of the technical, economic, institutional and environmental aspects of developing LFG recovery projects. Much of the information is already in our possession, and we will not have to expend significant effort to research the field. In-house information sources which can be utilized include:

- The contractor project files and databases.

: SWANA (Solid Waste Association of North America) Annual Landfill Gas Symposium - 15 years of proceedings (SWANA was formerly GRCDA).

- USEPA - Background Information Document for the New Source Performance Standards (NSPS) for Landfill Emissions.

- International Landfill Gas Conference proceedings (1986, 1988 and 1990), sponsored by UK Department of Energy - Energy Technology Support Unit (ETSU). 
- Handbook on Biogas Utilization, Gas Research Institute - The contractor coauthor.

- Trace Constituents in Landfill Gas - Task Report on Inventory and Assessment of Cleaning Technologies, Gas Research Institute - The contractor co-author.

- Methane Recovery From Landfill Yearbook, 1990 and 1992, Governmental Advisory Associates, Inc. (GAA).

- Vendor literature from developers, equipment suppliers, other consultants, etc.

These sources and the contractor's knowledge will serve as the basis for a summary of the major aspects of LFG recovery. A brief overview of the following topics will be provided:

- LFG collection methods (vertical wells, horizontal trenches, and cover venting systems).

- LFG utilization technologies.

- Medium Btu (direct combustion, on-site uses, space heating, boilers).

- High Btu/purification (pipeline quality natural gas, LNG).

- Electrical generation (engine/generators and gas turbines).

- Other uses (vehicular fuels, fuel cells, liquid fuels - diesel).

- Economic Aspects.

- Typical range of capital and operational costs.

- Revenue ranges for electricity, pipeline quality gas, and direct use.

- Summary of the Federal tax credits (Section 29) and the Renewable Energy Production Incentive (Section 1212 of the Energy Bill) available for LFG recovery projects.

- Institutional Issues.

- Types of ownership: municipal, utility, or independent.

- Public/private partnerships. 
- Environmental Issues.

- Subtitle D requirements (LFG control).

- Proposed New Source Performance Standards (NSPS) under the Clean Air Act.

- Condensate management.

The discussions will emphasize changes the industry has experienced over the past five years. With the extension of the Federal tax credits (Section 29) and the new renewable energy incentive payments for publicly-owned facilities, additional revenue sources are available to improve the project economics.

\section{DELIVERABLES}

A draft report will be prepared and submitted to the Center at the project kickoff meeting (to be scheduled a couple of weeks after contract award). This report will summarize the state of the industry and provide the reader with an understanding of many of the technical and non-technical elements affecting LFG recovery projects.

\section{TASK 2 - INTERVIEW LFG DEVELOPERS}

\section{APPROACH}

The contractor will contact developers/owners/investors/operators of LFG recovery projects to obtain information on both the technical and non-technical impediments to successful projects. The contractor will also gather information on reasons why potential LFG projects were not successful. Exhibit 1 is a listing of developers to contact.

The contractor will concentrate on the listed developers with multiple projects and a proven track record. The criteria for selection of firms to interview includes:

- Major LFG developers nationwide (Waste Management, BFI, O'Brien, Michigan Cogeneration, etc.).

- Active developers in the Northeast (Energy Tactics, Palmer Capital, Phillips Energy, etc.).

The contractor plans to contact small developers as well as larger developers (both are included in the above listing). Smaller developers are the firms likely to develop the smaller landfill sites due to the lower capital investment requirements and their desire to gain experience. 
Several landfill owners active in LFG recovery also will be interviewed. The following municipal agencies are active in the LFG field. Their insight will be valuable from landfill owner's perspective. Municipalities to be contacted may include:

- Los Angles County Sanitation Districts.

- New York City, Department of Sanitation.

- Connecticut Resource Recovery Authority.

- Rhode Island Solid Waste Authority.

- Delaware Solid Waste Authority.

- Fairfax County, Virginia. 
EXHIBIT 1. PROPOSED CONTACT LISTING OF LFG DEVELOPERS

\begin{tabular}{||l|l|l||}
\hline \multicolumn{1}{|c|}{ LFG Developer } & \multicolumn{1}{c|}{ Location } & \multicolumn{1}{c||}{ Key Contact } \\
\hline Air Products, Inc. & Allentown, PA & Paul Persico \\
\hline Bio Development Corp. & Bedford, NH & Joel Gordon \\
\hline Browning-Ferris Industries & Houston, TX & Dave Conrad \\
\hline Cambrian Energy Systems & Santa Monica, CA & Bob Hatch \\
\hline Emcon Associates & San Jose, CA & John Pacey \\
\hline Energy Tactics, Inc. & Yaphank, NY & Stan Drake \\
\hline Hayden-Wegman, Inc. & Boston, MA & John Murphy \\
\hline Hazox Alternate Energy & Chester, PA & Dan Snyder \\
\hline JWP Energy \& Environment & Purchase, NY & Bob Anderson \\
\hline Laidlaw Gas Resource & Newark, CA & Kenneth Wuest \\
Systems & & \\
\hline Michigan Cogeneration \\
Systems & Novi, MI & Scott Salisbury \\
\hline O'Brien Energy Systems & Philadelphia, PA & Doug Nielsen \\
\hline Ogden Martin Systems & Fairfield, NJ & Tom Rantas \\
\hline Pacific Energy & Commerce, CA & Tony Henrich \\
\hline Palmer Capital & Cambridge, MA & Jim Levitt \\
\hline Phillips Energy & Waitsfield, VT & Fran Woods \\
\hline Vermont Energy Recovery & Brattleboro, VT & Allan McLane \\
\hline Waste Management Inc. & Oak Brook, IL & Chuck Anderson \\
\hline Wehran EnviroTech & Middletown, NY & Fred Wehran \\
\hline \hline
\end{tabular}

Several utilities and other end users of the energy produced from LFG projects will be contacted, including:

- Brooklyn Union Gas - New York, New York

- Burlington Electric Department - Burlington, Vermont

- Long Island Lighting Company, New York

- New England Power

- Virginia Power

- Public Service of New Jersey 
In addition, The contractor will contact several financial institutions active in financing LFG recovery projects. Their concerns and requirements will be identified. Financial institutions to be contacted may include:

- State Street Bank and Trust Company - Boston, Massachusetts

- Michigan Bank - Detroit, Michigan

: First Union Bank - Atlanta, Georgia

- First Pennsylvania Bank - Philadelphia, Pennsylvania

An interview form will be prepared (see Exhibit 3 in the proposal for a preliminary outline) for use in obtaining consistent and complete (to the extent available) information about each LFG recovery project. Generally, the information to be obtained will include the following, to the extent that it is available:

- Project location, size, types, etc.

- Energy purchase price, terms/conditions, negotiating difficulties.

- Permitting and environmental difficulties.

- Tax incentives/subsidies.

- LFG developer/landfill owner relationship and terms.

- Permitting experience; i.e., difficulties and solutions; ease of gaining permits; time required.

The interview form will be provided to the Center for information purposes. The contractor' approach to conduct the interviews is as follows:

- Record on the interview forms what we already know about each site before contacting the developers and others.

: The interviews with the developers, landfill owners, end users, and financial institutions will be conducted by the contractor senior staff members. In most cases, this staff member will be known to the interviewee. We anticipate a onehour time period with each developer.

- Send each developer a follow-up letter to allow the opportunity for confirmation of the data, additional comments, etc. 


\section{EXHIBIT 3. LFG INDUSTRY INTERVIEW OUTLINE}

\section{Company Information}

- Company, contact name, address, phone and fax numbers

- Type of firm: LFG Developer, Landfill Owner, Energy User, Financial Institution

- The contractor contact person, date

\section{Company Experience in LFG Recovery}

- Number of projects and status (planned, active, shutdown, etc.)

- Recovery projects location, size (update of Exhibit 2-1 for Northeast projects)

- Years of experience in LFG recovery, year of first involvement

\section{Project Characteristics (separate sheet for each project)}

- Landfill characteristics - acreage, refuse volumes (or tons), age, configuration, . open or closed, etc.

- LFG recovery system - wellfield, utilization equipment, etc.

- Project economics

- Energy purchase and lease agreement provisions (energy payments, royalties, terms, duration, etc.)

- Tax credits and/or other economic incentives

: Environmental/regulatory issues, air emissions, condensate management, permits

\section{Impediments Encountered and Solutions}

- Landfill

- LFG collection system

- Energy generation equipment

- Financial

- Institutional 


\section{- Regulatory}

\section{Deliverables}

Task deliverables will include:

- Listing of LFG developers, owners, energy users, etc., to be contacted (an update of those listed herein)

- Interview form (an update of Exhibit 3)

- The survey results will be included in the Task 7 report

TASK 3 - PROJECT FEASIBILITY CRITERIA

\section{APPROACH}

Based on our knowledge of the industry, the limited literature review, and the developer interviews and industry contacts, The contractor will set forth typical criteria under each of the following major factors:

- Landfill characteristics.

- Energy sales agreement (ease of negotiation and revenue).

- Regulatory/environmental conditions.

- Tax incentives and subsidies.

- Landfill owner - LFG developer procurement requirements.

\section{DELIVERABLES}

The task outputs will be included in the Task 7 report.

TASK 4 - BARRIERS AND MEANS TO OVERCOME

\section{APPROACH}

Using information gathered during the interviews, The contractor will identify the barriers to LFG recovery. Potential barriers for discussion may include:

\section{Technical}

- Landfill characteristics.

- Insufficient refuse volumes. 
- High quantities of inorganic wastes.

- Shallow refuse depths.

- Poor final or intermediate cover systems.

- Perched liquids.

- Insufficient LFG quantities and/or poor quality.

- Overly optimistic LFG production estimates.

- Low heating value of recovered LFG.

- LFG collection systems.

- Incompatible wellfield designs, continually changing landfill operations which require extension of recovery system.

- Air intrusion due to poor final cover or over drawing.

- High landfill liquid levels that reduce the active well slotlines and reduce the effectiveness of the wells to recover LFG.

- Poorly operated and maintained collection systems.

- Condensate drainage problems and insufficient header slopes.

- Power generation or utilization systems.

- Poor maintenance.

- Equipment incompatibilities with LFG constituents.

- Improper compressor or blower sizing.

\section{Economic}

: Low energy purchase prices and future price stability.

- Unrealistic economic projections.

- Cyclical demands for medium Btu applications.

- Inadequate capitalization.

- Difficulties and time required to negotiate purchase agreement with the energy purchaser (utility company or direct user). 


\section{Institutional}

- Political impediments (e.g. conflicting priorities between LFG recovery project and filling operations or end-use plans).

- Size (i.e., small) of LFG project decreases interest by utility company.

- Inability to accurately estimate future production and relatively short production life.

: Zoning ordinances regarding noise or facility types.

- Lack of interest of energy users to purchase LFG or electricity generated using LFG as fuel.

Many of the above impediments have means by which they can be overcome on a case by case basis: Input from the interviews and the contractor's project experience will be used to develop suggested remedies to the barriers identified.

\section{DELIVERABLES}

The task outputs (to be presented in the Task 7 report) will include listing of project barriers, the relative level of difficulty (i.e., their likelihood of being overcome), and potential remedies.

\section{TASK 5 - TECHNICAL SITING CRITERIA}

\section{APPROACH}

Technical siting criteria will be developed based on experience at successful Northeast projects. Criteria may include the following:

- Landfill characteristics.

- Minimum size (acres).

- Minimum average refuse depth (feet).

- Minimum capacity in-place (cubic yards and/or tons).

- Minimum capacity at closure (cubic yards and/or tons).

- Maximum age of refuse - years since closure.

- Landfill status - open or closed.

- Refuse types (MSW, not construction and demolition debris, liquids, etc.).

- Landfill final cover system. 
- LFG Utilization Requirements.

- Direct use (medium Btu).

-. Distance to user.

-- User requirements - hours/day, quantity, seasonality.

-- Minimum revenue (\$MM Btu).

- Electricity generation.

-- Minimum revenue $(\$ / k W h)$.

-- Onsite use or tie-in to utility grid

- High Btu (pipeline quality).

-- Distance to pipeline.

-- Cost of electricity to power purification process

-- Minimum revenue (\$/MM Btu)

\section{DELIVERABLES}

The technical criteria will be presented in the Task 7 report. These criteria will be subsequently used in Phase II to make a first cut at identifying sites with the greatest potential for LFG recovery.

\section{TASK 6 - NON-TECHNICAL FACTORS}

\section{APPROACH}

The contractor will develop a framework of non-technical factors that are necessary for a project to be successful. These factors will be based on the Task 2 interviews and project experience. Non-technical factors to be considered may include:

- Institutional factors.

- Types of ownership which have been successfully applied.

- Methods to assist successful public/private partnerships.

- Appropriate levels of risk-sharing by the major parties (landfill owner and LFG developer).

- Financial factors.

- Revenue ranges for electricity, pipeline quality gas, and direct use. 
- Methods to structure project to take advantage of the Federal Tax Credits (Section 29) and the Renewable Energy Production Incentive (Section 1212 of the Energy Bill).

- Financing alternatives.

- Regulatory factors.

- Identify permitting requirements for each of the states. For example, New York a LFG recovery project must have a solid waste management facility permit to comply with specific design and operational criteria.

- Identify air emissions and condensate management requirements for each state or region.

\section{DELIVERABLES}

The non-technical criteria will be presented in the Task 7 report.

\section{TASK 7 - DRAFT REPORT/HANDBOOK}

The contractor will prepare a draft report/handbook incorporating the results of Tasks 1 through 6 . The report will be geared towards potential developers of LFG recovery projects in the Northeast.

\section{DELIVERABLES}

The draft report/handbook. Four copies of this draft document will be submitted to the Center for their review and comments. Comments from the Center will be incorporated in the Phase II final report/handbook.

\section{PHASE II - Identify Landfills for LFG Development}

The Phase Il objectives as presented in the RFP are as follows:

- Identify candidate landfill sites in the Northeast for LFG recovery.

- Estimate the total energy potential available from LFG in the Northeast.

- Provide information that might be used to affect state and federal energy policy.

- Encourage development of LFG recovery projects. 
The contractor has reviewed the RFP and identified the following tasks to meet the objectives:

- Task 1 - Compile Landfill Database

- Task 2 - Identify and Group Landfills for LFG Development Based on Technical Criteria

- Task 3 - Rank Landfills for LFG Development, Applying Non-Technical Factors

- Task 4 - Develop Criteria and Methodology for Qualifying Landfills for LFG Development

- Task 5 - Final Report/Handbook

Our approach and task deliverables follow.

\section{TASK 1 - COMPILE LANDFILL DATABASE}

\section{APPROACH}

The contractor will access existing landfill databases to identify candidate sites for LFG recovery. A listing of the databases that the contractor will access, along with the type of information included in each, is summarized below:

- 1986 Solid Waste Landfill Survey - by the EPA. Approximately 1,000 landfill sites were surveyed. Information collected includes:

- Contact information.

- Facility area - acres.

- Design capacity - cubic yards.

- Annual waste quantities - metric tons/year.

- Solid Waste Digest, Northeast Edition - Facility Index.

- Contact information.

- Tip fee.

- Capacity (tons per day).

- NSWMA Tip Fee Survey Database.

- Contact information.

- Tip fee.

- SWANA database on 4,300 landfill sites - contact information only. 
- State solid waste regulatory agencies - most states have contact information on permitted facilities. The contractor has contacted the 11 Northeast states and requested copies of their solid waste management plans (SWMP's) and landfill databases. We have in our possession landfill listings for Delaware, Maryland, New York, and Pennsylvania.

- New York State - Analysis of Methane Recovery Potential at New York State Sanitary Landfill Sites. This 1981 report identified 34 landfills in the state with over 1 million tons in-place with an average refuse depth of at least 40 feet. Of these 34 sites, 15 were identified as candidate recovery projects.

The contractor will contact each of the 11 state solid waste regulatory agencies to acquire updated landfill databases or listings (active and closed sites). The information in the databases or landfill listings is often incomplete. Specific landfill capacity data (volume or tonnage in-place or permitted) is often not included in the state's listings. The contractor plans to visit up to four state solid waste regulatory agencies to attempt to obtain capacity data. One day visits to New Jersey, Pennsylvania, Massachusetts, and New York are anticipated.

The contractor will compile the database from the above sources into a PC-based system (Dbase, Paradox, Q\&A).

The type of information desired for each prospective landfill site (if available) includes:

- Landfill name, owner, address and contact names.

- Landfill size (acres), capacity (yards or tons in-place or total).

- Average refuse depths.

- Filling rate in cubic yards or tons/day.

- Year open/expected closure.

: Existing LFG control or recovery system (or planned).

Acquiring landfill capacity (in-place) and filling histories will be the most difficult aspects of this task. Available databases do not include this detailed information todate. The SWANA database may include much of this data by the end of 1993, based on their current projections.

\section{DELIVERABLES}

The landfill database will be submitted on a suitable database format (Dbase, Paradox, or Q\&A) in both printed and disc formats. 
TASK 2 - IDENTIFY AND GROUP LANDFILLS FOR LFG DEVELOPMENT BASED ON TECHNICAL CRITERIA

\section{APPROACH}

The siting criteria previously developed in Phase I (Task 5) will be applied to the potential landfill sites. The database will be sorted and landfills which meet each criteria will be identified.

An example criteria is:

: Minimum refuse tonnage in-place $-1,000,000$ tons.

- Minimum average refuse depth - 40 feet.

- Minimum acreage - 20 acres.

For New York State, The contractor will rely on a NYSERDA project (Analysis of Methane Recovery Potential at New York State Sanitary Landfill Sites) for background data on existing sites. Since only a few landfills have opened in New York in the past 10 years, we will only need to update capacity data from existing sites.

The contractor has reviewed the database of active landfills in the Northeast prepared by Solid Waste Digest. The number of landfills and daily capacity ranges in tons per day (TPD) are presented in Exhibit 4. 
EXHIBIT 4. OPEN LANDFILLS IN THE NORTHEAST

\begin{tabular}{||l|c|c||c|c||}
\hline \multicolumn{1}{|c|}{ State } & $\begin{array}{c}\text { Number of } \\
\text { Active } \\
\text { Landfills }\end{array}$ & $\begin{array}{c}\text { Total } \\
\text { Tonnage } \\
\text { Landfilled } \\
\text { (Tons/day) }\end{array}$ & $\begin{array}{c}\text { Number of } \\
\text { Landfills } \\
\text { Over 100 } \\
\text { TPD }\end{array}$ & $\begin{array}{c}\text { Number of } \\
\text { Landfills } \\
\text { Over 500 } \\
\text { TPD }\end{array}$ \\
\hline Connecticut & 40 & 4,179 & 10 & 1 \\
\hline Delaware & 3 & 2,600 & 3 & 1 \\
\hline Massachusetts & 74 & 15,917 & 18 & 7 \\
\hline Maryland & 26 & 17,191 & 19 & 8 \\
\hline Maine & 12 & 842 & 1 & 0 \\
\hline New Hampshire & 35 & 3,280 & 5 & 2 \\
\hline New Jersey & 15 & 12,689 & 12 & 6 \\
\hline New York & 107 & 26,378 & 33 & 11 \\
\hline Pennsylvania & 44 & 42,226 & 42 & 24 \\
\hline Rhode Island & 5 & 2,252 & 1 & 1 \\
\hline Vermont & 37 & 2,017 & 4 & 0 \\
\hline TOTAL & 398 & 129,571 & 148 & 60 \\
\hline
\end{tabular}

To reduce the number of landfills to a more manageable number, landfills smaller than 100 TPD will not be addressed. This criteria reduces the number of active landfills from 398 to 148 . Within this group of 148 landfills, efforts will concentrate on the 60 listed sites receiving 500 TPD or more. These sites likely have the most potential.

\section{DELIVERABLES}

\section{Outputs of this task are:}

- Listing of candidate landfill sites which meet each of the specified criteria.

- Listing of sites which meet more than one criteria (i.e., over 1 million tons and over 40 feet average refuse depth).

- Listing of candidate sites which meet additional criteria. These sites potentially should be the best candidates for LFG recovery based on technical factors. 


\section{TASK 3 - RANK LANDFILLS FOR LFG DEVELOPMENT, APPLYING NON- TECHNICAL FACTORS}

\section{APPROACH}

The contractor will apply the non-technical criteria developed during Phase I (Task 6) to the grouping developed in Task 2. Not all of the non-technical criteria developed under Phase I can be employed in this ranking task due to a lack of readily available information. Such criteria requiring more in-depth information than can be obtained for individual sites will be included in the model developed under Task 4 of Phase II.

This ranking should result in a listing by state of the sites having the attributes (technical and non-technical) for LFG recovery.

\section{DELIVERABLES}

The landfills with the attributes (technical and non-technical) for LFG recovery will be identified in the Task 5 report.

\section{Task 4 - DEVELOP CRITERIA AND METHODOLOGY FOR QUALIFYING} LANDFILLS FOR LFG DEVELOPMENT

\section{APPROACH}

Based on the information gathered in Tasks 1 through 3 and the Phase I report, The contractor will have identified technical and non-technical criteria to evaluate candidate landfill sites for LFG recovery. A software model will be developed that can be used by others to estimate LFG yield and to estimate economic feasibility for potential projects.

The model will be developed to run on Lotus 123. Input parameters can be entered via an input screen with standard report outputs available from a report memo screen. The LFG model can be loaded on a computer software program named "Baler." Baler can be run in DOS, and does not require the user to access other software programs, such as Lotus 123. The use of Baler will keep users from altering the formulas in the program.

The major input parameters for the LFG recovery model may include:

- Landfill data - site name, location.

- Refuse filling history - (default - straight line projection).

- Estimated LFG collection efficiency.

- LFG collection system costs (default - \$MM cfd). 
- LFG utilization method (medium Btu use or electricity generation and cost (\$/Kwh or $\$ / M M$ cfd)).

- O\&M cost ( $\$ / K w h$ and/or $\$ / M M$ cfd).

- Revenues $(\$ / k w-h r$ or $\$ / M M B t u)$.

- Royalty Payments.

- Section 29 tax credits and Section 1212 Energy Payment Incentives (indicate whether to include in analysis).

Model outputs may include the following:

- Estimated LFG generation and collection rates.

- Annual revenues.

- Annual value of the royalty payments.

- Annual value of the Section 29 tax credits and Section 1212 Energy Payment Incentives (if applicable for the specific project).

- Present worth calculation.

The "heart" of the model is the estimated LFG generation and collection estimates. Based on landfill data and filling history, LFG production estimates over time can be made. The contractor has developed a PC-based LFG generation model based on our experience conducting extraction test programs and from active recovery projects. The contractor compiled pump test data from landfill sites around the country to estimate LFG generation rates. This data, along with an analysis of the GAA database and the contractor' experience, will be used to estimate LFG generation rates for the Northeast.

\section{DELIVERABLES}

- A computer LFG recovery economic model.

- Brief user's guide for imputing landfill and economic parameters.

\section{TASK 5 - FINAL REPORT/HANDBOOK}

\section{APPROACH}

The Phase I draft report/handbook will be expanded to include the results of the Phase II efforts and to incorporate the Center's comments on the Phase I draft. A draft of the final report/handbook will be submitted to the Center for review and 
comments. Comments will be incorporated, and the final document will be submitted for the Center's use and distribution.

\section{DELIVERABLES}

: Draft Final Report/Handbook - 1 copy.

- Final Report/Handbook - 1 bound and a photo ready original. The handbook also will be provided on a disc in WordPerfect 5.1. The LFG recovery economic model also will be provided on a disc.

- The contractor will prepare quarterly progress reports which will review progress to-date, identify upcoming activities, and identify problems encountered/solutions.

\section{PROJECT SCHEDULE}

Total project duration will be 12 months, effective February xx, 1993.

This is a fixed cost contract for $\$ 68,801$. 


\section{KELLIHER SAMETS VOLK}

\section{Clean Heat Woodstove Exchange}

PUBLICITY PROGRAM 
Page 2

\section{SITUATION}

Although air pollution caused by emissions from non-certified wood stoves is not the crisis it is in the west, the east has problem pocket areas where unhealthy levels of wood smoke can accumulate.

To alleviate this problem, CONEG, in conjunction with the Northeast Hearth Products Association, is embarking on an information campaign designed to heighten awareness of EPAcertified wood stoves and of proper wood burning techniques. The campaign is centered around a retail changeout of non-certified stoves in New England and New York.

The changeout will occur in January and February. Owners who bring noncertified wood stoves into participating retailers will receive $\$ 200$ toward the purchase of a new stove. Old stoves will be destroyed, taking them permanently out of the air stream.

\section{OBJECTIVES}

- Raise consumer awareness of EPA-certified wood stoves and proper wood burning procedures.

- Raise consumer awareness of the Clean Heat Woodstove Exchange program

\section{STRATEGY}

Use an aggressive publicity program -- targeted primarily to newspapers and television stations -to educate consumers in New England and New York about EPA certified stoves and the Clean Heat Woodstove Exchange. 
Page 3

\section{TACTICS}

We will use the following tactics to accomplish our objectives:

\section{Press Effor to Medium and Large Markets}

This effort will consist of an aggressive outreach program to media in the medium and larger markets that have participating dealers. We will also approach regional and national media like The New York Times and the Associated Press.

We will contact media decision-makers, by phone, send a press packet, and then follow up. Once stories are placed, we will schedule interviews with participating local dealers and with a designated expert from CONEG and/or from NEHPA.

The press packet will contain:

- a press release announcing and describing the Clean Heat Woodstove Exchange

- a press release on earlier changeouts and their impact

- a press release on proper wood burning equipment and procedures

- a photograph of junked woodstoves from an earlier changeout

In addition to our initial outreach, we will also follow up with the press in those areas where the changeout has generated the greatest response. In those markets, will encourage media to report on the number of stoves changed out when numbers are significant.

There are also strong visual opportunities -- especially for television stations -- as stoves are being loaded on to trucks for shipment to the scrap metal facility where they will be destroyed. We will work with appropriate print and broadcast media to make place these stories.

As stoves accumulate at the recycling facilities, we will take photographs and shoot videotape for distribution in late January and February back to media in the home markets -- who would not have the resources to send personnel on location.

\section{$\underline{\text { Radio Tour }}$}

The radio tour will be scheduled for the beginning of January, when the changeout is just underway. We will schedule a series of radio interviews in our major markets -- primarily on talk shows - and will conduct them all by phone from Burlington over a one- or two-day period.

We will need to designate an "expert" to conduct the interviews, someone who is both informed about the subject and who projects well in the media. Kelliher/Samets/Volk recommends David Schaerer, who served as the on-air talent in "Bum It Clean, Bum It Right."

\section{Wire nion}

Relcasing a striking visual inage over wire services like $A \$ 2$ nd UPI is a highly effective way of geting information out to a large audience. 
Page 4

We will look for an unusual visual -- of stoves being loaded on trucks, or being destroyed at the scrap metal facility - for release on the wires in mid-to late January.

\section{Video News Release}

An effective way to get our message out early in the program is by producing and distributing a video news release - or VNR - to TV stations across our market area.

The VNR will tell our story as a television news feature would. We will include footage from earlier changeouts, footage of how certified and non-certified stoves work, and interviews with CONEG officials and/or participating dealers.

We will mail copies of the videotape to TV news deparments and will follow up aggressively to encourage use.

As the program encourages people to turn in their old stoves, we will issue a second VNR. In late January or early February, we will shoot footage of stoves being destroyed at the recycling facilities and will mail the videotape with a printed script -- that could be read by news personnel -providing information on the number of stoves turned in and the impact on the air stream.

\section{TARGET MEDIA}

The publicity program described above will target the following print and broadcast media:

\section{Newspapers}

\section{Connecticut}

Evening Sentinel (Ansonia)

Hartford Courant

The Herald (New Britain)

Nonvich Bulletin

Bridgeport Post

Manchester Journal Inquirer

New Haven Register

The Advocate (Stamford)

The News Times (Danbury)

Record-Journal (Meriden)

New London Day

Waterbury Republican American 
Page 5

Newspapers (con't)

Maine

Portland Press Herald

Bangor Daily News

Sun-Journal (Lewiston)

Massachusetts

Attleboro Sun Chronicle

The Christian Science Monitor (Boston)

Enterprise (Brockton)

Cape Cod Times (Hyannis)

Lynn Daily Evening Irem

The Patriot Ledger (Quincy)

Boston Globe .

Fall River Herald News

The Eagle Tribune (Lawrence)

The Standard-Times (New Bedford)

Salem Evening News

Boston Herald

Middlesex Daily News (Framingham)

Lowell Sun

Berkshire Eagle (Pittsfield)

Springfield Union News

Worcester Telegram \& Gazette

New Hampshire

The Union Leader (Manchester)

Concord Daily Monitor

The Telegraph (Nashua)

Foster's Daily Democrat (Dover)

New York

The Times Union (Albany)

Press \& Sun Bulletin (Binghamton)

Elmira Star-Gazette

Daily Freeman (Kingston)

New York Daily News

The New York Times

New York Daily Challenge (Brooklyn)

Glens Falls Post-Siar 
Page 6

Newspapers (con't)

New York (con't)

Newsday (Long Island)

New York Newsday

The Wall Street Journal (New York)

The Buffalo News

Jamestown Post-Journal

Middletown Times Herald-Record

New York Post

Poughkeepsie Journal

Rochester Democrat and Chronicle

Staten Island Advance

The Record (Troy)

Gannett Suburban Newspapers (White Plains)

Beaver County Times

Times-Union (Rochester)

Syracuse Herald Journal

Observer-Dispatch (Utica)

The Daily Gazette (Schenectady)

Syracuse Post-Standard

Watertown Daily Times

Rhode Island

The Evening Bulletin (Providence)

Providence Journal

W'oonsocker Call

Vermont

Burlington Free Press

Radio stations with talk programs

Connecticut

WLAD-AM (Danbury)

WGCH-AM (Greenwich)

WSUB-AM (Groton) 
Page 7

Radio stations with talk programs (cont.)

Maine

WDEA-AM (Ellsworth)

WABK-AM (Gardiner)

WAIZ-FM (Machias)

WLAM-AM (Lewiston)

WTOX-AM (Lincoln)

WMIEA-FM (Portland)

WRKD-FM (Rockland)

Massachusetts

WHAB-FM (Acton)

WARA-AM (Attleboro)

WBUR-FM (Boston)

WILD-AM (Boston)

WMEX-AM (Boston)

WRKO-AM (Boston)

WPEP-AM (East Taunton)

WSAR-AM (Fall River)

WHTB-AM (Fall River)

WHA V-AM (Haverhill)

WCCM-AM (Lawrence)

WCAP-AM (Lowell)

WATD-AM (Marshfield)

WBSM-AM (New Bedford)

WJCC-AM (Norfolk)

WHDH-AM (Boston)

WFGL-AM (Fitchburg)

WJJW-AM (North Adams)

WBRK-AM (Pittsfield)

WSPR-AM (Springfield)

WHYN-AM (Springfield)

WARE-AM (Ware)

WACM-AM (West Springfield)

WOCB-AM (West Yarmouth)

WTAG-AM (Worcester)

New Hampshire

WBNC-AM (Conway)

New York

WQBK-AM (Albany)

WFAN-AM (Astoria)

WEAS-AM (White Plains)

WBEN-AM (Buffalo) 
Page S

Radio stations with talk programs (con't)

New York (con't)

WHHO-AM (Homell)

WLEA-AM (Hornell)

WVIP-AM (Mount Kisco)

WABC-AM (New York)

WBAI-FM (New York)

WHCL-FM (Clinton)

WSYR-AM (Syracuse)

WRKS-FM (New York)

WKDR-AM (Peru)

WIBX-AM (Utica)

Rhode Island

WCTK-FM (East Providence)

WHUJ-AM (East Providence)

WRCP-AM (North Providence)

WALE-AM (Providence)

Vermont

WCFR-AM (Springfield)

WKDR (Burlington)

WVPR (Windsor and Colchester) 


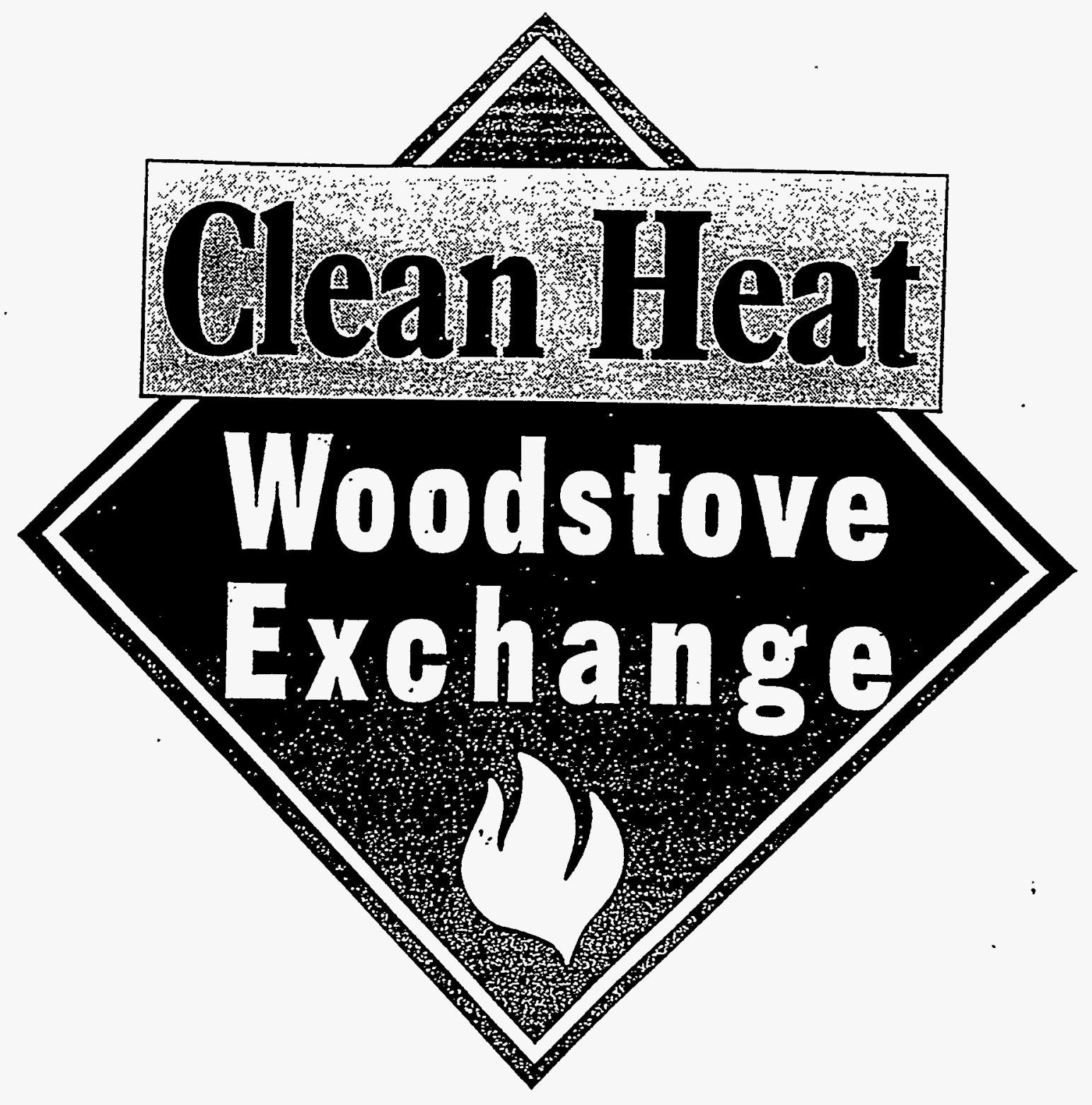




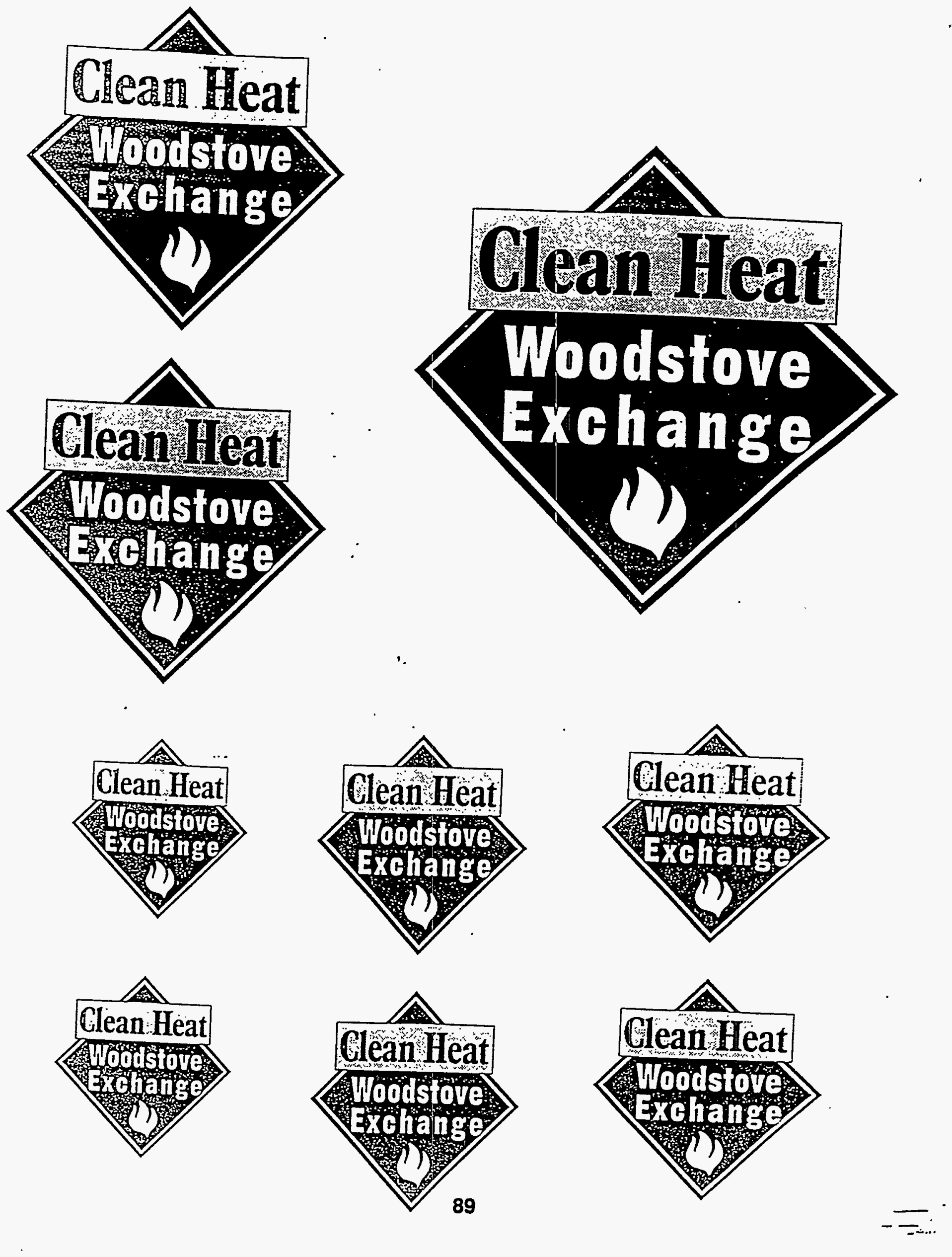




\title{
Save Up To $\$ 200$ On A New Woodstove.
}

\author{
(Insert Stove Picture Here)
}

Get up to $\$ 200$ trade-in allowance now during the Clean Heat Woodstove Exchange

There's never been a better time to trade-in your older woodstove for a cleaner burning, morc efficient, EPA-certified woodstove. Woodstove technology has advanced rapidly and today's woodstoves will help you save time, energy, money and the environment. The Clean Heat Woodstove Exchange is your chance to make a change for the better-and save some money.

- Get up to a $\$ 200$ trade-in allowance.

- Save money-heat with less fuel.

- Reduce pollution-new stoves reduce emissions up to $70 \%$.

Supponed by the U.S. Deparment of Encrgy Northeast Regional Biomass Program and the Northeast Hearth Products Association

(Dealer Logo Here)

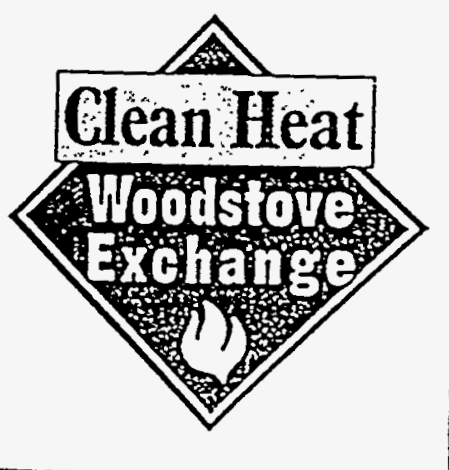




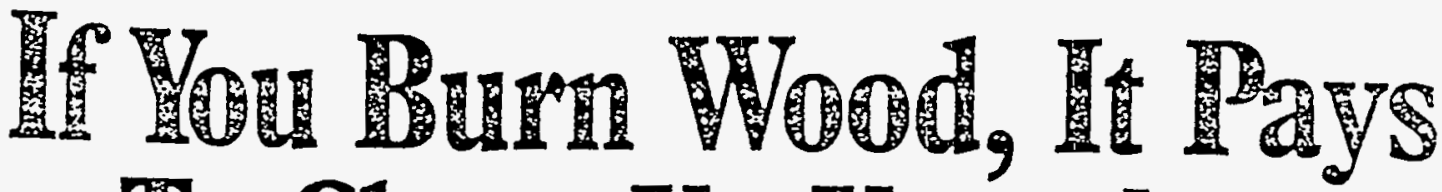 To Clean Up Your Act.
}

\author{
(Insert Stove Picture Here)
}

Get up to $\$ 200$ trade-in allowance now during the Clean Heat Woodstove Exchange

There's never been a better time to trade-in your older woodstove for a cleaner burning, more efficient, EPA-certified woodstove. Woodstove technology has advanced rapidly and today's woodstoves will help you save time, energy, money

and the environment. The Clean Heat Woodstove Exchange is your chance to make a change for the better-and save some money.

- Get up to a $\$ 200$ trade-in allowance.

- Save money-heat with less fuel.

- Reduce pollution-new stoves reduce emissions up to $70 \%$.

Supported by the U.S. Deparment of Energy' Northeast Regional Biomass Program and the Northeast Hearth Products Association

(Dealer Logo Here)

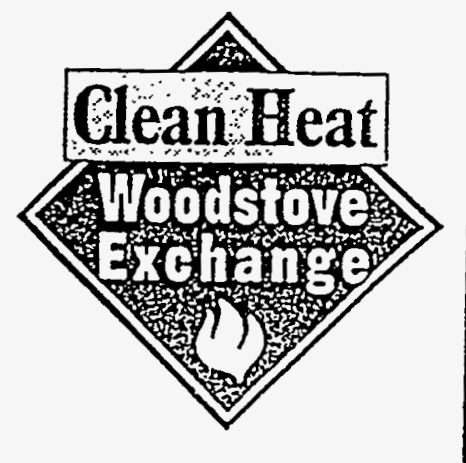




\section{Save Up To $\$ 200$ On A New Woodstove.}

(Insert Stove Picture Here)

Get up to $\$ 200$ trade-in allowance now during the Clean Heat Woodstove Exchange

There's never been a better time to urade-in your older woodstove for a clenner burning, more efficient, EPA-cerified woodstove. Woodstove tecbnology has advanced rapidly and today's woodstoves will he!p you save time, energy; money and the envitonment. The Clean Itest Foodstove Excinange is your chance to make a change for the better-anc sare sorae mone:

- Get up to a $\$ 200$ trade-in allowance.

- Save money - heat with less fuel.

- Reduce pollution-ner stores reduce emissions up to $70 \%$.

Supponed by the U.S. Deparment of Eraxy Northeast Retional Biomass Program and the Nonteass Hesnth Produas Asociation

(Dealer Logo Here)

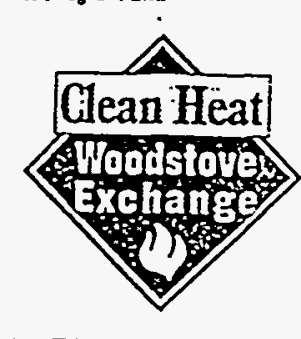

Âd 


\title{
If You Burn Wood, It Pays To Clean Up Your Act.
}

\author{
(Insert Stove Picture Here)
}

Get up to $\$ 200$ trade-in allowance now during the

Clean Heat Woodstove Exchange

There's never been a better time to trade-in your older woodstove for a cleaner burning, more efficient, EPA-cerified woodstove. Woodstove technolog: has advanced rapidly and today's woodstoves will help you save time, energ;; rooney and the environment. The Clean Heat Woodstove Exchange is your chance to

make a change for the better-and save some money.

- Get up to a $\$ 200$ trade-in allowance.

- Save money-heat with less fuel.

- Reduce pollution-neri stoves reduce emissions up to $70 \%$.

Supponed by the U.S. Depanment of Enero. Northeast Regional Biomass Program and the Northeast Hearst Producs Assaciation

(Dealer Logo Here)

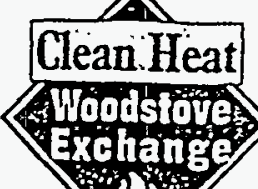




\section{Save Up To $\$ 200$ \\ On A New Woodstove.}

\section{Save Up To \$200 \\ On A New Woodstove.}

\section{If You Burn Wood, It Pays To Clean Up Your Act.}

If You Burm Wood, It Pays To Clear Up Vourio Act.

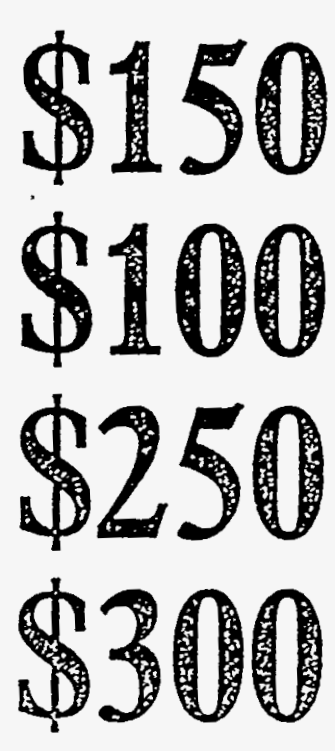

$\$ 15$

$\$ 1$

21

1) 
anuary February $12234567891011121314 \quad 15$

$\begin{array}{lllllllllllll}6 & 17 & 18 & 19 & 20 & 21 & 22 & 23 & 24 & 25 & 26 & 27 & 28\end{array}$

ave Now It Pays To Come Clean

lean Heat Stove Exchange Ends For A Limited Time Only!

xchange Ends Save Money Now! Act Now!

ffer Only Good Until

$! ! ! ! ! ! ! !,,,,,,,,,,:::::::::$ It Pays To Change

ee Pick Up

¿ Up To $\$ 200$ Trade-In Allowance! Save Up To \$200 Now!

re Up To $\$ 200$ On A New Woodstove! Only Days Left!

:'ll Really Clean Up Now's The Time To Really Clean Up

e $\$ \$ \$ !$

e Now! 

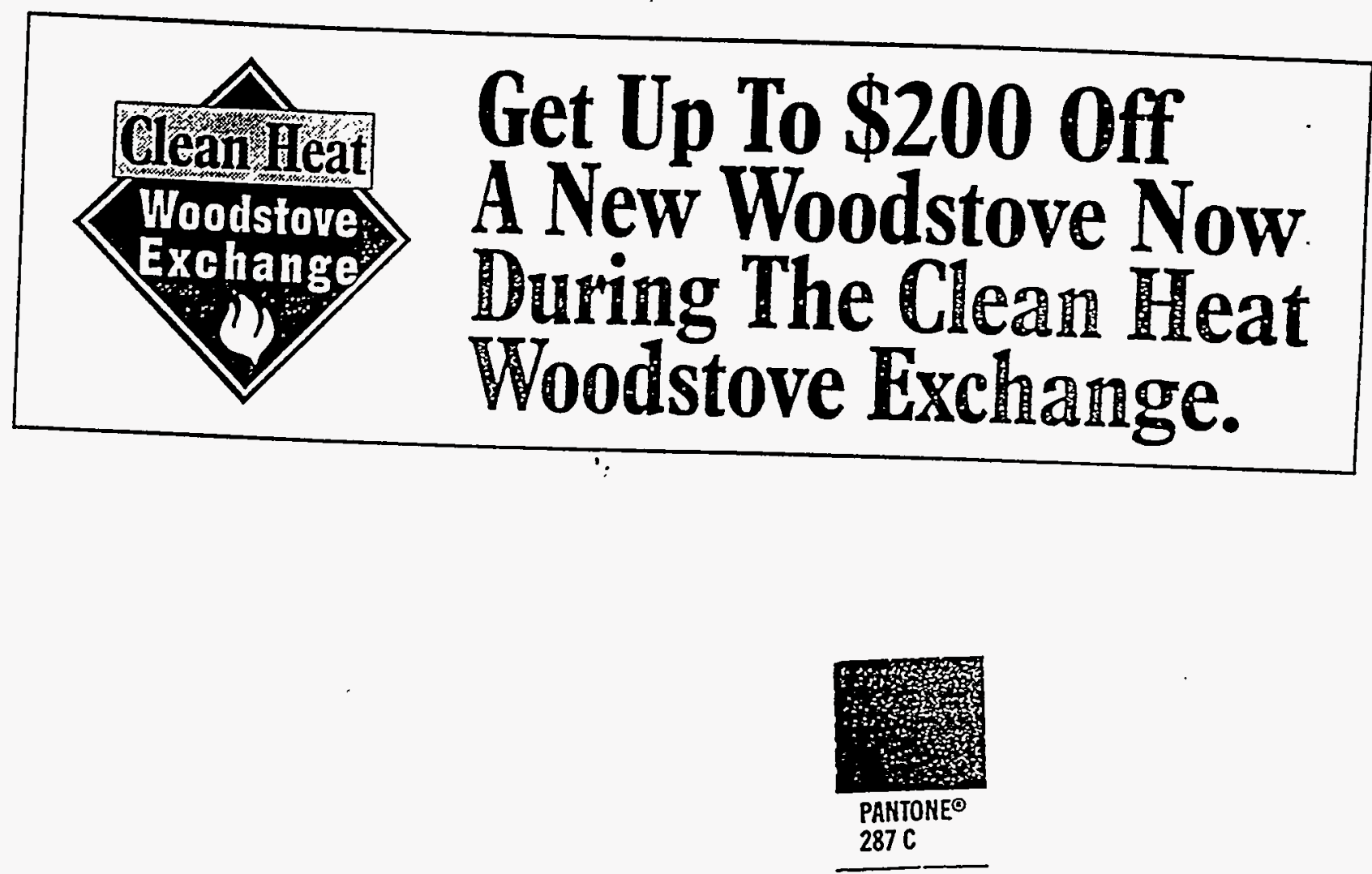

Banner 
I

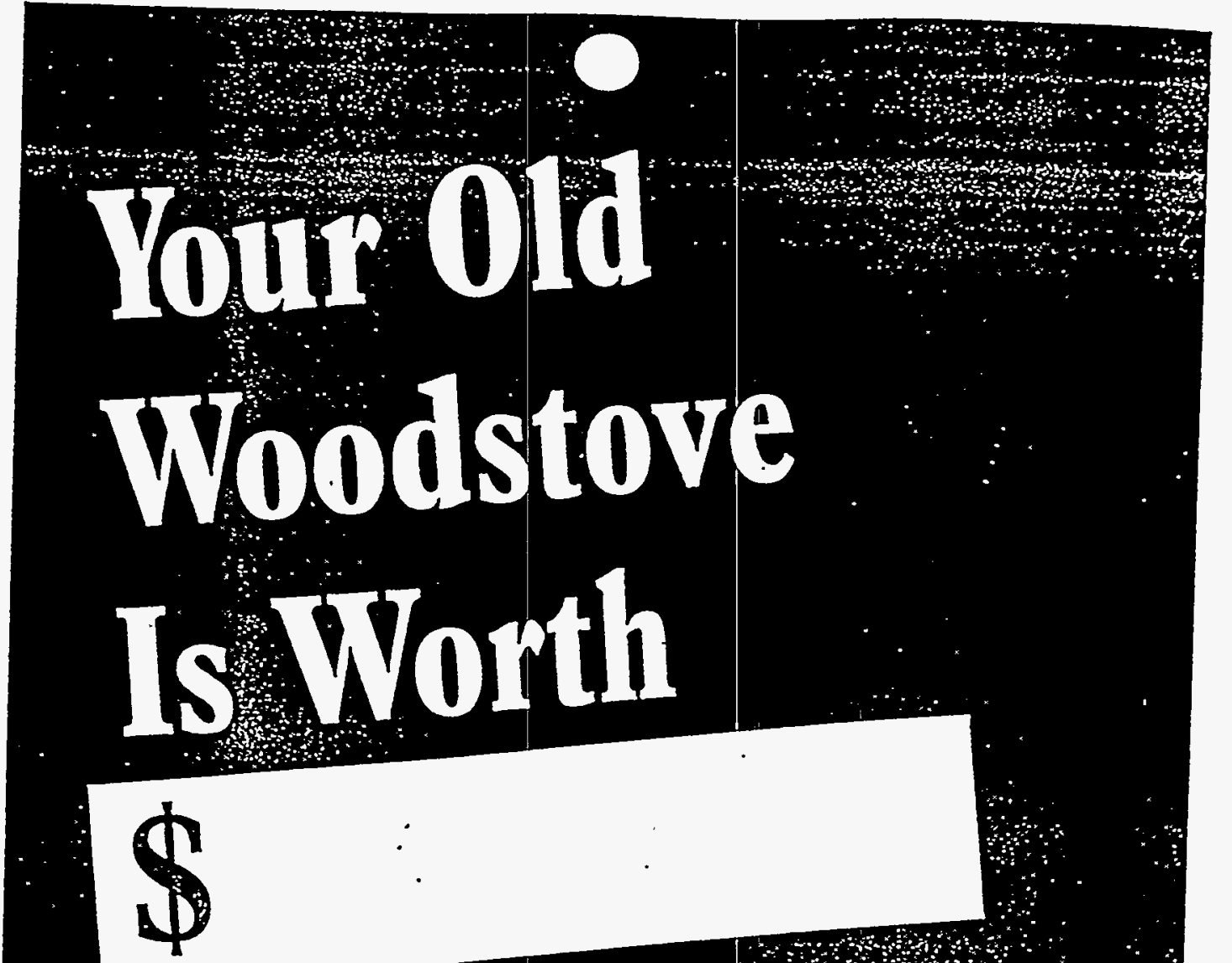

Toward This

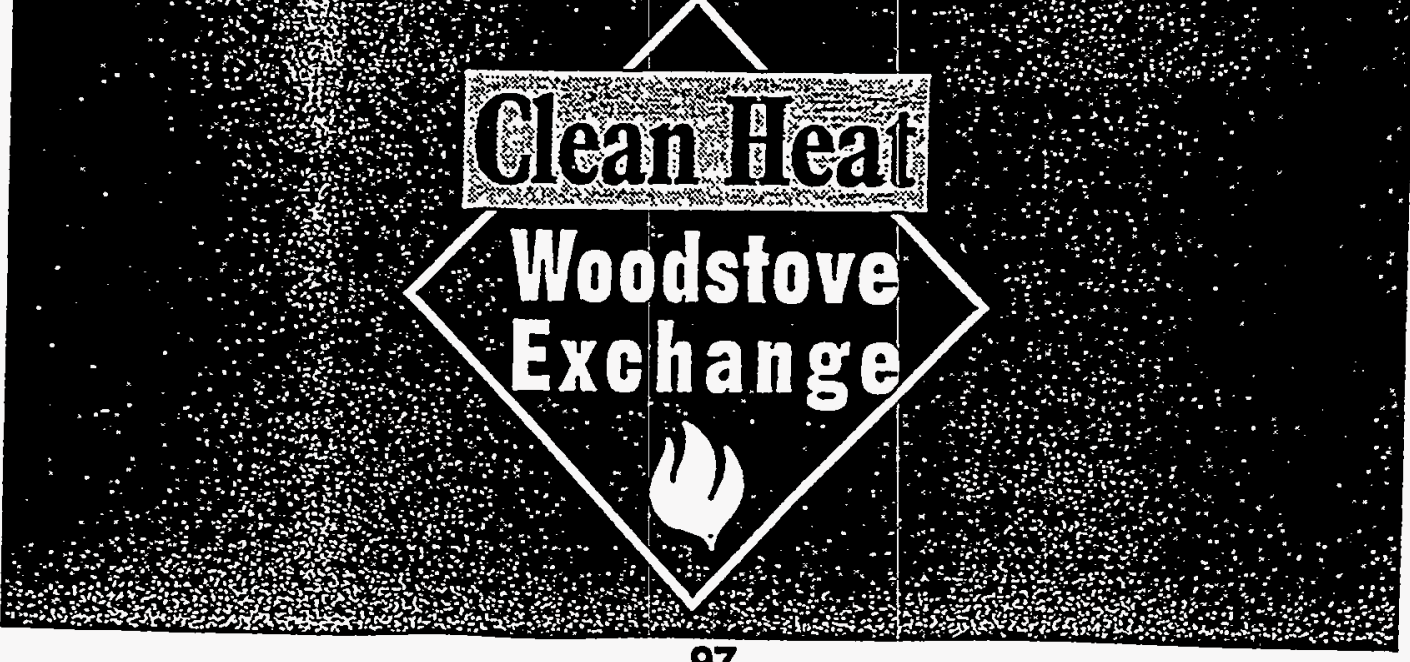




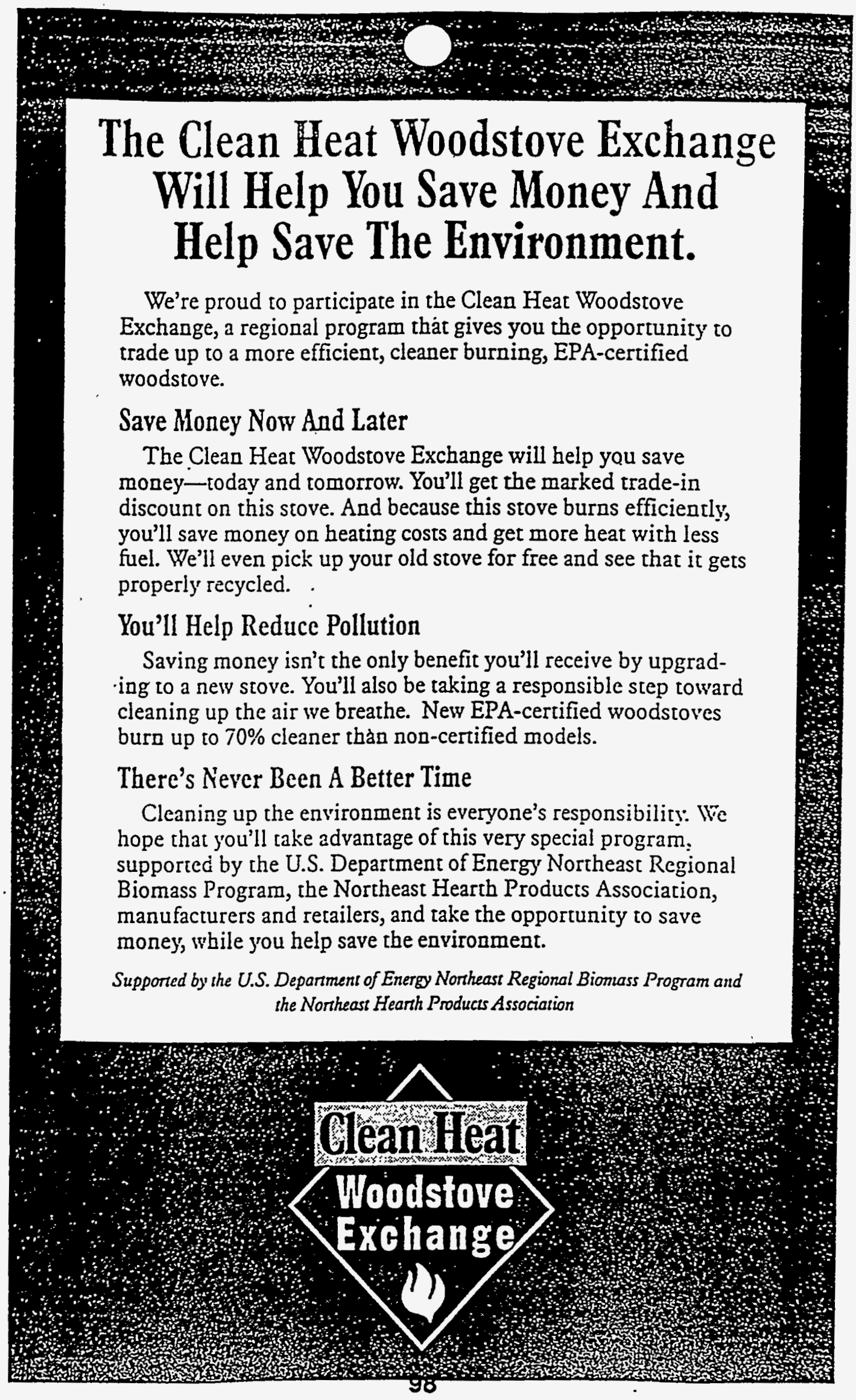




\section{TITLE: LANDFILL GAS ॥: TECHNOLOGIES}

\section{WORK STATEMENT}

1. Select and describe a typical landfill gas composition.

2. Perform a comparative analysis among several technologies, looking at both economic and environmental (air emissions) costs and benefits, including economic incentives which may be available to LFG projects.

The economic incentives shall include capacity and energy payments, tax incentives, and REPI payments. Develop system engineering designs for traditional and non-traditional low-cost, low-polluting conversion technologies, which are or could soon be commercially available for projects ranging in size from 1000 to $5000 \mathrm{KW}$. (At a minimum, system designs should be developed for projects at the 1000 and $3000 \mathrm{KW}$ size, and for at least one intermediate size.) Specific conversion technologies to be considered would include but would not necessarily be limited to: Otto Cycle (spark ignition engine); Organic Rankine Cycle (vapor turbogenerator system)'; Brayton Cycle, (gas turbine configuration); Stirling Cycle (external combustion engine) ${ }^{2}$.

In addition to being considered as a stand-alone system (using heat from a conventional LFG incinerator), the organic rankine cycle system (ORC) shall also be evaluated (as appropriate) as an add-on to other technologies as a waste heat recovery-to-electricity system.

Include process flow diagrams for each size configuration.

3. Given the system designs developed for Task 1, estimate capital investment, operating and maintenance costs.

4. Examine existing and pending regulations in the 11-state region as well at the federal level to ascertain whether reduction of emissions due to LFG energy projects qualify for any economic incentives, including off-site emissions reduction credits.

\footnotetext{
1 The ORC system, although in existence for over 30 years, is not widely available. Two companies known to make ORC systems are: (1) Perennial Energy, Inc. of West Plains MO, and (2) Ormat, Inc. of Reno/Sparks, Nevada.

2 The Stirling technology is an old concept, but only recently has surfaced as a potential contender across a wide range of industries (refrigeration, automotive and power generation). A company known to be working on the development of Stirling systems is Mechanical Technology, Inc. of Latham, New York.
} 
5. Determine the types of project partnerships that are necessary to maximize federal economic incentives, in terms of the PTC or the REPI, for each technology considered.

6. Obtain from Public Utilities Commissions current purchase prices regulated electric utilities are required to offer for electricity from LFG projects of $5,000 \mathrm{KW}$ capacity or less.

7. Obtain from each state's Public Utilities Commission what Environmental Externalities monetary values for air emissions, if any, which are either in effect or being considered.

8. Using the information developed in the preceding tasks, perform a comparative analysis (within the 1000 to $3000 \mathrm{KW}$ range) between all conversion technologies under consideration to compute and tabulate all pertinent parameters associated with each technology, including the following:

- efficiency;

- capital cost (in total $\$$ and in $\$ / K W$ installed);

- power generation cost, cents/kWh

- air emissions in $\mathrm{lbs} / \mathrm{kWh}$.

9. Prepare a tabulation comparing each conversion technology's air emissions (in $\mathrm{lbs} .(\mathrm{kWh})$ to those in the system margin of each utility, to the extent available data permit.

10. Review the CAAA and state regulations to ascertain whether a case could be made for legislative and regulatory action establishing mechanisms to credit the emissions reductions achieved by LFG projects and to enable such credits to be sold to help generate economic incentives for such projects. Consider in particular the credits which may be forthcoming with adoption of the pending New Source Performance Standards for nonmethane organic compounds (NMOC) and methane.

11. Prepare a tabulation comparing information obtained in Task 5 and 6. Also, indicate the states with monetary values for Environmental Externalities that allow trading of off-site emission reduction credits, similar to the case in Massachusetts.

12. Prepare a tabulation showing air emissions changes at the landfill site (before and following implementation of each LFG conversion technology considered) for the each of the following substances:

- Nox

- Sox

- NMOCs

- VOCs 
- TSP

- $\mathrm{CO}$

- $\mathrm{CO}_{2}$

- $\mathrm{CH}_{4}$

- $\mathrm{N}_{2} \mathrm{O}$

Establish "most common" project scenarios to assist formulation of these tabulations. Also describe scenarios that represent exceptions to these tabulations, exceptions in which one technology is favored over another.

\section{DELIVERABLES}

Interim Report summarizing the findings from each task.

Produce a comprehensive report delineating the results of the foregoing tasks and findings. The report will be geared towards potential public and private developers of LFG energy projects. The report should aim to demonstrate the availability of low cost conversion technologies, appropriate to landfill sites of different sizes and other conditions, which when combined with existing economic incentives (FPT or REPI) and pressing LFG control regulations, will accelerate the development of LFG energy projects.

The report shall also be directed to key constituencies, air, water, and solid waste regulators, environmental consultants, municipalities, landfill operators, and utilities. 


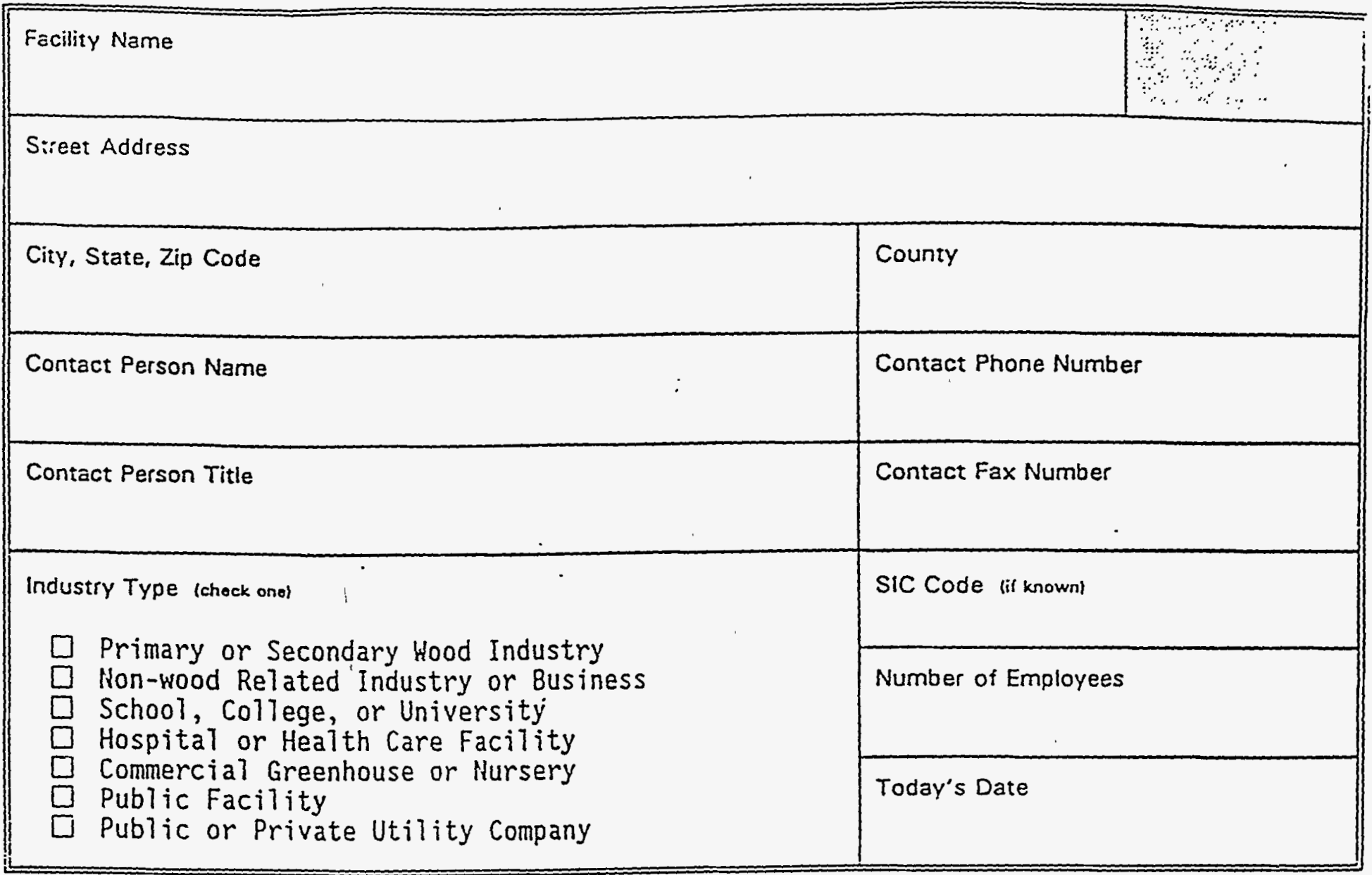

\section{Biomass Energy: System}

Eiomass Energy System Operating Status (check onel

I Planned

$\square$ Under Construction

Operational

$\square$ Temporarity Shutdown

$\square$ Permanently Shutdown

\begin{tabular}{l|l|l|l|}
\hline $\begin{array}{l}\text { Biomass Energy System Start Up } \\
\text { Date }\end{array}$ & $\begin{array}{l}\text { If Operational, Total Operating Time } \\
\text { for Downtime }(\%)\end{array}$ & If Shutdown, Planned Restart Date \\
\hline
\end{tabular}

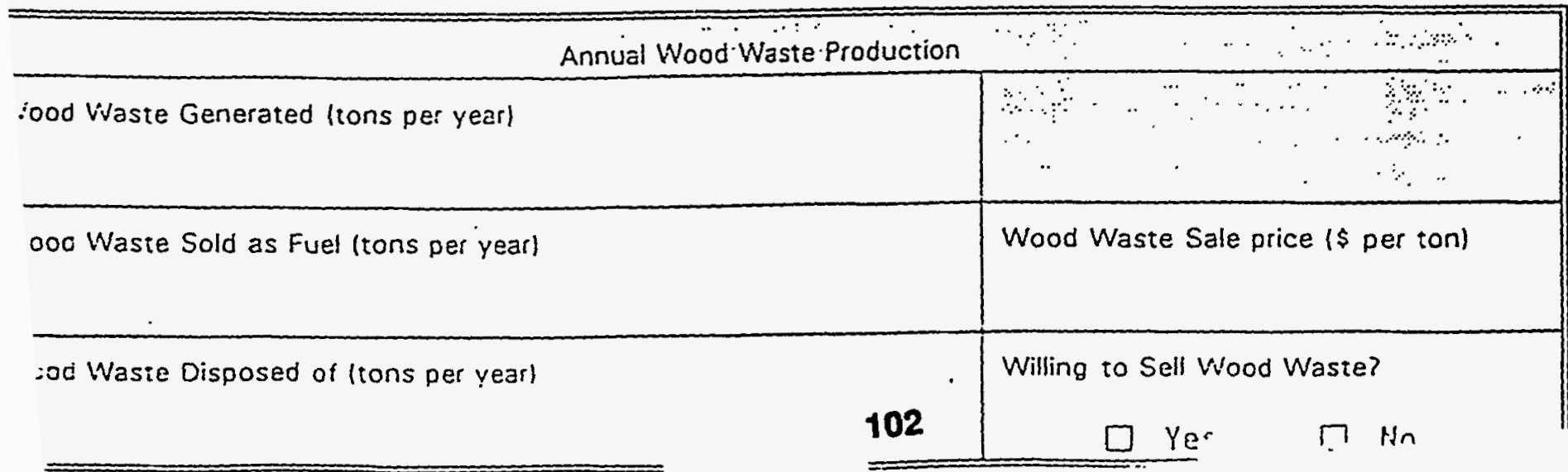




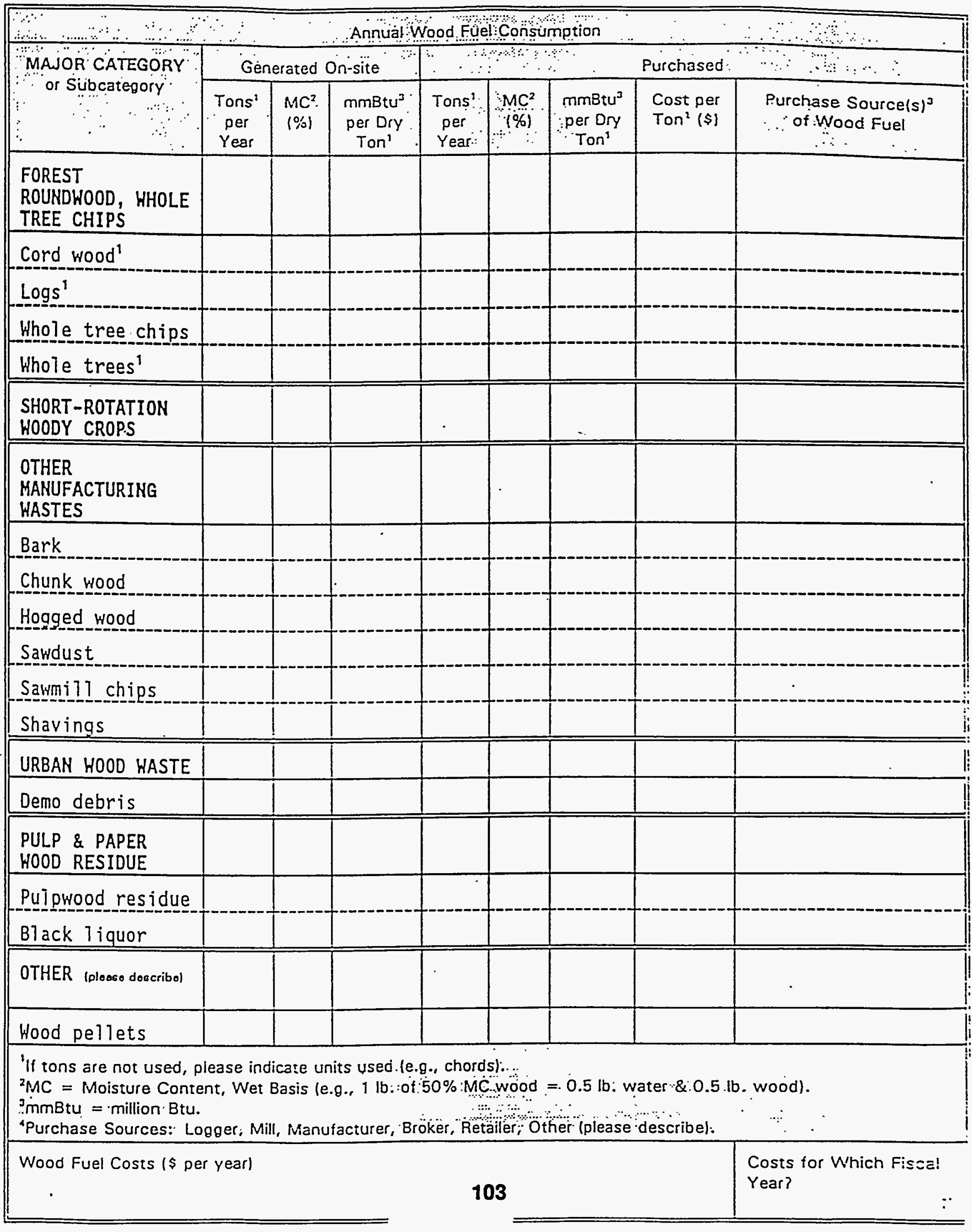




\begin{tabular}{|c|c|c|c|c|}
\hline \multicolumn{4}{|c|}{ ॥े। } & \multirow{2}{*}{$\begin{array}{l}\text { If Co-fired with Wood Fuel; } \\
\text { Describe Wood Fuel Type(s) }\end{array}$} \\
\hline$\because \quad$ Type & Units & $\begin{array}{c}\text { Units'per } \\
\text { Year. }\end{array}$ & $\begin{array}{c}\text { Cost pert } \\
\text { Unit. }\end{array}$ & \\
\hline Anthracite & Tons & & & $\vdots$ \\
\hline $\begin{array}{l}\text { Bituminous } \\
\text { Coal }\end{array}$ & Tons & & & 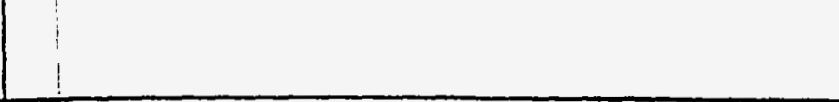 \\
\hline Lignite & Tons & & & $i$ \\
\hline Natural Gas & $\begin{array}{l}\text { Cubic } \\
\text { Feet } \\
\end{array}$ & & : & \\
\hline$\# 20 i i$ & Gallons & & & ! \\
\hline \#̈6 0 il & Gallons & & & 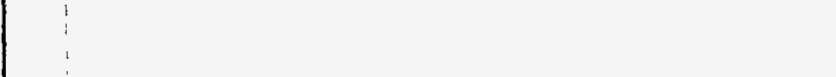 \\
\hline Propane & Gailons & & & ! \\
\hline \multicolumn{5}{|l|}{$\begin{array}{l}\text { Other Iploese } \\
\text { describal: }\end{array}$} \\
\hline \multicolumn{5}{|c|}{ If listed units are not used, cross out and replace :with unitsusused, } \\
\hline Fossil Fuel Costs 1 & per yearl & & & Costs for Which Fiscal Year? \\
\hline
\end{tabular}

\begin{tabular}{|c|c|c|c|c|c|c|}
\hline \multicolumn{3}{|c|}{$\begin{array}{r}\cdots \\
\therefore\end{array}$} & \multicolumn{4}{|c|}{ Energy Production: } \\
\hline$\therefore \quad$ Product. & Units' & $\begin{array}{c}\text { Production } \\
\text { Capacity } \\
\text { (units pers } \\
\text { hour) }\end{array}$ & Añnial & $\begin{array}{l}\text { Annual } \\
\text { Sales } \\
\text { funnits) }\end{array}$ & $\begin{array}{r}\text { Sale Price. } \\
\text { unpert } \\
\text { unit) } \\
\end{array}$ & 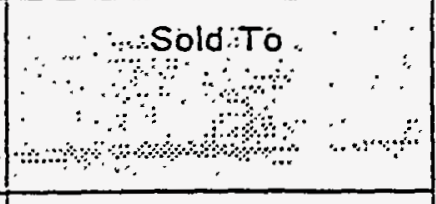 \\
\hline Heat & mmBtu & & & & & \\
\hline Steam & $\begin{array}{l}\text { Tbs/hour } \\
\text { IPSIG: }\end{array}$ & & & & & \\
\hline Electricity & kth & & & & & \\
\hline \multicolumn{7}{|c|}{$\begin{array}{l}\text { 'mmBtu = million Btu; Ibs = pounds;.PSIG = pounds per. square inch gauge; } k \text { Wh = kilowatt hour. } \\
\text { If listed units are not used, cross out and replace with units used. }\end{array}$} \\
\hline \multicolumn{3}{|c|}{ Electricity Cogenerated with Heat or Steam? } & \multicolumn{3}{|c|}{104} & \\
\hline
\end{tabular}




\begin{tabular}{|c|c|c|}
\hline$\therefore \quad=\quad 4$ & \multicolumn{2}{|l|}{ Egupment Description } \\
\hline Súbsystem & Typels) $1,2.3,4.6$ & Manufacturer(s) \\
\hline Delivery' & & \\
\hline Storage $^{2}$ & & . \\
\hline $\begin{array}{l}\text { Screening/ } \\
\text { Handling }\end{array}$ & & \\
\hline $\begin{array}{l}\text { Boiler/ } \\
\text { Combustion } \\
\end{array}$ & $\therefore$ & \\
\hline Air Emissions ${ }^{4}$ & & \\
\hline Ash Disposal ${ }^{5}$ & $=$ & \\
\hline $\begin{array}{l}\text { Turbine/ } \\
\text { Generator }\end{array}$ & & - \\
\hline 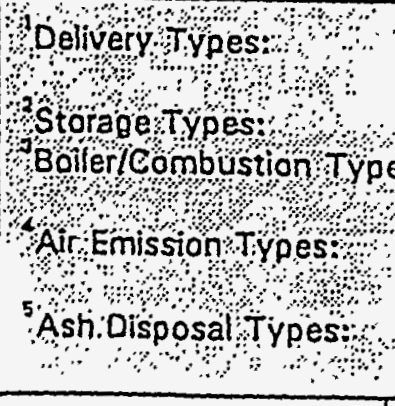 & 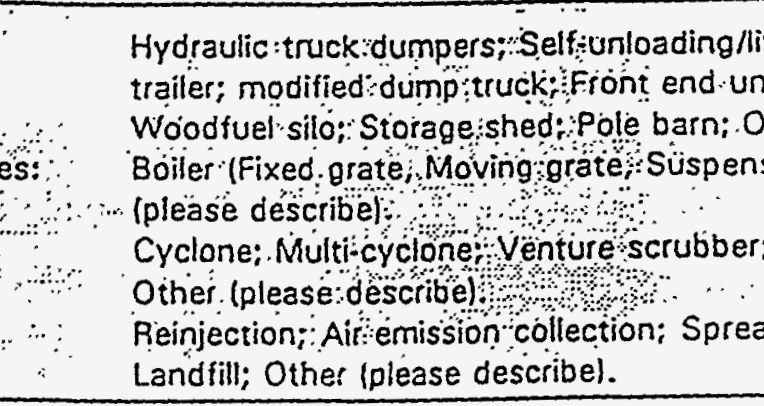 & 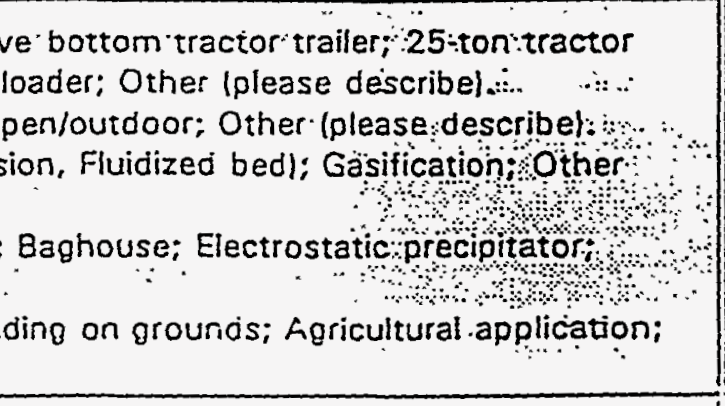 \\
\hline $\begin{array}{l}\text { Total Equipment } \\
\text { Costs (\$) }\end{array}$ & $\begin{array}{l}\text { Equipment Funding Sources (theck all that applyl } \\
\square \text { Conventionat Financing } \\
\square \text { Leasing } \\
\square \text { Third Party Ownership and Proje }\end{array}$ & $\begin{array}{l}\square \text { Tixx-exempt, State } \\
\square \text { Tix-exempt, Local } \\
\end{array}$ \\
\hline
\end{tabular}

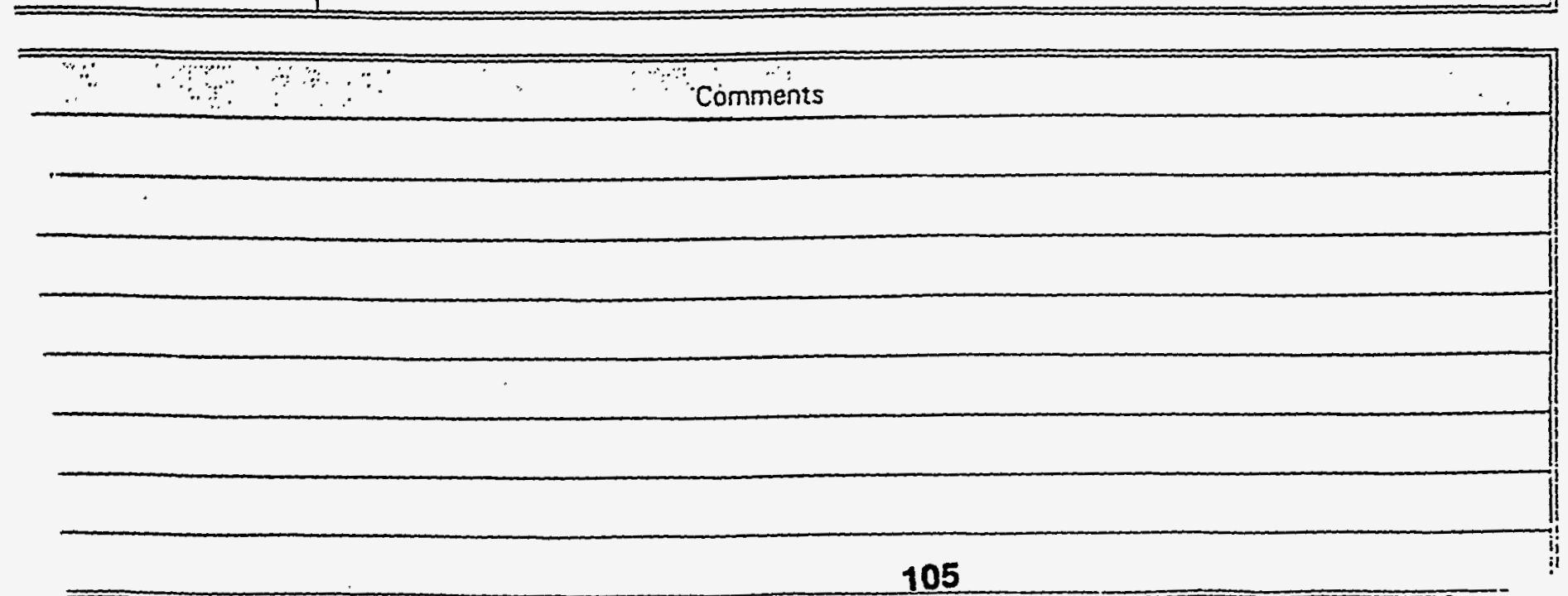





\section{TITLE: A METHODOLOGY FOR ENVIRONMENTAL EXTERNALITIES ACCOMMODATING BIOMASS FEEDSTOCKS}

Task 1: Examine proposed and existing regulations and related literature addressing environmental and economic externalities. For each of the 11 Northeastern states assess the status of existing or proposed methodologies for incorporating externalities into resource bidding or planning processes.

1.1 Carry out a literature review and interviews with consultants, PUC staff, commissioners and other experts to complete the following tasks:

- review of existing and proposed use of externalities for resource bidding or planning processes by regulators and utilities across the U.S., and particularly in the 11 Northeastern states;

- review of literature assessing general and specific methodologies for incorporating environmental externalities and economic impact considerations into utility rate structures and planning;

- review of total fuel-cycle analyses and approaches for addressing fossil fuels and biomass power, including data on:

- combustion emissions from current and emerging/advanced conversion technologies (such as gasification/combined-cycle systems), particularly $\mathrm{SO}_{2}$, $\mathrm{CO}_{2}$ and $\mathrm{NO}_{x}$;

- emissions related to supplying fuel: for fossil fuels this would include data on emissions from mining or drilling and transport of fuels; for wood fuel this would include $\mathrm{CO}_{2}$ sequestering with tree growth, as well as emissions related to producing, harvesting/collection and transport of wood fuel;

- collection of data and information on the economic impacts of supplying and converting biomass vs. fossil fuels, including:

- direct and indirect jobs and income;

- improved forest quality and value, through good forest management techniques in providing wood residues;

- projections of electric generating capacity needs of the 11 states within the Northeastern Regional Biomass Program (NRBP) area. 
- collection of other data relevant to biomass, such as:

- avoided costs and emissions from the use of wood waste (considering avoided landfill tonnages, reduced methane emissions by avoided decomposition of biomass in forests and landfills);

- biomass resource availability and costs (which will affect the ultimate impact and market penetration of biomass);

- generating capacity in the 11 NRBP states suitable for cofiring biomass (i.e., simultaneous cofiring of coal and wood).

1.2. Document effects on the resource mix due to competitive bidding and IRP processes through the use of contractor data bases, interviews and the additional information collected under Task 1 , identify

- utilities in the Northeast that have prepared resource plans or implemented competitive bidding processes which include externality factors;

- particularly relevant examples from states outside the Northeast; and

- documentation regarding the effects of these approaches on the resource mix.

Task 2: Draft report outlining the status and key features of existing/emerging methodologies, documenting the impacts considered, how values are assigned to those impacts and applied to resource planning. In particular, identify,

- the value (explicit or implicit) assigned to $\mathrm{CO}_{2}$;

- whether and under what circumstances wood is treated as a renewable;

- whether resources are ranked on basis of total fuel-cycle or combustion impacts only; and

- documented impacts of existing methodologies on the resource mix.

Include sections in the report which address the following topic areas:

- The range of values assigned to other environmental externalities including, but not limited to, $\mathrm{SO}_{2}, \mathrm{NO}_{x}$, solid wastes, and waste water streams -particular attention will be paid to value systems which include benefits or credits for emission reductions;

- Environmental factors that are not being allocated a value, or included in the utility resource selection processes, which may be of interest with respect to biomass applications (e.g., reductions in emissions for co-firing biomass at coal plants, socioeconomic impacts such as jobs and use of indigenous resources, waste minimization, etc.); 
- Definitions of technologies/fuel-cycles as renewable energy resources, the reasoning behind the definitions and the pros and cons of specific definitions;

- A description of the various methodologies utilized -- quantitative versus qualitative -- and how those methodologies were developed including a discussion of the considerations taken into account by regulators in developing the process;

- How the values and methodologies are being applied by the utilities under the jurisdiction of the regulators and the means for incorporating these into the resource selection process including integrated resource planning and competitive bidding;

-What real impacts environmental externalities or total energy cycle analyses are having on the future resource mix including why certain approaches either fairly or unfairly treat biomass as a resource option;

-Whether environmental externalities or total energy cycle concepts are being applied on a systematic basis which addresses both future and existing energy resources (for example, are potential negative impacts from biomass, such as PM10 emissions or impacts on habitat being given more attention than impacts of coal mining on land and habitat); and

- Differences in basic methodologies for addressing the externality cost factors for $\mathrm{CO}_{2}$-- some methods address the cost of control (such as tree planting), while others address damage costs (such flooding of coastal areas);

-What actions or research has been undertaken to address the many economic "externalities," the pros and cons of including economic externalities, and the arguments and positions of various key stakeholders in the industry.

The draft report will include appendices which incorporate all bibliographic references and citations for interviews.

Task 3: Taking account of findings discussed in Tasks 1 and 2, propose one or more approaches for appropriate life-cycle evaluation of biomass energy projects, considering total fuel-cycle impacts.

3.1 As part of this work, include an accounting framework to:

(1) identify the emissions burden from a biomass fuel-cycle stage;

(2) name and identify impacts and if possible, give quantitative ranges of named impacts, and 3) translate these impacts into estimates of damages or benefits; 
(3) address environmental characteristics of the biomass supply portion of the full fuel-cycle, including production/procurement, harvesting, processing, and delivery;

3.2 Develop an evaluation matrix for the environmental impacts for several key biomass conversion technologies including stoker boilers, fluidized-bed conversion, gasification gas turbine technology (STIG, ISTIG and combinedcycle systems), and the Whole-Tree Burner ${ }^{\mathrm{TM}}$ technology, to characterize the material/chemical agents generated by biomass power systems, plant waste streams and their impact on air, water, land, and habitat.

In these evaluation frameworks, the contractor will also account for the environmental benefits of biomass-fueled plants. The evaluation will explicitly consider:

Utility Control: is the cause of the externality effect or economic impact within the control of an electric utility? IOU vs. other utilities?

Commission Jurisdiction: Is the cause of the externality effect or economic impact within the jurisdiction of the Commission?

Existing Regulations: Is there existing federal or state legislation which addresses(to any degree) the causes of the externality effect/state economic impact?

Geographic Scope: What is the geographic scope of the externality effect? Local, regional, or global?

Scientific debate: Is there scientific debate about the role or magnitude of the externality effect?

High Risk: What is the relative risk of the externality effect in relation to the number of affected sites or scale of the problem?

Task 4: Beyond fuel-cycle impacts, evaluate the arguments for and against establishing an absolute externality value or percentage adder to account for the development of economic development impacts of utilizing various energy resources. Propose an approach and approximate measures of the job creation and associated benefits of energy from wood, natural gas, coal, and oil, for subregions within the Northeast.

To complete this task, the contractor will examine the trade-offs between distributional issues (related to jobs and income creation, etc.) and efficiency (such as least-cost, economic dispatch approaches) in addressing aspects of resource decisions. 
Task 5: Project the likely impacts of the proposed methodology on electric power generation in the region, and on resulting total fuel-cycle emissions levels, electric rates, and job creation within the region as compared with the likely impact of twothree representative IRP methodologies now employed in the region. Address when and how quickly the proposed approach or approaches, if adopted, might affect the regional resource mix.

To accomplish this task, undertake at a minimum the following tasks:

- a projection of potential capacity needs in the 11 states covered by NRBP, as the target market for biomass capacity;

- analysis of base case (no externalities) and current (with representative environmental factors in use in the Northeastern states) evaluation methods on biomass competitiveness and the potential for overcoming the competitive disadvantages of biomass versus conventional technologies by applying TFCA methods;

- an estimate of the market penetration of biomass technologies over time as the result of plausible externality valuations, in the context of capacity needs and their current cost competitiveness (including cofiring at existing coal plants and new stand-alone biomass power plants);

- impacts of potential biomass market penetration on job creation, electric rates, emissions and environmental impacts, and regional resource mix.

Consider life extension and repowering possibilities as well as incremental additions to capacity. Also consider co-firing wood with coal at existing coal plants as an option undertaken to reduce current sources of pollutants at these sites.

In the geographic analysis of the region which matches specific capacity needs to biomass resource and technology options, consider explicitly at a minimum the following:

- negative impacts of not acting to use biomass waste streams, like waste wood, when they contribute to landfill capacity shortages and landfill methane emissions;

- local opportunities to reduce reliance on imported fuels;

- the constraints wildlife, endangered species and land use impacts can have in limiting biomass development; and

- biomass potential in areas where their contributions to air quality improvements could be more highly valued because of particular criteria air pollutant problems. 
Task 6. Identify opportunities to influence or modify the region's resource planning processes. Assess the relative value of promoting such modifications. Given the prospects for adoption of total fuel-cycle approaches, and the likely resulting impacts on the resource mix, outline a strategy for pursuing the recommended modifications.

Identify particular utilities and public utility commissions in the region where one or more strategies may be successful.

Task 7. Draft a final report incorporating the findings, analyses, methodologies and recommendations in Tasks 1-6.

The report shall include a stand-alone executive summary of 8-12 pages. The full report shall also include in its appendices a full bibliography of important references and interviews. 


\section{TITLE: ECONOMIC IMPACTS OF WOOD ENERGY IN THE NORTHEAST}

\section{Phase 1: Economic Impact Model}

Task 1.1: Consult with CONEG and Northeast States on Final Product Needs. Before engaging in the major tasks of model design and data compilation, consult with state governments and CONEG to determine the form the estimates should take and the types of economic impacts that are of particular interest to decision makers.

Distribute a summary of project deliverables and a summary of the approach to representatives of each state identified by CONEG. Invite comments by completing telephone interviews with each state representative.

Provide a workplan and specification of final deliverables.

Task 1.2: Design Economic Impact Model.

Based in part on information gathered in Task 1.1, determine structure and parameters of economic impact model. While the model used to generate initial economic assessment and projections may be more complex, it should be designed with an eye to how it may later be modified to provide a simplified version that states can run on a PC to determine the impact (on such outcomes as direct and indirect employment, income, and energy cost savings) of projects that increase the state's overall wood energy use.

The computer program shall include standardized input templates for state-specific data, automatic lookup functions for the indirect impact multipliers, and standardized tabular and graphic outputs of impacts in terms of jobs, income and taxes generated. The model will cover the commercial and industrial, and residential sectors.

The product will be a preliminary spreadsheet model design with blank spaces for data and multipliers.

Tasks 1.3 and 1.4: Program and Test-Run Model on Mock Data.

Test-run the model on mock data derived from a quick literature search. The model should at a minimum be able to estimate direct and indirect employment impacts, as well as impacts on income and fossil fuel displacement, and to distinguish between residential and commercial/industrial wood energy use impacts. The model should account for employment and income that might have been generated by energy sources (e.g., oil) displaced by wood energy. Data on employment and income and economic multipliers for oil and other energy sources will be calculated from available published and unpublished sources.

Utilize the IMPLAN I/O model (Version 91F) with the 1991 data which are the most recent state data available. Test the model before the data collected in tasks 2.1 - 3.2 become available to insure that the work on the model is not delayed. 
Phase 2: Survey Employment and Economic Characteristics of Wood Energy Industry

Task 2.1: Design a Survey of Employment and Salaries.

Drawing on existing studies of wood energy using industries, including industrial and commercial boiler users, pellet producers, loggers, whole tree chippers, truckers, foresters and others, as well as available case studies and data from state and federal agencies, design a survey to determine the numbers and types of jobs associated with the various parts of the wood energy system in the region. The survey will generate data on which to base quantitative estimates of the direct employment and income generated (both per green ton of wood and per Btu) at every stage of every form of production of energy from wood. The survey will need to address geographic variations in energy use, as well as variations among the residential, commercial, and industrial sectors.

CONEG shall approve the survey instrument after it is pretested with five subjects from different wood constituencies, but before it is implemented.

Task 2.2: Conduct the Survey and Interpret the Results.

Conduct the survey using mail and telephone. Complete the survey after successfully reaching a minimum of 40 companies in the wood energy industry. Tabulate results on employment and salaries, and integrate with existing data and interpret for use in the economic impact model, using a consistent format for all states.

\section{Phase 3: Compile Data and Estimate Present Economic Impacts.}

Task 3.1: Compile Wood Fuel Use and Plant Data on a State-by-State Basis. Compile data from existing studies and from public agencies to produce estimates of current wood energy use by state. This task need not involve new data collection beyond that available from the state representative, state air quality offices, EPA, NWEA, and the American Paper Institute.

\section{Task 3.2: Estimate Present Wood Energy Use.}

Using the data compiled in task 3.1, estimate 1992 wood energy use in each of the eleven NRBP states. Consult closely with each of the states on this task, particularly where extrapolation of data is necessary due to the lack of current survey data. That state-specific data should be broken out by sector: commercial, industrial, residential and utility. 
Task 3.3: Run Model to Estimate Present Economic Impacts.

Drawing on the survey and data compilation of employment and income in wood energy-related industries, and the data on present wood use by sector, estimate the net economic benefits from wood energy use in the region in 1992. Benefits should be estimated at the state level, and aggregated for the region. This will be a major component of the final report.

Impacts shall be expressed in terms of direct and indirect jobs, income and taxes. The effects of savings and displacements will be reported.

\section{Phase 4: Develop Scenarios}

Task 4.1: Develop Wood Energy Use Scenarios for the States.

Using existing forecasts, develop three realistic scenarios for future wood energy use in each of the eleven NRBP states over the next fifteen years (and beyond, if possible). Include high and low growth scenarios, and provide "snapshot" forecasts of wood energy use for the years 2000, 2005 and 2010. These scenarios will become the basis for running the economic impact assessment model for future impacts, after consultation with the NRBP states and the approval of CONEG.

Task 4.2: Run Model to Estimate Economic Impact through 2010. In accordance with the wood use scenarios developed in task 4.1, extend the model estimates of net economic benefits from wood energy (developed in task 3.3) to the years 2000,2005 , and 2010 . These estimates of future economic net benefits should likewise be provided on a state and regional basis.

Explain the limitations of this analysis, both in terms of the scenarios themselves and the limitations of the $1 / O$ based analysis.

Tasks 4.3 and 4.4 - Develop Simplified Project Version of the Economic Impact Model for PC and Write a Supporting Manual and Workbook.

Simplify the economic impact model developed in the previous tasks to provide states with the capability to make estimates of the economic impacts of specific wood energy projects. The project specific model shall distinguish between construction and operation phase impacts. This program should be able to estimate the effects of projected increases in wood energy use at the state or local level, but it need not be as complex or as complete as the main model used in the earlier subtask.

Produce a manual and user-friendly program which can be run on a PC to estimate employment, income and effect on energy mix of specific projects.

Task 4.5 - Test and Assist States in Use of the Project Model.

Test the simplified project model in a selected number of states before releasing it to all states participating in the NRBP. Conduct a workshop to educate state officials and CONEG staff on the use of the project economic impact assessment model. 


\section{Phase 5: Reporting and Presentations}

Task 5.1 - Compile Final Report.

In addition to delivering three (3) quarterly reports during the course of the project, produce a final report for use and dissemination by CONEG and state officials. The report must include a brief executive summary that includes the key results and that could be distributed as a stand-alone document. The final report must include the state-specific data and economic impact assessments gathered in the earlier tasks. The report will also include charts to illustrate the results; it will be accompanied by a disk copy of the spreadsheet model in Lotus or Excel.

Task 5.2 - Regional Presentations

In addition to presenting the final report to the NRBP Steering Committee, make two presentations on the findings of the study to appropriate audiences in the region.

Summary of Project Deliverables:

- three quarterly reports

- final report summarizing work on all of the above tasks and detailing study results

- Computer program and associated manual for a microcomputer designed to allow the evaluation of the economic impact of specific wood energy projects. 


\section{PROJECT: WOOD FUEL PELLET CONFERENCE}

\section{SCOPE OF SERVICES}

\subsection{Scope of Work}

CONEG and the Northeastern Forest Alliance (NEFA) are jointly funding a regional wood fuel pellet Conference for the purpose of assisting with the implementation of the recommendations forthcoming from the Wood Pellet Action Plan developed in the Wood Pellet Forum last June. In accordance with the Action Plan, the conference will be held to: educate wood stove retailers, chimney sweeps, air and solid waste regulators, energy and forestry office officials, fire marshals, wood waste haulers and processors, the forest products industry, and others about the opportunities and barriers associated with wood pellet appliances and fuel. The anticipated result of this conference will be growth in the demand for biomass fuel pellets.

The conference will be organized around general sessions with breakout sessions directed to specific audiences and topics. The general sessions will cover such topics as:

- the technical problems associated with the conveyance of fuel and combustion of pellet stoves;

- the importance of ash and moisture content in pellets to efficient and safe appliance operation;

- better understanding of the emerging residential markets for pellet stoves;

- discussion of existing capacity and planned additions to the pellet manufacturing industry in the Northeast;

- the merits and sources of waste wood feedstocks;

- the merits and technical issues associated with establishing standards for grading pellet fuels;

- a comparison of pellet fuels by price per ton and price per million BTUs of delivered energy to: electricity, coals, natural gas and oil in the region;

The breakout sessions will cover such topics as:

- potential trade association and government roles in the regulation and promotion of the industry;

- improving stove retailers' capacities to accurately communicate to consumers the technical advantages and disadvantages of pellet stoves, and appropriate 
methods for operating and maintaining pellet appliances; and discuss the merits of dealer training certification

- one or more case studies of successful fuel pellet manufacturing and distribution operations.

It will be the responsibility of the contractor to develop the curriculum for the conference with input and approval of the Steering Committee and NRBP Project Director.

The conference will be hosted at a suitable site in central New England that will accommodate 150-200 attendees, and appropriate speakers and panelists from around the country.

A conference notebook, containing appropriate technical materials shall be produced for all conference attendees.

Exhibit space shall be available for industry participants.

NEFA will provide $\$ 4,000$ as a minimum cost-share toward the expenses of the Conference.

The Subcontractor shall be responsible for performing the following tasks:

Task 1. Form Steering Committee. The same constituent organizations involved in the initial forum may be reconstituted for the Conference Steering Committee. The Steering Committee shall advise the Subcontractor on all subsequent tasks and teleconference or meet in person at the outset of the subcontract.

Task 2. Prepare Conference Program. This program will be consistent in its objectives with the statements listed above. NEFA will be responsible for developing detailed curricula for each general and breakout session. All curricula will be reviewed by the Steering Committee and the NRBP Project Director.

Task 3. Contact and confirm key participants. NEFA will be responsible for identifying and inviting knowledgeable, and where possible, recognized experts, to conduct conference training. Initial and confirming contact by telephone during November and December, followed by confirmation letter. The target date for completion is March 1994. Confirmation of speakers will be coordinated with conference activities in order that they will be included in pre-conference mailings and registration materials.

Task 4. Prepare materials for Program. The case study reference above, attendance lists, relevant articles, and information shall be prepared in notebook format for all conference attendees. 
Task 5. Secure Program co-sponsors and co-funding. In close collaboration with the Center, approach the Fibre Fuels Institute, the Northeast Hearth Products Association, and other stakeholder organizations about co-sponsoring and co-funding the Conference. The amounts and stipulation for co-funding must meet prior approval of the Center before invitations are tendered. The solicitation shall take place no later than 1994.

Task 6. Arrange Conference Site and facilities. The date and location for the Conference shall be determined by the Steering Committee. The Conference shall be held no later than 1994. The Conference facility must accommodate up to 225 participants and include enough space for up to 25 exhibitors.

Task 7. Establish Registrant and Exhibitor Fee Schedules and Collect Fees. Prior approval of Center and funding co-sponsors will be required for fee schedules. Fees should be consistent with the goal of covering conference expenses.

Task 8. Organize and conduct the Conference. The conference shall take place over a 2-3 day period.

Task 9. Account for Conference Expenses and Revenues. The Subcontractor must carefully and fully account for all expenditures and revenues associated with the Conference. Revenues generated from co-sponsors, vendors, and registrations may be used to cover expenses as they occur. NRBP funds will be used to cover any shortfall in anticipated revenues to provide insurance that the pellet conference will be held, and be a quality project reflective of the NRBP and NEFA.

Task 10. Capture a record.' Make arrangements to transcribe or take notes at the Conference proceedings to summarize significant points of discussion and recommendations. Also record all names, addresses, and affiliations of participants, exhibitors, and other attendees and distribute a list to all attendees.

Task 11. Prepare draft report on Conference findings and recommendations. The Subcontractor shall ensure that an initial draft report is prepared for review and comments by Steering Committee members. The target date for completing this task is 1994

Task 12. Prepare Final Report. Incorporating comments of the Steering Committee, the Subcontractor shall draft a final report for review by the Center. The target date for completion is 1994.

Task 13. Publication of Training Booklets. The NRBP funds that remain at the conclusion at the conclusion of the conference will be used to cover all reasonable and necessary expense to compile training booklets directed to the conference's target audiences. The Subcontractor, after consultation with the Steering Committee and Center Project Director, will submit a plan for compiling and publishing the content of sector-specific sessions such as training for fire code officials, state air regulators, 
chimney sweeps, etc and shall print sufficient copies for NRBP and other co-sponsors. The target date for completion is ., 1994.

\subsection{Period of Performance}

The Subcontractor shall complete all work hereunder within nine (9) months of the effective date of this subcontract.

\subsection{Reporting Requirements}

The Subcontractor shall prepare and submit to the Center Project Director or his appointee reports as set forth below.

\subsection{Interim Progress Reports}

A progress report shall be submitted bi-monthly with the 1st report due April 15, 1993. The report may be in letter form and shall, at a minimum, address the following areas:

- progress made to date on the specific work to be accomplished;

0 work in progress;

0 problems and difficulties encountered;

0 problems and difficulties solved; and

- assistance or guidance required of the Center.

\subsection{Financial Status Report}

At the end of the Subcontract, the Subcontractor shall furnish tow (2) copies of a Financial Status Report showing cumulative expenditures to date and the balance remaining in at least the following categories of cost: Personal Services (by position), Expenses by line-item, Indirect, and Total Costs.

Any deviation from the reporting schedule set forth herein must be approved in writing by the Center Project Director.

\subsection{Final Report Requirements}

Two copies of a final report shall be submitted to the Center Project Director within 30 days of the completion date of this subcontract agreement.

\subsection{Records: Retention and Standards}

Financial records shall be kept in accordance with Generally Accepted Accounting Principles. The Center shall be notified in writing of any deviations or changes from Generally Accepted Accounting Principles made by the Subcontractor. Accompanying this notification shall be a supporting explanation of those changes and/or deviations. Such changes and/or deviations from Generally Accepted Accounting Principles shall 
be the sole responsibility of the Subcontractor and subject to the review of DOE, the U.S. Comptroller General, the Center and their duly authorized representatives.

All records of the Subcontractor for this subcontract shall be kept for three years following the final payment made to the subcontractor by the Center. Records are defined as all books, documents, papers and financial records related to the Subcontractor's subcontract.

\subsection{Access to Records}

The USDOE, the Comptroller General of the United States, the Center or any of their duly authorized representatives, shall have the right of access to any books, documents, papers or other records of the Subcontractor which are directly pertinent to the Subcontract in order to make audit examinations, excerpts and transcripts.

\subsection{Direction}

The Subcontractor's Principal Investigator for this Subcontract is Tom Wood. The Principal Investigator or appointee shall monitor and direct he progress for the work and shall issue direction as required. Such direction is defined in the Scope of Work and Specific Tasks. Direction must be within the general scope of work stated in the Subcontract.

\subsection{Payment}

Invoices or vouchers shall be identified by Subcontract Number and shall be submitted in the original and two (2) copies within five (5) days following the month reported on (for inclusion inn the Center submission for reimbursement to the Government), and sent to the following address:

CONEG Policy Research Center, Inc.

400 North Capitol St. NW

Suite 382

Washington, D.C. 20001

Attention: BIOMASS

Payment shall be made to the Subcontractor within forty five (45) days of the date invoices are received. However, payment shall be contingent upon receipt of reimbursement from the USDOE, and shall be within five (5) days following USDOE reimbursement if that occurs after the forty five day period.

Any requests for advance payments must be approved by the Center Project Director.

Allowable costs charged to this subcontract shall be effective the date of this subcontract. 


\subsection{Final Payment}

Ten percent of the total Subcontract amount shall be withheld by the Center pending satisfactory completion of the duties of the Subcontractor. Before final payment, the Subcontractor must execute and deliver:

o the deliverables satisfactory to the Project Director;

0 any rebates, refunds, credits or other offsetting expenses for which the Subcontractor has been reimbursed by outside parties, and previously paid for by the Center; and

o sign a release discharging the Center and its respective authorized representatives from all liabilities, obligations and claims arising out of or under this Subcontract. 


\section{TITLE: CHARACTERIZATION OF AIR TOXIC EMISSIONS FROM WOODSTOVES}

\section{Scope of Services}

Residential wood combustion (RWC) is a significant source of particles, volatile organic compounds (VOC), and carbon monoxide. Not only can RWC be considered a major source of these pollutants, even when compared to other nationwide pollutant source categories such as motor vehicles and industrial point sources, but locally the impact can be very high due to its regional and seasonal nature. Exceptionally high atmospheric concentrations of RWC pollutants are often reached during the heating season in communities with poor dispersion caused by valley terrain and wintertime inversions. Due to the near-roof-level stack height and residential location of RWC emissions, human exposure (both indoors and outdoors) is high.

Emission factors (mass pollutants per mass fuel) are high for woodstoves as compared to industrial sources due to their relatively simple design, and the associated incomplete combustion of wood fuel. Products of incomplete combustion (PIC) from burning cellulose, other polysaccharides, lignin, and resins which comprise wood have been shown to contain many toxic compounds. The toxic content is particularly problematic because RWC pollutants are predominately either in respirable-sized particles or in the vapor phase. Pollutants contained in respirablesized particles, or that are in the vapor phase, represent the highest human exposure risk due to their direct and penetrating entry into the respiratory system.

Unlike more traditional industrial point sources, the combustion emissions from RWC are difficult to characterize in a representative manner. A wide variety of woodstove appliances are in use, a wide variety of wood fuel (wood species and moisture) is burned, and operating practices vary widely with climate and from home to home within a given community. This large number of possible parameters makes the laboratory testing of a few appliances of limited utility and has been responsible for the development of in-home sampling systems that permit the study of a larger number of cases under realistic conditions. In addition to the variability which is characteristic of RWC, woodstove emissions are pragmatically difficult to sample. Slow stack gas velocities, high condensable organic content, and high water vapor content require special modifications of traditional sampling techniques to obtain accurate, reproducible results.

There is a paucity of woodstove air toxic data. Most woodstove air quality research has dealt primarily with the criteria pollutants, carbon monoxide or PM10 (particulate material with an aerodynamic diameter less that 10 microns). The most notable air toxic research to date is either over a decade old or was performed with limited resources as part of the criteria pollutant work. The need for a study that focusses on air toxics, utilizing state-of-the-art technology and the current RWC knowledge base, is critical. 


\title{
TASK 1. EVALUATION OF TESTING PARAMETERS
}

The chemical composition of woodstove emissions is expected to be highly variable. The key parameters contributing to the variability are thought to be (1) the burn rate and the burn cycle, (2) turbulence, residence time, and combustion conditions related to firebox size and stove design, (3) fuel loading density and the physical dimensions of the fuel pieces, (4) fuel moisture content, (5) woodstove technology type (e.g., catalytic verses noncatalytic and airtight versus older non-airtight models); (6) installation factors (i.e., draft) and (7) wood species and origin.

The following proposal from the Canadian Combustion Laboratory now constitutes the draft statement of work under consideration:

\section{PROPOSAL FOR PARTIAL AIR TOXICS TESTING OF WOODBURNING STOVES AT CCRL/CANMET}

\author{
(A cooperative activity with AEERL/EPA) \\ Prepared by: Ron Braaten \\ CCRLCANMET . \\ October 25, 1993
}

\section{Background:}

The Joint Woodstove Air Toxics Project brings together a number of agencies in the United States and Canada including NYSERDA, US EPA, CONEG, Oregon, CCRLCANMET, and HPA. A major goal of the project is to deter air toxics emissions of current certified woodstoves relative to older design uncertified equipment. The experimental activity in support of this project would be carried out at AEERL/EPA and at CCRLCANMET. This proposal details that portion of the testing to be carried out at CCRL/CANMET.

\section{Objectives:}

The primary objective of this project is to compare the toxics emissions of current certified equipment to older uncertified appliances to evaluate the impact of the EPA certification of woodstoves on air toxics emission from this source. An additional goal is to quantify emissions of priority pollutants in this class for both new and older equipment, to determine relationships between the impact of various emission control technologies on toxics emissions. 


\section{Approach:}

The portion of this project in which CCRL/CANMET is involved will have two components. The first has as its goal the detailed characterization of PAH emissions from two wood stoves using standard sampling techniques for PAH emissions, as well as determining the levels of emissions of the priority pollutants.

At the same time, a realtime continuous $\mathrm{PAH}$ analyzer will be operated; results from the reference method will be used to establish correlations with the continuous system. The continuous system will be then be used to evaluate emissions for several additional woodstoves.

The continuous analyzer offers the possibility of dramatically lowering the cost and complexity of PAH testing of woodstoves. As well, the continuous, realtime nature of the results can help identify emissions peaks and is potentially powerful tool in aiding appliance designers in minimizing emissions. If the level of agreement with reference methods for woodstove testing is as good as expected, this should greatly expand the effort possible in investigating woodstove performance.

\section{Work Plan:}

\section{CCRL/CANMET PART I}

The first portion of the project to be carried out at CCRL/CANMET will both characterize the two stoves and provide simultaneous sampling using the reference EPA procedure and the continuous realtime analyzer to establish the level of agreement between the two. At the same time, continuous measurements would be made of $\mathrm{CO} 2, \mathrm{CO}$ (both IR), 02 (paramagnetic, Nox (chemilluminescent) and hydrocarbons (FID) (and particulates). To maximize the likely range of emission levels it is suggested that one of the test stoves be a design typical of pre-regulation stoves, and the other be a state-of-the-art 1990-approved stove.

For the uncertified stove, a unit such as the Fisher Mama Bear is suggested as typical of the many simple box stoves sold in large quantities from the seventies through to the establishment of emission standards in the eighties. if it proves impractical to obtain a used Mama Bear stove in good condition, it may be necessary to obtain a new uncertified stove (still sold in Canada). In this case, particulate emission pretesting and stress testing would be conducted to ensure that emissions performance is not unduly good.

The second stove should represent of the better certified stoves currently available, ideally a non-catalyst canadian stove from our perspective. Experience from previous studies should be useful in selecting a unit with demonstrated above-average performance.

The stove operation during testing is anticipated to be based on the requirements of EPA part 40 method 28. While studies have shown little effect on particulate emission 
rates due to fuel species or the use of the "EPA crib" rather than cordwood, it is not known whether this is also true of PAh emissions. Accordingly, it is proposed that cordwood be used for the tests, and that one of the comparison runs be cordwood compared to the EPA crib.

Hence, the stoves to be tested under CCRLCANMET Part I are as follows:

1. "Typical" uncertified (for emissions) airtight box stove \#1

2. Certified non-catalyst low emission stove \#1 (small firebox)

\section{CCRL/C1 II}

If the results from the continuous $\mathrm{PAH}$ analyzer show reasonable agreement with the reference method, additional stove would be tested to compare performance expanding the data base significantly. there are a number of possibilities for testing and comparison including catalyst vs. non-catalyst, very low particulate emissions appliances vs. units just passing the standard, and small vs. large firebox capacity units. Because the testing is much less time-consuming and complex using the continuous analyzer, stoves could be tested for significantly less cost than the full procedure, allowing evaluation of several design parameters or duplicate sampling within a stove type.

A number of test scenarios are possible for CCRLCANMET Part II. Four possible test options are outlined in Table I below, based on testing of a total of six additional stoves/parameters. Option I involves 2 additional non-cat's, 2 cat's, a pellet stove and a comparison between cordwood and the EPA crib. Option II is similar, but substituting an additional conventional stove for the pellet stove. Option III uses one with softwood and the EPA crib. Option IV is similar to I, but substitutes a zeroclearance fireplace for the second small non-cat.

CCRL is most willing to change or even expand the number of additional . stoves/parameters which would be tested. A final selection of tests should be made following input from all parties involved. 
Table I. Potential Options for CCRL/CANMET Part II Testing.

\begin{tabular}{||l|l|l|l||}
\hline \multicolumn{1}{|c|}{ OPTION I } & \multicolumn{1}{|c|}{ OPTION II } & \multicolumn{1}{|c|}{ OPTION III } & \multicolumn{1}{|c|}{ OPTION IV } \\
\hline $\begin{array}{l}\text { Non-cat \#2 } \\
\text { large firebox }\end{array}$ & Uncertified \#2 & $\begin{array}{l}\text { Uncertified \#1 } \\
\text { softwood }\end{array}$ & $\begin{array}{l}\text { Non-cat \#2 } \\
\text { large firebox }\end{array}$ \\
\hline $\begin{array}{l}\text { Non-cat \#3 } \\
\text { small firebox }\end{array}$ & $\begin{array}{l}\text { Non-cat \#2 } \\
\text { large firebox }\end{array}$ & $\begin{array}{l}\text { Non-cat \#1 } \\
\text { softwood }\end{array}$ & $\begin{array}{l}\text { Non-cat \#1 } \\
\text { EPA crib }\end{array}$ \\
\hline $\begin{array}{l}\text { Non-cat \#1 } \\
\text { EPA crib }\end{array}$ & $\begin{array}{l}\text { Non-cat \#3 } \\
\text { Medium firebox }\end{array}$ & $\begin{array}{l}\text { Non-cat \#1 } \\
\text { EPA crib }\end{array}$ & Catalyst \#1 \\
\hline Catalyst \#1 & $\begin{array}{l}\text { Non-cat \#1 } \\
\text { EPA crib }\end{array}$ & Catalyst \#1 & Catalyst \#2 \\
\hline Catalyst \#2 & Catalyst \#1 & $\begin{array}{l}\text { Catalyst \#1 } \\
\text { softwood }\end{array}$ & $\begin{array}{l}\text { Zero-clearance } \\
\text { Fireplace }\end{array}$ \\
\hline Pellet Stove & Catalyst \#2 & $\begin{array}{l}\text { Catalyst \#1 } \\
\text { EPA crib }\end{array}$ & Pellet Stove \\
\hline
\end{tabular}

The PAH compounds to be analyzed are assumed to be those listed in Appendix A. Modest cost savings could be made be to reduce this list; however this should be done with care to avoid the possibility of missing a relatively high volume contributor.

To improve the accuracy of the testing and more closely duplicate actual emissions into the air it is recommended that the PAH sampling point be located in a dilution tunnel into which the stove chimney exhausts. This will provide a uniform flow rate for sampling purposes, otherwise a major problem in woodstove stack sampling.

\section{Costing:}

Costs are estimated as follows:

Part I - testing of two stoves using the reference method and continuous PAH analyzer: $\$ 75,300 \mathrm{Cdn}$ (approx. $\$ 58,000$ U.S.)

Part II - testing of additional stoves using continuous PAH analyzer only: $\$ 12,500$ Can (approx. $\$ 9,700$ U.S.) per stove.

Under the six stove parameter scenario of CCRLCANMET Part II, total cost for the CANMET portion of the project (CCRL/CANMET Parts I and II). would be $\$ 150,000$ Cdn (approx. $\$ 117,000$ U.S.)

It is anticipated that CANMET management would authorize our laboratory to underwrite $1 / 3$ of this cost (39k U.S.), leaving about $\$ 78 \mathrm{~K}$ U.S. to be funded by the partners in the study. 


\section{Deliverables:}

A report in ten copies including detailed descriptions of the test procedures used, test results, and graphical/tabular comparison of significant results.

\section{Scheduling:}

The work at CCRL/CANMET is anticipated to begin as soon as required after funding has been secured, and to require 400 person-hours over a ten week period for completion of Part $\mathrm{I}$, the intense study of the two original stoves, and 560 person hours over a 24 week period for completion of Part II, the latter giving data on six additional stove parameters.

Task 1 entails reviewing the literature to determine what sets of parameters should be chosen for testing. Parameter sets which represent the most common scenarios for various regions of the country, those which may show potential reductions in air toxic emissions by the use of certified stoves and well-seasoned fuels, or those which may illustrate causal relationships (e.g., coniferous wood fuels with a high resin content influencing specific aromatic compound emissions) are examples of parameter sets which may be chosen. Cordwood of moderately consistent spatial distribution, moisture content and species should be an important consideration. Documentation and rationales for the final selection should be provided in a pre-test report. The proposer may suggest specific parameter sets. The entire testing plan developed by the contractor shall be submitted to the Advisory Committee for review and approval. 


\section{ANNOUNCEMENT OF GRANT AVAILABILITY}

TITLE:

Northeast Regional Biomass Program State Grants

ELIGIBLE GRANTEES:

State agencies of the following eleven states: Connecticut, Delaware. Maine, Maryland. Massachusetts. New Hampshire, New Jersey, New York. Pennsylvania. Rhode Island and Vermont.

PROGRAM DESCRIPTION: This is the eleventh year of an ongoing program designed to increase biomass energy development and use in the Northeast. The state grants component of this program is aimed at improving state agency coordination and strengthening state capabilities with regard to biomass energy development. Specific activities which may be undertaken include: information dissemination. state agency planning and coordination, technical assistance, research, development and demonstration projects designed to expand biomass energy use in the state.

DEADLINE FOR

PROPOSAL:

September 30, 1993.

STATE GRANT AMOUNT: Up to $\$ 30,000$, subject to state in-kind match equal to 50 percent of the grant amount.

PERIOD OF

PERFORMANCE:

12 Months: with renewal possible depending on grantee performance and availability of funds.

SUBMIT PROPOSAL TO: CONEG Policy Research Center. Inc. 400 North Capitol Street, NW, Suite 382

Washington, D.C. 20001

NUMBER OF COPIES: 1 Original and 2 Copies

FOR FURTHER INFORMATION CONTACT: $\quad$ Richard Handley

CONEG Policy Research Center (202) 624-8454 


\section{INTRODUCTION}

The Coalition of Northeastern Governors Policy Research Center, with funds from the U.S. Department of Energy, is continuing for an eleventh year a program that includes sponsorship of biomass energy programs in eleven states. In prior years, states have initiated programs primarily, in four general areas: industrial conversion assistance, resource availability and use assessments; technical information development and dissemination; and conversion of public facilities.

In each state, the Northeast Regional Biomass Program has provided the beginning of a constructive, on-going relationship between at least two agencies. Unlike most other energy sources, biomass requires the involvement of several agencies and jurisdictions. Therefore, the center piece of the state grants program will continue to be interagency cooperation within the appropriate State offices (i.e. energy, forestry, environmental).

Each of the eleven states participating in the NRBP have previously put together imaginative proposals that address each state-specific concerns. The projects mainly focused on wood energy due to the overwhelming promise of this particular biomass feedstock and the commercial viability of existing technology in this area. The NRBP will continue to focus on wood, however. where it is appropriate. states are encouraged to examine opportunities to address barriers to the greater use of other biomass energy sources including municipal solid waste, landfill gas and co-firing biomass with conventional energy sources.

\section{PROGRAM DESCRIPTION}

The state grants program constitutes approximately one half of the Northeast Regional Biomass Program. The other component is a series of technical reports and studies which will concentrate on technical assistance to business and industry, wood stove emissions, air quality standards and biomass technology development.

Technical studies will continue to be designed to compiement the efforts of state agencies in a variety of ways. For example, staff conducting a state wood energy program may have occasion to refer a plant manager to the assistance program for help in determining the feasibility to converting to a wood energy system. Every opportunity will be provided for state agency staff to take advantage of the technical studies and the information gained therefrom. A central purpose of the technical studies is to provide background data and resources to states officials.

\section{PROGRAM OBJECTIVES}

The goals of the state grants program is to develop the capability among state agencies to promote and develop wood and other biomass energy resources. Specific objectives for this program include:

- Improve the effectiveness, coordination and planning capability among state agencies to promote and develop wood and other biomass energy-related responsibilities. 
- Provide information to private companies. residential and commercial consumers. and public institutions regarding the economic potential. safety requirements. and versatility of biomass and wood energy use.

- Mitigate environmental impacts associated with wood harvesting and combustion.

- Protect and improve the forest resource base.

- Increase the efficiency of wood energy use in the residential, industrial and commercial sectors.

- Increase the safety and protect the health of residential energy consumers.

\section{STATEMENT OF WORK}

Funding of each state program will be provided at a level of up to $\$ 30,000$ for a period of 12 months (this period may be extended). Congress has not appropriated funds for a continued program in FY94, therefore, state proposals which anticipate following year activities would not be anticipated. Additional funding will be sought beyond the current appropriations.

Beyond the requirement that the proposed program must represent a cooperative effort between state agencies, projects should respond to a demonstrated state need. Legitimate uses of project funds include hiring or retaining a staff person to serve as liaison between agencies or funding specific research, development or demonstration projects. Information transfer. including the use of public media, should be a key component of any program. Likewise, involvement of other agencies, offices, universities, private industry groups, and trade associations, to increase the resources and expand the reach of the program will strengthen the application.

A broad spectrum of possible projects include the following topical areas:

- resource inventory and use surveys

- biomass conversion at public facilities

- wood burning in the residential, commercial and industrial section

- pollution control of wood combustion emissions

- institutional factors, such as inter-agency coordination or public/private cooperative efforts

- consumer issues, such as wood stove safety

- technology improvement for wood chips or pellets

- wood supply and marketing mechanisms

- financial incentives for expanded biomass energy use 
- landowner issues related to woodlot management

- research. development and demonstration of improved combustion technology

- utilizing municipal waste and recycled biomass waste as an energy resource

- co-firing biomass with conventional energy sources

Additional topics. where they address a specific state need. will be given full consideration.

\section{PROCESS FOR EVALUATING PROPOSALS}

State grant proposals will be reviewed by CONEG staff and the technical coordinator for the Northeast Regional Biomass Program (NRBP). Proposals will be evaluated according to their degree of impact on the overall goals of the Northeast Regional Biomass Program. Specific criteria include the following:

\section{Institutional Coordination}

- Cooperation between state energy, forestry and other appropriate agencies in the design and implementation of the program.

- Potential to involve other organizations, institutions and association as participants in the program.

- Likelihood of improving private sector, state agency, interstate and local government involvement in biomass and wood energy issues.

- Beneficial impact on government rules and regulations.

\section{State Impact}

- Number of individuals, industries, and institutions reached.

- Amount of conventional fuels replaced with wood or other biomass resources.

\section{APPLICATION INSTRUCTIONS}

Applications should be coordinated between appropriate state offices. and submitted by the Governor. Agencies should work together to assess state needs and determine a cooperative program designed to meet those needs. The final proposal should not exceed ten pages and should contain the following components:

I. A cover letter of transmittal, signed by the Governor.

II. A one-page summary of the proposed project. 
III. A narrative proposal with the tollowing components:

A. Problem Statement

1. statement of general and speciiic wood energy related issues and needs: and

2. a summary of prior year projects under the NRBP and other biomass energy-related work.

B. Statement of Work

NOTE: Information requested in items 1 and 2 should be arranged in the form of tasks as contained in the previous years contract.

1. Objectives--A description of the goals and measurable impacts of the grant program.

2. Strategies--An outline of the methods and approaches to be used to achieve the stated objectives.

3. Project Description--A description of the program structure and the day-to-day operations and activities.

4. Implementation Plan--An outline of the project timetable, the development of interagency cooperation and the relationship to current agency programs.

5. Relation to Previous State Program--The grant funds may be used to fund existing programs and activities only if the state clearly demonstrates that the program would not be funded otherwise.

6. Relation to Prior Year NRBP Projects--A description of how this year relates to the prior year project.

7. Schedule--The proposed timeline for completion of project activities, including key milestones in the project's development.

8. Participants--Identify participating state agencies and staff names if available. Indicate evidence of approval of program proposal by chief forestry and energy officials.

9. Project Management--Describe the program management structure including the names and titles of key personnel.

10. Deliverables--Indicate program products (e.g., seminars, training materials, publications, research reports etc. Products must include three quarterly progress reports and a final project report. 
C. Budget proposal narrative discussion of budget proposal including a detailed description of state in-kird match.

IV. Cost proposal using Standard Form 1411 (see Attachment A). The project budget must include auditable in-kind contribution equalling 50 percent of the grant award (i.e. one-third of the total project budget). The matching funds may not be borne by another Federal grant. contract or other Federal government tunds. However. general revenue sharing funds under 31 U.S.C. 1212 are not considered a Federal grant. Source of in-kind contributions must be identified in the cost proposal.

\section{FREEDOM OF INFORMATION NOTIFICATION (FOIA)}

Please be advised that applications submitted in response to this solicitation are subject to disclosure under the Freedom of Information Act (FOIA). To assist the Department of Energy in determining whether or not to release information contained in an application in the event an FOI request is received. applicants may. through clear earmarking or otherwise, indicate those portions of their applications which they believe should not be disclosed. While an applicant's advice will be considered by the Department of Energy in its determination whether to release requested information or not, it must be emphasized that the Department is required by the FOIA to make an independent evaluation as to the release of all information requested, and that accordingly, information may be released notwithstanding the applicant's views.

Attachments: A-Standard Form 1411 